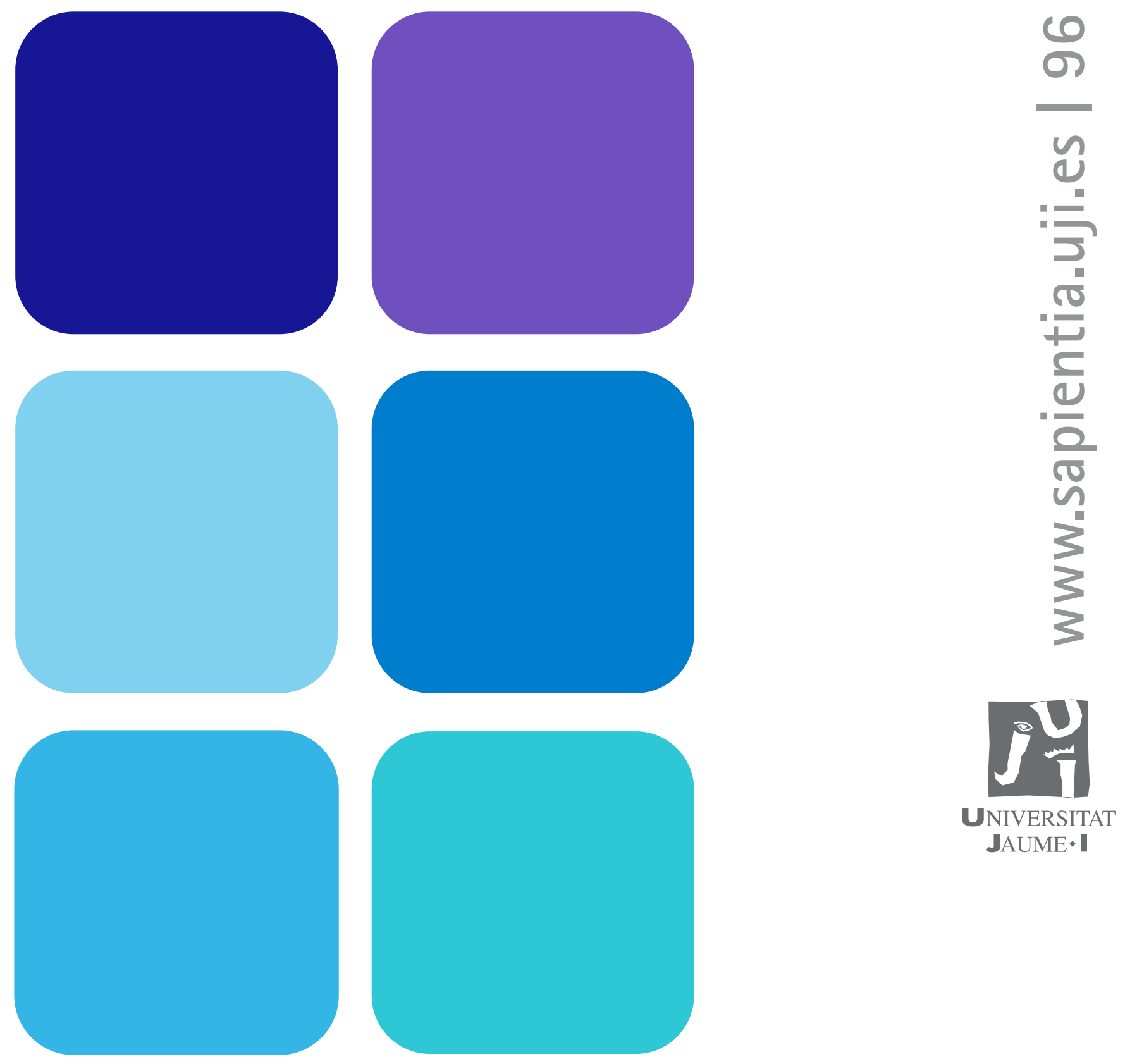

\title{
Els nombres enters i racionals, les magnituds i la mesura a l'aula de primària
}

Inmaculada Pérez Serrano Manuel Alcalde Esteban Gil Lorenzo Valentín 


\section{Els nombres enters}

i racionals, les magnituds

i la mesura a l'aula

de primària

Inmaculada Pérez Serrano

Manuel Alcalde Esteban

Gil Lorenzo Valentín

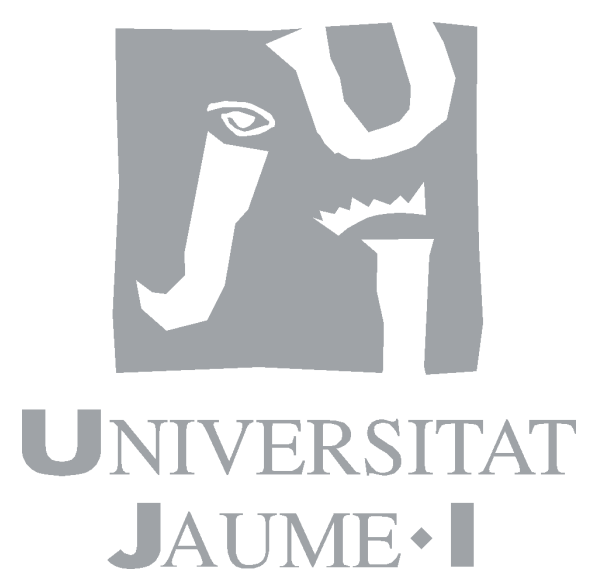

Departament d'Educació

- Codi d'assignatura MP1019 
Edita: Publicacions de la Universitat Jaume I. Servei de Comunicació i Publicacions Campus del Riu Sec. Edifici Rectorat i Serveis Centrals. 12071 Castelló de la Plana http://www.tenda.uji.es e-mail: publicacions@uji.es

Col·lecció Sapientia 96. Els nombres enters i racionals, les magnituds i la mesura a l'aula de primària http://dx.doi.org/10.6035/Sapientia96

Col-lecció Sapientia 97. Los números enteros y racionales, las magnitudes y la medida en el aula de primaria

http://dx.doi.org/10.6035/Sapientia97

www.sapientia.uji.es

Primera edició, 2014

ISBN: 978-84-697-1442-3 Publicacions de la Universitat Jaume I és una editorial membre de l'UNE,
cosa que en garanteix la difusió de les obres en els àmbits nacional i interUnión de Epitoriales
Uviterstitakias Fspax̃oLas nacional. www.une.es

\section{(c) (1) (2)}

Reconeixement-Compartirlgual

CC BY-SA

Aquest text està subjecte a una llicència Reconeixement-CompartirIgual de Creative Commons, que permet copiar, distribuir i comunicar públicament l'obra sempre que s'especifique l'autor i el nom de la publicació fins i tot amb objectius comercials i també permet crear obres derivades, sempre que siguen distribuïdes amb aquesta mateixa llicència.

http://creativecommons.org/licenses/by-sa/3.0/legalcode 


\section{ÍNDEX}

Introducció

Tema 1. Nombres enters

1. Introducció

1.1. Històrica

1.2. Al tema

2. Formalització del conjunt de nombres enters

2.1. Construcció dels nombres enters

2.2. Operacions amb nombres enters

2.3. Immersió dels naturals en els enters

2.4. Ordre a Z .

3. Els nombres enters a l'aula de primària

3.1. Situacions on poden aparèixer

3.2. Introducció dels nombres enters a l'aula

3.3. Les operacions amb nombres enters a l'aula

3.4. Dificultats més freqüents amb els nombres enters

Tema 2. Nombres racionals

1. Introducció

1.1. Històrica

1.2. Al tema

2. Preliminars

3. Formalització del conjunt de nombres racionals

3.1. Construcció dels nombres racionals

3.2. Operacions amb nombres racionals

3.3. Signe a $Q$.

3.4. Immersió dels enters en els racionals

3.5. Ordre a $Q$

4. Els nombres racionals a l'aula de primària

4.1. Algunes consideracions

4.2. Quadre de capacitats

4.3. Desenvolupament de les capacitats....

\section{Tema 3. Magnituds i mesura}

1. Introducció

1.1. Històrica

1.2. Al tema 
2. Formalització dels conceptes de magnitud i mesura

2.1. Magnitud

2.2. Mesura d'una magnitud.

2.3. Unitat de mesura

3. Les magnituds i la mesura a l'aula de primària

3.1. Consideracions prèvies

3.2. Quadre de capacitats

3.3. Desenvolupament de les capacitats

Annex

Bibliografia

Índex de figures 


\section{Introducció}

Presentem en aquest document un material per a la formació inicial i permanent del professorat d'Educació primària, on es mostren propostes didàctiques per treballar els continguts referents als Nombres Enters i Racionals, i a les Magnituds i la Mesura en aquesta Etapa Educativa, com a continuació de la publicació referida als Nombres Naturals (col·lecció Sapientia, números 89 i 90, en valencià i castellà, respectivament), la qual és necessari conèixer per a una comprensió fonamentada dels continguts que es desenvolupen en el present text.

Encara que els esmentats continguts estan treballats en publicacions d'altres autors, pretenem amb aquesta oferir-los de manera unificada als nostres lectors en un text estructurat al voltant de les capacitats matemàtiques que cal treballar amb l'alumnat d'Educació primària. L'ordre en el que apareixen els conjunts numèrics en el text respecta l'ordre matemàtic lògic dels mateixos, encara que aquest no se segueix quan es desenvolupen els aspectes didàctics corresponents a l'aula de primària, on es treballen els nombres racionals abans que els enters.

Cadascun dels temes compta amb una introducció que ens permet reflexionar respecte de dues qüestions que considerem importants. Una és l'evolució històrica dels continguts que estudiem: els Nombres Enters i Racionals, els seus usos i significats diferents, així com les operacions que es poden realitzar amb aquests nombres i les relacions que es donen entre ells; els conceptes de Magnitud i Mesura, els passos que la humanitat ha hagut de donar fins arribar a l'universal sistema actual d'unitats. Creiem que, quan l'estudiantat de Grau coneix el moment en el què han aparegut els diferents conceptes en la història i també com s'han desenvolupat fins els nostres dies, els afegeix entitat i els dota d'una perspectiva que va més enllà del treball que es fa a l'aula. L'altra és l'aspecte teòric d'aquests conceptes, que s'exposa en un resum per fonamentar-los matemàticament i que parteix de la Teoria de Conjunts de G. Cantor, per tal d'apropar el lector als conceptes estudiats.

A continuació, com a part més important del text i com a nucli que justifica aquesta publicació, s'inclou en cada tema un extens apartat referent al tractament didàctic dels diferents continguts per tal de treballar-los en l'aula de primària $i$ aconseguir, d'aquesta manera, el desenvolupament de la competència matemàtica de l'alumnat.

En l'esmentat apartat didàctic es presenten els continguts matemàtics a partir de la realitat $i$ per a ser aplicats en ella. Com a conseqüència, $i$ atorgant-li la importància màxima a aquesta qüestió, totes les situacions que s'enuncien acompanyant el contingut didàctic del text formen part d'altres situacions més complexes que es treballen a l'aula, en les quals els conceptes matemàtics són essencials per a la seua interpretació i resolució. De vegades les activitats matemàtiques sorgiran del desenvolupament d'alguns projectes de treball globalitzats, en altres ocasions es plantejaran a partir de les necessitats que generen de les altres matèries del currículum. Sols quan es contemplen alguns continguts que no hagen aparegut en cap 
activitat com les esmentades abans, el docent afavorirà de manera intencionada l'aparició de situacions que provoquen les incògnites que els portaran al descobriment dels esmentats continguts.

En tots els casos, partirem de les idees prèvies de l'alumnat sobre cadascun dels conceptes a treballar i, en particular, de les seues propostes personals i emergents de resolució de les diferents situacions que es plantegen. Continuarem amb la recerca dels procediments generals de representació numèrica i de càlcul amb nombres enters i racionals, com a forma d'oferir-los les eines matemàtiques que socialment s'utilitzen per a representar aquests nombres i les diferents activitats en les què intervenen. Tanmateix, trobarem les unitats del Sistema Internacional com les eines què ens permeten resoldre les dificultats que la relativitat de la mesura provoca i, a la vegada, entendre'ns amb qualsevol altra persona.

Atenent les recomanacions del Parlament Europeu i del Consell d'Europa sobre les competències clau per a l'aprenentatge permanent, entenem que la competència matemàtica sols es concreta i cobra sentit en la mesura que els elements $i$ raonaments matemàtics que s'estudien són utilitzats per enfrontar-se a aquelles situacions quotidianes que els necessiten. Per això, el seu desenvolupament a l'escola s'aconseguirà partint d'una àmplia varietat d'activitats reals, derivades d'altres camps del coneixement, de les situacions habituals que es donen a l'aula i de les pròpies experiències i vivències de l'alumnat. Es tracta en definitiva, d'aconseguir que els xiquets $i$ les xiquetes sàpiguen aplicar les destreses i actituds que els permeten raonar matemàticament, comprendre una argumentació matemàtica i expressar-se i comunicar-se en el llenguatge matemàtic per a donar una millor resposta a les situacions de la vida de diferent nivell de complexitat.

L'objectiu del material és proporcionar una eina per als professionals de la docència i per a l'estudiantat del Grau en Mestre, que els ajude a reflexionar sobre els fenòmens educatius que ocorren a l'aula escolar i els permeta enfrontar-se a ells des d'un plantejament que considera l'ensenyament-aprenentatge de les Matemàtiques com una tasca interdisciplinària i globalitzadora que parteix d'una concepció sociocultural de l'educació en general i de l'educació matemàtica en particular. En concret i de cara a l'estudiantat de Grau en Mestre d'Educació Primària de la Universitat Jaume I, aquest document representa un material complementari per a les classes presencials, en les quals s'aprofundeix en el text relacionant la fonamentació matemàtica dels conceptes i la didàctica d'aquests mitjançant la realització de diferents activitats que es realitzen al llarg del curs acadèmic.

Pressuposem que en les aules de primària on es treballen els continguts d'aquest document, es troben els materials estructurats que descriurem més endavant o altres semblants ideats i fabricats pels docents i/o l'alumnat, que hauran de compartir en la seua essència allò que és fonamental per a la construcció dels continguts matemàtics que es persegueixen en aquesta publicació. Aquests materials constitueixen un suport imprescindible pel treball a l'aula referent als conceptes estudiats en aquest llibre. 
El present document no esgota l'activitat que el mestre ha de realitzar a l'aula. La gran varietat de possibles dispositius didàctics que pot oferir als seus alumnes és impossible de reflectir-la en qualsevol publicació. El nostre interès és posar l'atenció en el que ha de treballar per fonamentar matemàticament els procediments emprats per l'alumnat i donar indicacions de com ha de fer-ho. Mai esgotarem la creativitat didàctica que un docent ha de tenir en la seua tasca diària.

En finalitzar els temes comentats, s'inclou un Annex que tanca aquesta publicació, en el qual es recullen alguns conceptes bàsics de la Teoria de Conjunts, que fonamenten els continguts referents als Nombres Enters i Racionals i a les Magnituds i la Mesura, treballats en aquest llibre. S'ofereix aquest Annex com una guia consultiva que al lector interessat li permeta ampliar els seus coneixements, entenent que no són objecte d'estudi obligatori en les aules de formació inicial dels mestres. 


\section{TEMA 1}

\section{Nombres enters}

En aquest tema es treballa la construcció del concepte de nombre enter a partir del producte cartesià $\mathbf{N} \times \mathbf{N}$. Comença el tema amb una referència històrica sobre l'esmentat concepte, continua amb una formalització de l'estructura del conjunt dels nombres enters, i finalitza amb un tractament didàctic d'aquests continguts en l'aula de primària.

\section{Introducció}

\subsection{Històrica}

Històricament, la matemàtica sorgeix amb la finalitat de fer els càlculs en el comerç, i també amb la de mesurar la Terra i predir els esdeveniments astronòmics. Aquestes tres necessitats poden ser relacionades, en certa manera, amb la subdivisió àmplia de la matemàtica en l'estudi dels nombres, l'espai i el canvi.

L'estudi dels nombres comença amb els naturals i els enters i ens porta finalment a les estructures algebraiques.

Pel que fa als nombres negatius, tot i que es coneixien a Europa a través de textos àrabs, la majoria dels matemàtics dels segles XVI $\mathrm{i}$ XVII no els acceptaven com a nombres. La introducció conceptual ha estat un procés d'una lentitud sorprenent. Durant molt de temps, els nombres negatius van ser un útil de càlcul que facilitava aspectes financers com guanys i pèrdues i alhora també facilitava la resolució d'equacions.

Els nombres negatius es van començar a utilitzar segles abans de Crist, per a representar coses o dades que faltaven, però a poc a poc deixaren d'emprar-se. S'ha d'esperar fins el Renaixement per a tornar a trobar-los i amb aquest nom: «negatius». Per aquest motiu, es van considerar nombres del dimoni i es perseguia la seua utilització, però per necessitats d'expressar quantitats de qualsevol índole, es van tornar a utilitzar al segle XIX (Ifrah, 2001).

Fins a l'acabament d'aquest segle i principis del xx, no es va formalitzar la Teoria de Conjunts de Georg Cantor i, per tant, no es va produir tampoc la formalització del conjunt dels nombres enters basada en ella. Serà aquesta la que s'utilitzarà en el present tema. 


\subsection{Al tema}

Els nombres enters són una extensió dels nombres naturals, formada pels propis nombres naturals no nuls $(1,2,3 \ldots)$, els seus corresponents negatius $(-1,-2,-3 \ldots)$ i el zero (0). El conjunt de tots els enters es denota per la lletra Z, per ser la primera de la paraula «nombre», en alemany $z a h l$, i es representa per:

$$
\mathbb{Z}: \ldots . .3,-2,-1,0,1,2,3 \ldots
$$

Els enters engloben els nombres naturals i, al mateix temps, són un subconjunt dels nombres racionals. A la figura 1 es pot veure una representació d'aquestes relacions d'inclusió.

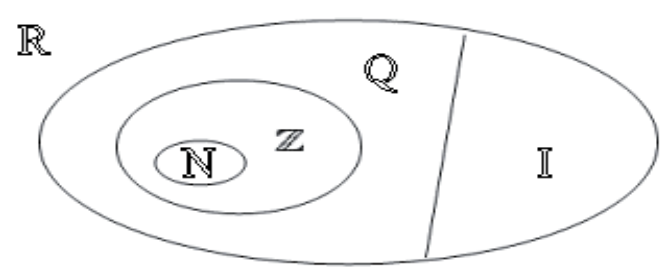

Figura 1. Representació de conjunts numèrics

On $($ representa els nombres racionals, II els irracionals i la unió dels racionals i els irracionals forma el conjunt dels nombres reals, $\mathbb{R}$.

\section{Formalització del conjunt de nombres enters}

\subsection{Construcció dels nombres enters}

Per tal de construir els nombres enters, s'ha de partir dels que ja coneixem, que són els naturals. No hi ha cap conjunt numèric més que puguem utilitzar, i només amb les propietats que dels nombres naturals es poden derivar, s'ha de construir un conjunt on aquests mateixos estiguen inclosos.

Aleshores, cal partir de $N: 0,1,2, \ldots$ i, tenint en compte un seguit de consideracions, arribar al conjunt dels nombres enters.

Per a començar la construcció d'aquest conjunt, és convenient recordar que anomenem producte cartesià de dos conjunts $\boldsymbol{A}, \boldsymbol{B}$ i ho simbolitzem per $\boldsymbol{A} \mathrm{x} \boldsymbol{B}$, a tots els parells ordenats d'elements que es poden formar agafant com a primer element, un del conjunt $\boldsymbol{A}$ i com a segon, un del $\boldsymbol{B}$, és a dir $\mathbf{A} \times \mathbf{B}=\{(\mathbf{a}, \mathbf{b}) / \mathbf{a} \in \mathbf{A} \wedge \mathbf{b} \in \mathbf{B}\}$. 
Així doncs, primer cal considerar el conjunt definit pel producte cartesià $\mathbf{N} \times \mathbf{N}$ on $N$ és el conjunt dels nombres naturals:

$$
\mathbf{N} \times \mathbf{N}=\{(\mathbf{a}, \mathbf{b}) / \mathbf{a} \in \mathbf{N} \wedge \mathbf{b} \in \mathbf{N}\}
$$

Gràficament aquest conjunt seria una xarxa de punts graduada, que començaria al $(\mathbf{0 , 0 )}$ i tendiria a l'infinit, com es mostra a la figura 2.

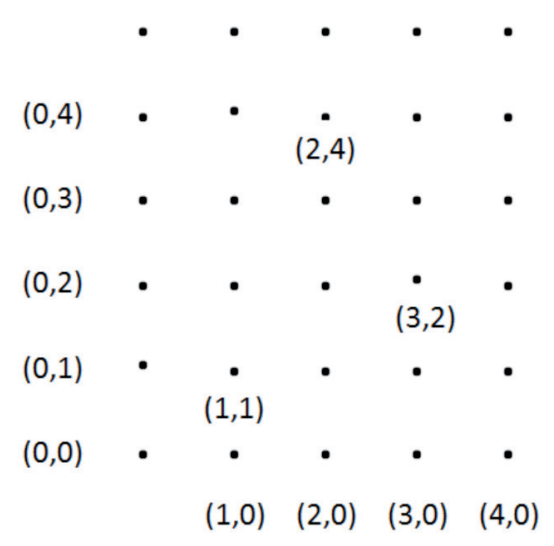

Figura 2. Representació parcial de $\mathbf{N} \times \mathbf{N}$

De la mateixa manera que al pla cartesià, la primera coordenada correspon a l'eix $\mathbf{X}$ i la segona a l'eix $\mathbf{Y}$, per tant, és fàcil observar que tots els parells de naturals situats en la mateixa columna, comparteixen la primera coordenada i, si es troben en la mateixa fila, comparteixen la segona.

Però hi ha una tercera manera d'observar-los, no tant evident, que ens permetrà la construcció dels nombres enters: és la que considera els parells situats en la diagonal amb origen en $(0,0)$ o en qualsevol de les direccions paral·leles a ella (Colectivo Periódica Pura, 1982). Considerem l'esmentada diagonal, els elements de la qual serien de la forma $(\mathbf{0 , 0}),(\mathbf{1}, \mathbf{1}),(\mathbf{2}, \mathbf{2}) \ldots$ i les seues paral·leles (figura 3 ).

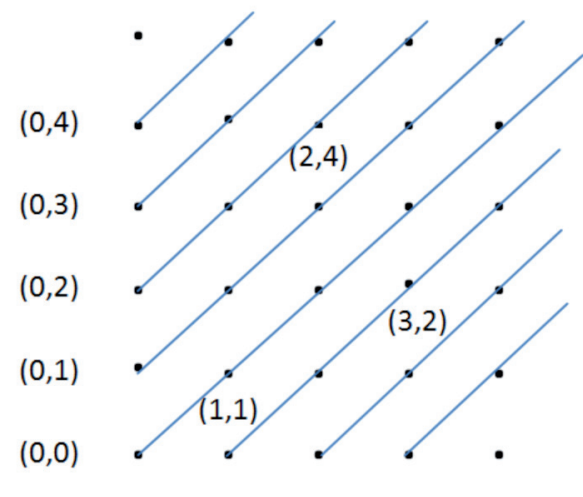

$(1,0) \quad(2,0) \quad(3,0) \quad(4,0)$

Figura 3. Representació d'alguns parells de $\mathbf{N} \times \mathbf{N}$ 
Si agafem dos punts qualssevol, $(\boldsymbol{a}, \boldsymbol{b})$ i $(\boldsymbol{c}, \boldsymbol{d})$, d'una d'aquestes semirectes es pot comprovar que $\boldsymbol{a}+\boldsymbol{d}=\boldsymbol{b}+\boldsymbol{c}$. Per exemple, en l'agafar de l'esmentada diagonal $(0,0)$ i $(1,1)$, es compleix que $0+1=0+1$; si agafem $(1,1)$ i $(5,5)$, es compleix que $1+5=1+5 \ldots$

Com que en aquesta direcció els dos valors de cada parell ordenat són iguals, no queda suficientment clar que la igualtat es verifique per a qualsevol parell de punts d'altres semirectes. Per a comprovar-ho en algun cas més es pot agafar la semirecta immediatament a la dreta de la diagonal principal, és a dir, aqueixa els elements de la qual són de la forma: $(1,0),(2,1),(3,2) \ldots$ i procedir de manera semblant al cas anterior. Si agafem $(1,0)$ i $(2,1)$ es compleix $1+1=0+2$; si agafem $(2,1)$ i $(3,2)$ es compleix $2+2=1+3 \ldots$

Es podria comprovar reiteradament amb qualssevol de les paral·leles a la diagonal. Aquest fet s'utilitza per a definir la següent relació R:

$$
\forall(a, b),(c, d) \in N \times N:(a, b) R(c, d) \leftrightarrow a+d=b+c
$$

que és una relació binària d'equivalència, perquè verifica les propietats reflexiva, simètrica i transitiva. Les classes d'equivalència que d'aquesta se'n deriven formen una partició del conjunt $\mathbf{N} \times \mathbf{N}$, perquè qualsevol dels seus elements pertany sempre a una de les classes i no n'hi ha cap element que forme part de dues classes d'equivalència alhora. La representació gràfica de cadascuna d'aquestes classes és un conjunt de punts situats a sobre d'una de les semirectes de la figura anterior.

Formalment, aquesta partició del conjunt $\mathbf{N}$ x $\mathbf{N}$ és un conjunt quocient, l'expressió del qual és:

$$
\mathbf{N} \times \mathbf{N} / \mathbf{R}=\{[(\mathrm{x}, \mathrm{y})] /(\mathrm{x}, \mathrm{y}) \in \mathbf{N} \times \mathbf{N}\}
$$

on $[(x, y)]=\{(a, b) \in N \times N /(x, y) R(a, b)\}$ és una classe d'equivalència genèrica, que rep el nom de nombre enter.

Aquest nou conjunt serà el dels nombres enters, i es denota per $\mathbb{Z}=\mathbf{N} \times \mathbf{N} / \mathbf{R}$

Però encara els nombres enters no tenen la forma que habitualment presenten $\mathrm{i}$ com tots $i$ totes els coneixem: ..., $\mathbf{- 3}, \mathbf{- 2}, \mathbf{- 1}, \mathbf{0}, \mathbf{1}, \mathbf{2}, \mathbf{3} .$. caldrà, doncs, encara un pas més.

El pas és convertir una simbologia formada per un parell de nombres entre claudàtors, en un únic nombre amb un signe (bé positiu, bé negatiu) o sense signe, en el cas del zero. Per a aconseguir-ho fem el següent càlcul: $\forall(a, b) \in N \times N$, el nombre enter $\boldsymbol{m}$ corresponent a la classe d'equivalència de $(\boldsymbol{a}, \boldsymbol{b})$ es defineix com: 
- $\mathbf{m}=\mathbf{0}$, si $\mathbf{a}=\mathbf{b}$

- $\mathbf{m}=+(\mathbf{a}-\mathbf{b})$ si $\mathbf{a}>\mathbf{b}$, és a dir, un enter positiu

- $\mathbf{m}=-(\mathbf{b}-\mathbf{a})$ si $\mathbf{b}>\mathbf{a}$, és a dir, un enter negatiu

Per exemple, si agafem de nou punts de la diagonal amb origen en $(0,0)$ : $(\mathbf{0 , 0})$, $(\mathbf{1}, \mathbf{1}),(\mathbf{2}, \mathbf{2}) .$. en tots ells la primera component és igual a la segona $(\mathbf{a}=\mathbf{b})$, per tant, el nombre enter que correspon a aquesta classe d'equivalència és el $\mathbf{0}$.

Si agafem punts de la paral-lela immediata a la dreta de l'anterior: $(\mathbf{1 , 0}),(\mathbf{2}, \mathbf{1})$, $(\mathbf{3}, \mathbf{2}) \ldots$ en tots ells la primera component és major que la segona $(\mathbf{a}>\mathbf{b})$, per tant, el nombre enter corresponent a aquesta classe és positiu. Quin serà? En tots els parells d'aquesta classe d'equivalència $\mathbf{a}-\mathbf{b}=\mathbf{1}$, aleshores, el nombre enter que s'obté és el +1. De manera anàloga, agafant les semirectes que tenen el seu origen en l'eix horitzontal, s'obtenen els altres enters positius.

Agafant novament punts d'altra paral·lela, en aquest cas, la immediata a l'esquerra: $(\mathbf{0 , 1}),(\mathbf{1}, \mathbf{2}),(\mathbf{2}, \mathbf{3}) \ldots$ en tots ells la segona component és major que la primera $(\mathbf{b}>\mathbf{a})$, per tant, el nombre enter corresponent a aquesta classe és negatiu. Quin serà ara? En tots els parells d'aquesta classe d'equivalència $\mathbf{b}-\mathbf{a}=\mathbf{1}$, aleshores, el nombre enter que s'obté és el -1. De manera anàloga, si considerem les semirectes que tenen el seu origen en l'eix vertical, s'obtenen els altres enters negatius (figura 4).

Gràficament tindríem:

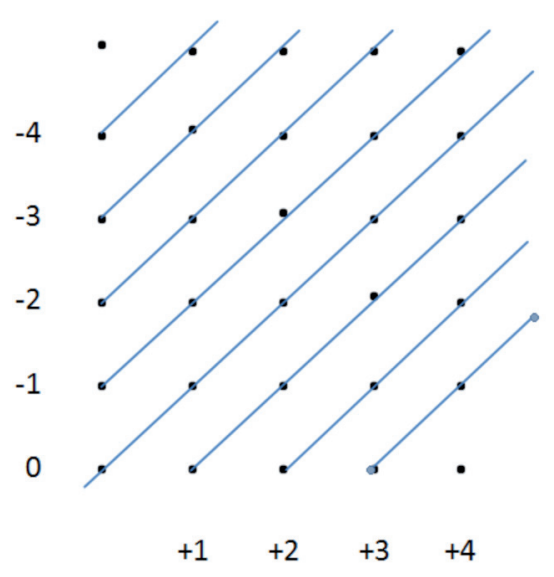

Figura 4. Representació d'alguns nombres enters a partir de les seues classes d'equivalència

Si en esta taula cartesiana fem l'abatiment de l'eix d'ordenades cap a l'esquerra obtenim la representació d'alguns nombres enters en la recta numèrica (figura 5).

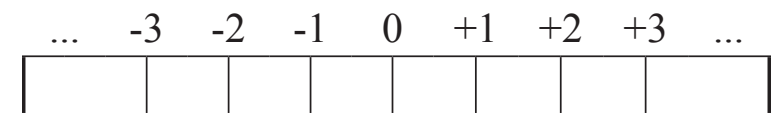

Figura 5. Representació d'alguns nombres enters en la recta numèrica 
Cal notar que, segons el que acabem de veure, qualsevol nombre enter pot tenir un representant amb el zero en una de les dues components, anomenat representant canònic de la classe. És a dir, si tenim el -2, podem representar-lo per multitud de parells $(2,4),(8,10),(5,7),(1.000,1.002) \ldots$ Entre aquests, trobarem el $(0,2)$, que és el seu representant canònic. De manera semblant, +3 té com a representant canònic $(3,0)$, encara que hi ha uns altres representants de la mateixa classe d'equivalència, com per exemple $(5,2)$. En general, els representants canònics dels enters positius en tenen un nombre natural no nul en la primera component y un zero en la segona, y els dels negatius, un zero en la primera component y un nombre natural no nul en la segona.

Com a conseqüència de l'anterior, tenim el conjunt $\mathbf{Z}$ descompost en tres subconjunts: $\boldsymbol{Z}^{-},\{0\}_{i} \boldsymbol{Z}^{+}$, és a dir: $\boldsymbol{Z}=\boldsymbol{Z}^{-} \cup\{0\} \cup \boldsymbol{Z}^{+}$.

\subsection{Operacions amb nombres enters}

\section{Addició}

Si s'estableix l'aplicació $\mid \begin{array}{rll}(+): \mathbf{Z} \times \mathbf{Z} & \rightarrow & \mathbf{Z} \\ (\mathbf{j}, \mathbf{k}) & \rightarrow & \mathbf{j}+\mathbf{k}\end{array}$ per definir l'addició de nombres enters de manera molt genèrica, no es concreten totes les possibles combinacions de signes que ens podem trobar, per exemple:

- $(+3)+(+2)$

- $(+3)+(-2)$

- $(-3)+(+2)$

- $(-3)+(-2)$

Hauríem de recórrer a la representació de cada nombre enter per un parell de la seua classe d'equivalència, per tal de determinar d'una manera més clara la definició de l'addició per a nombres enters.

Si representem +3 pel parell $(3,0),-3$ per $(0,3),+2$ per $(2,0),-2$ per $(0,2)$, les addicions anteriors es poden expressar com:

- $(+3)+(+2)=[(3,0)]+[(2,0)]$

- $(+3)+(-2)=[(3,0)]+[(0,2)]$

- $(-3)+(+2)=[(0,3)]+[(2,0)]$

- $(-3)+(-2)=[(0,3)]+[(0,2)]$

I el resultat es calcularà sumant les primeres components dels dos parells, per un costat i les segones per l'altre, és a dir:

- $[(3,0)]+[(2,0)]=[(3+2,0)]=[(5,0)]$, per tant $(+3)+(+2)=+5$

- $[(3,0)]+[(0,2)]=[(3,2)]=[(1,0)]$, aleshores $(+3)+(-2)=+1$ 
- $[(0,3)]+[(2,0)]=[(2,3)]=[(0,1)]$, llavors $(-3)+(+2)=-1$

- $[(0,3)]+[(0,2)]=[(0,3+2)]=[(0,5)]$, és a dir $(-3)+(-2)=-5$

Així, l'aplicació que realment defineix l'addició de nombres enters és:

$$
\begin{aligned}
& (+): \quad \quad Z \times Z \quad \rightarrow \quad Z \\
& ([(a, b)],[(\mathbf{c}, \mathbf{d})]) \rightarrow[(\mathbf{a}+\mathbf{c}, \mathbf{b}+\mathbf{d})]
\end{aligned}
$$

Aquesta operació compleix les propietats:

- Associativa.

- Commutativa.

- Element neutre $[(\mathbf{0 , 0})]$.

- Element simètric de $[(\mathbf{a}, \mathbf{b})]$ serà $[(\mathbf{b}, \mathbf{a})]$, perquè $(\mathbf{a}+\mathbf{b}, \mathbf{b}+\mathbf{a})$ és un element de la classe del $(\mathbf{0 , 0})$. A l'element simètric per l'addició de qualsevol enter se l'anomena oposat. És clar que l'oposat de $+\mathbf{a}$ és $-\mathbf{a}$ i a l'inrevés i que l'element neutre $[(\mathbf{0 , 0})]$ és el simètric de sí mateix.

Per tant, el conjunt $\boldsymbol{Z}$ amb l'operació que s'acaba de definir, $(\boldsymbol{Z},+)$, té estructura de grup abelià (vegeu l'annex).

Definim la subtracció de dos nombres enters $\boldsymbol{z}$ i $\boldsymbol{k}$ com el nombre enter $\boldsymbol{p}=\boldsymbol{q} \boldsymbol{- k}$, de manera que $\boldsymbol{p}+\boldsymbol{k}=\boldsymbol{z}$. A nivell pràctic $\boldsymbol{z}-\boldsymbol{k}=\boldsymbol{q}+(-\boldsymbol{k})$. És a dir, restar un nombre enter és el mateix que sumar l'oposat d'aquest.

Cal tenir en compte que $\forall \mathbf{z}, \mathbf{k} \in \mathbf{Z}$ :

$-(-q)=q$

$-(z+k)=-q-k$

$-(\mathrm{z}-\mathrm{k})=-\mathrm{z}+\mathrm{k}$

\section{Multiplicació}

En la multiplicació, arribar a deduir l'aplicació amb els parells de nombres que representen els enters és més complicat que no pas en el cas de l'addició. La primera aplicació que hi podem considerar és:

$$
\begin{aligned}
& \text { (.): } \mathrm{Z} \times \mathrm{Z} \quad \rightarrow \quad \mathrm{Z} \\
& (\mathrm{j}, \mathrm{k}) \quad \rightarrow \quad \mathrm{j} \cdot \mathrm{k}
\end{aligned}
$$

Aquesta aplicació defineix la multiplicació de nombres enters, com sabem de manera molt genèrica, però tampoc concreta totes les possibles combinacions de signes que ens podem trobar. Amb exemples semblants als de l'addició tindríem: 
- $(+3) \cdot(+2)$

- $(+3) \cdot(-2)$

- $(-3) \cdot(+2)$

- $(-3) \cdot(-2)$

En aquest cas, no és tant senzill com en l'addició veure com funciona l'operació. Això ens obliga a definir-la de manera formal des del primer moment:

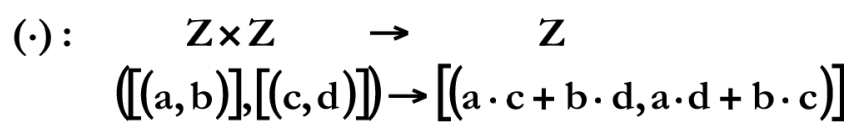

Així, representant +3 pel parell $(3,0),-3$ per $(0,3),+2$ per $(2,0),-2$ per $(0,2)$, les multiplicacions anteriors es poden expressar com:

- $(+3) \cdot(+2)=[(3,0)] \cdot[(2,0)]=[(3 \cdot 2+0 \cdot 0,3 \cdot 0+0 \cdot 2)]=[(6,0)]=+6$

- $(+3) \cdot(-2)=[(3,0)] \cdot[(0,2)]=[(3 \cdot 0+0 \cdot 2,3 \cdot 2+0 \cdot 0)]=[(0,6)]=-6$

- $(-3) \cdot(+2)=[(0,3)] \cdot[(2,0)]=[(0 \cdot 2+3 \cdot 0,0 \cdot 0+3 \cdot 2)]=[(0,6)]=-6$

- $(-3) \cdot(-2)=[(0,3] \cdot[(0,2)]=[(0 \cdot 0+3 \cdot 2,0 \cdot 2+3 \cdot 0)]=[(6,0)]=+6$

Observant els signes dels factors i dels productes, ens adonem que quan els factors tenen el mateix signe, el resultat és positiu, però si aquests són diferents, el producte és negatiu:

- $(+) \cdot(+)=+$

- $(+) \cdot(-)=-$

- $(-) \cdot(+)=-$

- $(-) \cdot(-)=+$

Aquesta regla s'acompleix per a tots els casos, com es pot comprovar en les següents expressions amb representants canònics:

- $(+a) \cdot(+b)=[(a, 0)] \cdot[(b, 0)]=[(a \cdot b, 0)]=+(a \cdot b) \in \mathbf{Z}^{+}$

- $(+a) \cdot(-b)=[(a, 0)] \cdot[(0, b)]=[(0, a \cdot b)]=-(a \cdot b) \in \mathbf{Z}^{-}$

- $(-a) \cdot(+b)=[(0, a)] \cdot[(b, 0)]=[(0, a \cdot b)]=-(a \cdot b) \in \mathbf{Z}^{-}$

- $(-a) \cdot(-b)=[(0, a)] \cdot[(0, b)]=[(a \cdot b, 0)]=+(a \cdot b) \in \mathbf{Z}^{+}$

Nota: L'anterior demostració de la regla de signes és la que correspon a la formalització dels conjunts numèrics per G. Cantor a finals del segle XIX. Això no vol dir que abans d'ella no s'haguera treballat per altres mètodes aquesta qüestió. Un parell d'exemples són:

Mac Laurin (1748):

Per a tots els valors «a, n» naturals, i partint de $(+a)+(-a)=0$, tenim que: 
Cas 1, enter negatiu per enter positiu és un enter negatiu:

Multiplicant la igualtat per $(+n):[(+a)+(-a)] \cdot(+n)=0$ i aplicant-hi la propietat distributiva, obtenim: $(+a) \cdot(+n)+(-a) \cdot(+n)=0$. Aleshores, és clar que l'oposat de $(+a)$ $\cdot(+n)$ és $(-a) \cdot(+n)$, és a dir, $-[(+a) \cdot(+n)]=(-a) \cdot(+n)$, i per tant «menys per més és menys». Anàlogament, i aplicant-hi la propietat commutativa, «més per menys és menys».

Cas 2, enter negatiu per enter negatiu és un enter positiu:

Si multipliquem la igualtat per $(-n):[(+a)+(-a)] \cdot(-n)=0$ i apliquem la propietat distributiva, obtenim: $(+a) \cdot(-n)+(-a) \cdot(-n)=0$. Així doncs l'oposat de $(+a) \cdot$ $(-n)$ és $(-a) \cdot(-n)$, és a dir, $-[(+a) \cdot(-n)]=(-a) \cdot(-n) i$, per tant, «menys per menys és més».

HANKEL (1867)

Per a tots els valors «a, b» naturals, s'ha de partir de dues possibilitats, i extraure conclusions:

$0=(+a) \cdot 0=(+a) \cdot[(+b)+(-b)]=(+a) \cdot(+b)+(+a) \cdot(-b)$

$0=0 \cdot(-b)=[(+a)+(-a)] \cdot(-b)=(+a) \cdot(-b)+(-a) \cdot(-b)$

De la primera igualtat, com que l'oposat del positiu $(+a) \cdot(+b)$ és $(+a) \cdot(-b)$, es dedueix que $-[(+a) \cdot(+b)]=(+a) \cdot(-b) i$, per tant, «més per menys és menys». Aplicant-hi la propietat commutativa, és evident que «menys per més és menys».

De la segona igualtat, com que l'oposat de $(+a) \cdot(-b)$ (que pel paràgraf anterior sabem que és negatiu) és $(-a) \cdot(-b)$, aleshores aquest valor ha de ser positiu. És a dir, «menys per menys és més».

Amb les propietats associativa, commutativa i amb l'existència d'element neutre $+\mathbf{1}=[(\mathbf{1 , 0})],(\mathbf{Z}, \cdot)$ és un semigrup abelià i unitari. Com que, a més, es compleix la propietat distributiva de la multiplicació respecte de l'addició, $(\mathbf{Z},+, \cdot)$ és un anell commutatiu i unitari (vegeu annex).

\subsection{Immersió dels naturals en els enters}

El conjunt dels nombres naturals és un subconjunt dels nombres enters. Per tal de formalitzar aquesta inclusió, definim la següent aplicació:

$\begin{array}{ccc}f: N & \rightarrow & Z \\ n & \rightarrow & f(n)=[(n, 0)]\end{array}$ negatiu. Aplicació que acompleix les següents propietats: 
- $\mathbf{f}$ és injectiva (les imatges de dos elements originals diferents són diferents).

- $\forall \mathrm{m}, \mathrm{n} \in \mathrm{N}: \mathrm{f}(\mathrm{m}+\mathrm{n})=\mathrm{f}(\mathrm{m})+\mathrm{f}(\mathrm{n})$

- $\forall \mathrm{m}, \mathrm{n} \in \mathrm{N}: \mathrm{f}(\mathrm{m} \cdot \mathrm{n})=\mathrm{f}(\mathrm{m}) \cdot \mathrm{f}(\mathrm{n})$

- $\mathbf{f}(0)=[(0,0)]$ que és l'element neutre de l'addició.

- $\mathbf{f}(\mathbf{1})=[(1,0)]$ que és l'element neutre de la multiplicació.

Així doncs, com que l'aplicació que acabem de definir és injectiva i conserva les operacions dels nombres naturals, es pot identificar cada nombre natural amb la seua imatge i considerar que el conjunt dels naturals és part dels enters.

\subsection{Ordre a $Z$}

Ens fem ara la pregunta: «hi ha ordre en el conjunt de nombres enters?». Si observem la representació gràfica de la figura 4 de les classes d'equivalència en sentit de dalt a baix i d'esquerra a dreta, contestaríem, "sí i l'ordre és $\ldots \leq-3 \leq-2 \leq-1 \leq$ $0 \leq+1 \leq+2 \leq+3 \leq \ldots$, que és precisament el que podem veure si ens desplacem per la recta numèrica en el mateix sentit (figura 5).

La formalització d'aquest ordre amb les classes d'equivalència de parells de nombres naturals seria: $[(\mathbf{a}, \mathbf{b})] \leq[(\mathbf{c}, \mathbf{d})]$ si i sols si (en endavant sii) $\mathbf{a}+\mathbf{d} \leq \mathbf{b}+\mathbf{c}$

Aquesta relació binària verifica les propietats reflexiva, antisimètrica, transitiva $\mathrm{i}$ connexa. És, per tant, una relació d'ordre total i fa que els nombres enters estiguen totalment ordenats. A més, l'ordre definit conserva el seu sentit amb l'addició i amb la multiplicació per enters no negatius:

- $\forall x, y, z \in Z$ amb $x \geq y \Rightarrow x+z \geq y+z$

- $\forall x, y, z \in Z$ amb $x \geq y, z \geq 0 \Rightarrow x \cdot z \geq y \cdot z$

En el cas de la multiplicació por enters negatius, s'inverteix el sentit de l'ordenació:

- $\forall \mathrm{x}, \mathrm{y}, \mathrm{z} \in \mathrm{Z}$ amb $\mathrm{x} \geq \mathrm{y}, \mathrm{z}<0 \Rightarrow \mathrm{x} \cdot \mathrm{z} \leq \mathrm{y} \cdot \mathrm{z}$

Si expressem aquesta relació d'ordre amb nombres enters qualssevol $\mathbf{z}_{1}$ i $\mathbf{z}_{2}$, i no amb parells de nombres naturals, tindrem que: $\mathbf{z}_{\mathbf{1}} \leq \mathbf{z}_{2}$ sii $\mathbf{z}_{1}-\mathbf{z}_{2} \leq \mathbf{0}$.

Com a resum de totes les propietats expressades per al conjunt dels nombres enters direm que $(\mathbf{Z},+, \cdot, \leq)$ és un anell commutatiu i unitari totalment ordenat (vegeu annex) 


\section{Els nombres enters a l'aula de primària}

\subsection{Situacions on poden aparèixer}

Al nostre voltant hi ha contextos on els nombres enters s'utilitzen en situacions quotidianes en les que és necessari representar un estat o una variació:

- Termòmetres. Per a diferenciar temperatures per dalt i per sota de $0^{\circ} \mathrm{C}$ (nombres positius i negatius, respectivament) i expressar canvis (augments o disminucions) de temperatura.

- Ascensors. Per a indicar pisos per dalt i per sota del nivell del carrer (nombres positius i negatius, respectivament), o pujades i baixades des d'un nivell qualsevol.

- Comptes bancaris. Per a indicar si hi ha dèficit o superàvit de diners (nombres negatius i positius, respectivament) o augment i disminució de capital.

- Avions $i$ submarins. En aquest cas, el nivell del mar seria el 0 i es podria representar les posicions d'aquests mòbils o les seues variacions.

- Línies temporals. Per tal de diferenciar temps anterior o posterior a un moment determinat (nombres negatius i positius, respectivament) o l'evolució temporal d'alguns fets històrics.

Aquestes situacions i d'altres conviuen amb els xiquets i xiquetes fora de l'escola. Poden aparèixer en qualsevol moment a dintre de l'aula des de $1 \mathrm{r}$ fins $4 \mathrm{t}$ de primària i s'ha de fer referència al signe per a indicar el problema que resol, però no es treballaran els nombres enters com a conjunt numèric fins a 6é de primària. La justificació formal serà la impossibilitat de calcular subtraccions en el conjunt dels nombres naturals quan el subtrahend siga major que el minuend. Cal ampliar l'horitzó numèric en el qual han treballat per a poder resoldre aquest problema.

\subsection{Introducció dels nombres enters a l'aula}

A l'aula de primària, s'introduiran els nombres enters a partir de les situacions abans esmentades que necessiten, per a la seua correcta representació, l'ús dels signes i la diferenciació entre els nombres positius i negatius, que s'han de representar amb els signes $+\mathrm{i}-$ respectivament, $+3{ }^{\circ} \mathrm{C},-9{ }^{\circ} \mathrm{C}$, soterrani $2(-2)$, perdre $1.000 €(-1.000 €) \ldots$

Una manera d'ajudar els alumnes a comprendre el funcionament i significat del signe i dels nombres negatius, és la utilització del mètode d l'escala (figura 6). Consisteix a considerar dos trams d'escala separats per un replanell, que representa el 0 , de manera que sempre s'ha de passar per aquest quan el moviment siga de positius a negatius o a l'inrevés. 


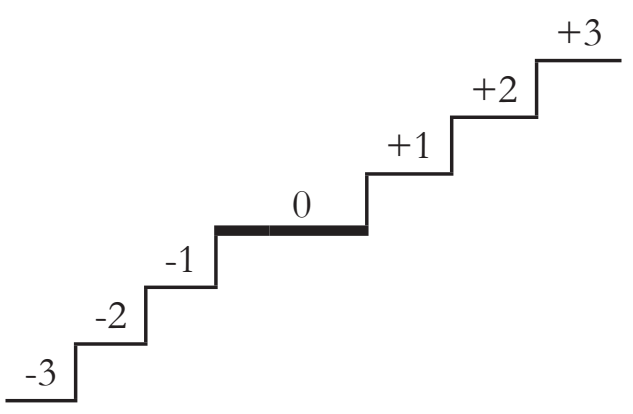

Figura 6. Representació del model didàctic de l'escala per a nombres enters

De les dues possibilitats de dibuixar l'escala, ascendent o descendent d'esquerra a dreta, creiem més convenient la primera, perquè quan procedim a traslladar els nombres enters des de l'escala fins a la recta horitzontal apareixeran representats com a la recta numèrica anterior (figura 5).

La disposició dels nombres enters a sobre de l'escala ens aprofita per a ordenar-los i dir que l'enter d'un graó és menor que el corresponent del graó superior i cadascun situat en un graó serà major que tots els corresponents en els graons inferiors. Això, que per als nombres naturals és intuïtiu i immediat, ens permet ordenar, sense cap problema, els enters no negatius $i$ es converteix en una ajuda quan ens referim als que sí que ho són. Per exemple -4 i -1. Quin és major? La intuïció els fa dir que el -4 , perquè 4 és major que 1 , però en situar-los a sobre de l'escala, observem que el nombre -1 està per damunt de -4 i, per tant, és major.

\subsection{Les operacions amb nombres enters en l'aula}

Després de resoldre algunes situacions com les del punt 3.1 de manera intuïtiva, a partir de les accions reals, el diàleg i la reflexió amb l'alumnat, i per ajudar-los a automatitzar l'operativitat amb els nombres enters (si és què es treballa en el darrer curs de primària), usarem de nou el mètode de l'escala, que ens permet explicar les addicions de nombres enters. Consistirà en situar el primer sumand en l'escala i pujar o baixar tants graons com indique el segon nombre, segons siga positiu o negatiu, respectivament

Per exemple, per a trobar la solució a la situació problemàtica que es crea si ens preguntem: "Anem de compres a un gran centre comercial. Si estem al soterrani quart de l'aparcament i pugem tres pisos, a quin pis arribarem?», necessitem resoldre l'addició $(-4)+(+3)$.

Ens situem al -4: 


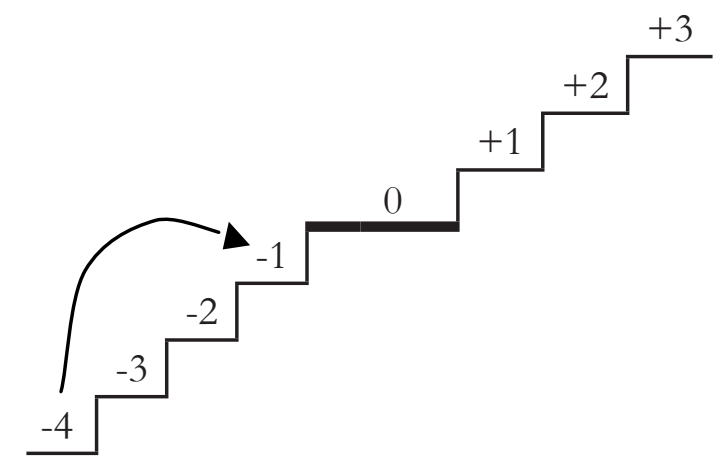

Figura 7. Representació de l'addició $(-4)+(+3)$ amb l'ajuda de l'escala

$\ldots$ i +3 , significa pujar 3 graons, així arribarem al 1r soterrani (figura 7). L'operació que ens ha permès obtenir al resultat numèric és, per tant, $(-4)+(+3)=-1$.

En un primer moment, per a distingir el signe del nombre del de l'operació podem escriure $+(+3)$. Després, una vegada els xiquets i xiquetes hagen assolit la identificació dels naturals amb els enters no negatius, afavorirem que passen a expressar +3 com 3 i aleshores $(-4)+(+3)$ com $(-4)+3$.

Si l'addició que s'ha de fer és $(+2)+(-3)$, la situació problemàtica seria «Si estem al $2 \mathrm{n}$ pis d'un gran centre comercial i baixem tres pisos per agafar el cotxe, a quin pis arribarem?», la solució gràfica seria:

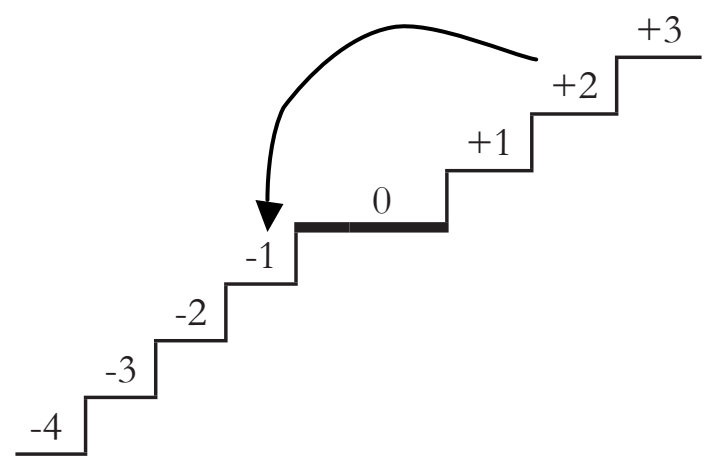

Figura 8. Representació de l'addició (+2) + (-3) amb l'ajuda de l'escala

$\ldots$ i, per tant, $(+2)+(-3)=-1$. Ara, arribarem també al primer soterrani (figura 8).

Es faran més exemples d'addicions reflexionant amb l'alumnat sobre els sumands i la suma, ajudant-los a que mitjançant les situacions problemàtiques treballades arriben a resoldre les operacions numèricament, sense utilitzar el model de l'escala.

Recordem que en operar amb nombres naturals la subtracció és l'operació contrària a l'addició, aquesta mateixa idea es manté en operar amb nombres enters. Per 
la qual cosa, si el signe de l'addició de nombres enters implicava pujar o baixar graons segons el signe positiu o negatiu del segon sumand, ara el signe de la subtracció implicarà fer el contrari del que indica el segon terme, el subtrahend, és a dir, si aquest és positiu, caldrà baixar, i si és negatiu, caldrà pujar.

Podem practicar aquesta operació utilitzant situacions com per exemple: «En un dia d'hivern, a la població de Morella s'enregistren $5{ }^{\circ} \mathrm{C}$ sobre zero com a temperatura màxima i $8^{\circ} \mathrm{C}$ sota zero com a mínima. Quina ha estat la diferència de temperatura al llarg d'aquest dia?».

Per la idea que tenen de subtracció de nombres naturals, associaran aquesta operació amb la resposta que han de donar. Per tant, caldrà restar: $(+5)-(-8)$ i seguint les indicacions anteriors del model de l'escala, pujar 8 esglaons. És a dir, $(+5)-(-8)=$ $=(+5)+(+8)=+13$. La diferència de temperatura ha estat 13 graus .

Si observem aquesta operació podrem adonar-nos que per restar -8 , hem sumat +8 . Es faran més exemples de subtraccions reflexionant amb l'alumnat sobre el canvi de signe que s'aplica al subtrahend de qualsevol subtracció de nombres enters (vegeu punt 2.2), arribant així a la idea que restar un nombre enter serà el mateix que sumar el seu oposat, és a $\operatorname{dir}( \pm \mathbf{a})-( \pm \mathbf{b})=( \pm \mathbf{a})+(\mp \mathbf{b})$.

Respecte de la multiplicació, si es plantejara el cas de treballar-la en l'aula, buscarem situacions que puguen reflectir les quatre possibles combinacions de signes comentades al punt 2.2.

En primer lloc i per treballar multiplicacions de dos enters positius, podem utilitzar una situació com la següent, relacionada amb l'assignatura Coneixement del Medi: «El muntacàrregues d'una bodega de Requena es troba a la planta baixa. Si puja 4 pisos per minut, en quin pis es trobarà en 2 minuts?».

Com l'alumnat ja sap per la multiplicació de nombres naturals, el dos termes d'aquesta operació tenen significats distints. Ara el multiplicand correspondrà a «la velocitat de l'ascensor» (si puja la velocitat serà positiva, si baixa serà negativa) i el multiplicador correspondrà al «temps de desplaçament del l'ascensor» (positiu si és en el futur i negatiu si fos en el passat).

Per a resoldre la situació ens situem a la planta baixa (el 0), que seria el punt de partida. En el primer minut l'ascensor pujarà 4 pisos, arribant al +4 , i en el minut següent altres 4 pisos, arribant ara al +8 . Es trobarà, per tant, al pis 8é. L'operació que ens ha permès obtenir al resultat numèric és $(+4) \cdot(+2)=+8$ (cal notar que s'ha substituït el signe de la multiplicació x pel signe · entre els factors per a evitar l'abundància de signes en aquestes expressions).

De la resolució de més situacions semblants els xiquets i les xiquetes arribaran a concloure que el producte de dos nombres positius és també positiu. 
Per treballar multiplicacions d'un nombre negatiu per un positiu podem relacionar aquest contingut amb les extraccions de minerals a les mines i els desplaçaments que els miners fan per baixar al seu lloc de treball: «El muntacàrregues de la mina es troba a nivell del carrer. Si baixa 4 pisos per minut, en quin pis es trobarà en 2 minuts?».

Ens situem a la planta 0 , que seria el punt de partida del muntacàrregues. En el primer minut baixaria 4 pisos, arribant al -4 , i en el minut següent baixaria altres 4 pisos, arribant al -8 . L'operació serà ara: $(-4) \cdot(+2)=-8$ i el muntacàrregues es trobarà al 8é soterrani.

De manera semblant al cas anterior, i per multiplicar un nombre positiu per un negatiu, podem imaginar una situació en un gran centre comercial com la següent: «Un ascensor es troba a la planta baixa. Si puja 4 pisos per minut, en quin pis es trobava fa 2 minuts?».

Després dels dos minuts l'ascensor es troba a la planta baixa. Com la velocitat d'ascens és de 4 pisos per minut, si en el darrer minut de desplaçament va parar en la planta baixa, degué ser perquè en eixe últim minut va pujar del pis -4 al pis 0 . Seguint en el raonament, en el primer minut de moviment hagué de desplaçar-se del pis -8 al -4 .

Per representar numèricament l'operació que respon aquesta pregunta, els minuts s'han d'escriure amb signe negatiu per a indicar que ens referim a un temps anterior al moment present i el resultat serà negatiu perquè indica que l'ascensor estava, al principi, per sota de la planta baixa, és a dir, al 8é soterrani. Tindrem aleshores: $(+4) \cdot(-2)=-8$.

En el darrer cas, per tal de multiplicar dos enters negatius seguirem en el centre comercial anterior i plantejarem una situació com la següent: «Un ascensor es troba a la planta zero. Si baixa 4 pisos per minut, en quin pis es trobava fa 2 minuts?».

Després dels dos minuts l'ascensor es troba a la planta baixa. Com la velocitat de descens és de 4 pisos per minut, si en el darrer minut de desplaçament va parar en la planta baixa, degué ser perquè en eixe últim minut va baixar del pis +4 al pis 0 . Raonant de manera anàloga, en el primer minut de moviment hagué de desplaçar-se del pis +8 al +4 .

En aquest cas, tant els pisos com els minuts s'escriuran amb signe negatiu per a indicar que ens referim a baixar i a un temps anterior al moment present. L'operació serà ara: $(-4) \cdot(-2)=+8$ i la resposta és que l'ascensor es trobava al 8é pis.

Com es pot comprovar en les quatre situacions anteriors, les diferents combinacions de signes donen els mateixos resultats que s'havia vist en tractar l'operació de manera formal: 
- $(+) \cdot(+)=+$

- $(+) \cdot(-)=-$

- $(-) \cdot(+)=-$

- $(-) \cdot(-)=+$

Es faran més exemples de multiplicacions reflexionant amb l'alumnat sobre els signes dels factors i del producte, ajudant-los a que mitjançant les situacions problemàtiques treballades arriben a descobrir i assimilar la regla dels signes per ser aplicada de manera automàtica en situacions semblants.

A més del model de l'escala per treballar les operacions amb nombres enters a l'aula de primària, també podem ajudar-nos de la recta numèrica mostrada en la figura 5.

\subsection{Dificultats més freqüents amb els nombres enters}

Hi ha preconceptes de situacions en la vida real que fan que els nombres enters presenten moltes dificultats a l'hora d'integrar-los en la quotidianitat. Per exemple, hi ha el costum de dir: «Tinc $50 € » \mathrm{o}$ «dec $50 € »$, però mai direm en el llenguatge col·loquial: «Tinc $+50 € » \mathrm{o} \ll$ tinc $-50 € »$.

De vegades, considerar l'addició com una operació que augmenta una quantitat, és un obstacle per a trobar el nombre que sumat a +9 done com a resultat +4 . De la mateixa manera, trobar un nombre que restat a +4 resulte +9 és una altra complicació.

També sorgeixen problemes amb l'ordre en el conjunt dels nombres enters. S'ha comentat ja, però cal ser conscients de la diferència entre l'ordre dels nombres naturals i dels enters negatius.

Hi ha autors que consideren que el coneixement del nombre enter exigeix la ruptura amb la idea del nombre com a expressió d'una quantitat existent, de l'addició i la multiplicació com a augment d'aquesta quantitat, de la subtracció com a disminució, i de l'ordre numèric com l'establert per als nombres naturals. Totes aquestes dificultats es continuen treballant amb l'alumnat al llarg de l'etapa d'educació secundària obligatòria. 


\section{TEMA 2}

\section{Nombres racionals}

En aquest tema es treballa la construcció del concepte de nombre racional a partir del producte cartesià $\mathbf{Z} \times \mathbf{Z}^{*}$. Comença el tema $\mathrm{amb}$ una referència històrica sobre aquest concepte, seguida d'una reflexió sobre la utilització de les fraccions i les expressions decimals per representar aquests nombres. Continua amb una formalització de l'estructura del conjunt dels nombres Racionals i finalitza amb un extens tractament didàctic dels corresponents continguts en l'aula de primària.

\section{Introducció}

\subsection{Històrica}

Els egipcis, amb el seu sistema de numeració jeroglífica (que consisteix en denominar cadascun dels nombres clau $-1,10,100,1000 \ldots-$ amb un símbol i la resta per modificacions d'aquest símbol), desenvoluparen les fraccions, però sols les que tenen $1 \mathrm{com}$ a numerador, $1 / \mathrm{n}$. La resta s'expressaven com a combinacions d'aquestes (Mankiewicz, 2005).

La civilització mesopotàmica, amb el seu sistema de numeració posicional sexagesimal, va desenvolupar de manera eficaç un sistema de notació fraccionària, amb el qual s'establien aproximacions decimals vertaderament sorprenents.

L'antiga civilització xinesa, amb un sistema de numeració decimal jeroglífica, estableix que per a l'addició de fraccions és indispensable la prèvia reducció a comú denominador.

La cultura hel·lènica, creadora d'un imperi invisible i que perdura fins els nostres dies, anomenat matemàtiques, va descobrir, de manera taxativa, els nombres irracionals, demostrant, per exemple, la irracionalitat de l'arrel quadrada de 2 per reducció a l'absurd. Es va elaborar la teoria de la divisibilitat, preludi dels nombres Racionals (Ifrah, 2001).

Els àrabs, a partir del segle VIII, començaren el procés de traducció de les obres gregues conegudes, en un moment de silenci científic a la resta del món i aprofundiren en el que, posteriorment, es va conèixer com a àlgebra.

Fins a finals del segle XIX, i principis del xx, no es va formalitzar la Teoria de Conjunts de Georg Cantor i, per tant, no es va produir tampoc la formalització del conjunt dels nombres racionals basada en ella. 


\subsection{Al tema}

Els nombres racionals apareixen com a conseqüència de la insuficiència dels nombres enters per a representar moltes situacions de la vida diària i matemàticament, amb l'ànim de resoldre la igualtat $\mathbf{a} \cdot \mathbf{x}=\mathbf{b}$ sempre que $\mathbf{a} \neq 0$ i $\mathbf{b}$ no és múltiple d'a. L'objectiu del tema serà identificar les situacions reals en les quals necessitem els nombres racionals i les dificultats del maneig d'aquests, per a descobrir la necessitat de formalitzar aquest conjunt i com i quan el traslladarem a l'aula de primària.

\section{Preliminars}

Un dels objectius de les matemàtiques és descriure la realitat i expressar-la. La visió matemàtica de l'entorn està sotmesa a un llenguatge propi, a una manera d'expressar el que passa al nostre voltant. Aquest llenguatge tendirà a ser pràctic, concís, exacte, però global i general alhora, de tal manera que les situacions semblants estiguen representades sota un model únic i, quan hi apareguen diferències notables, aquestes també estiguen contemplades i el model canvie.

S'ha de tenir en compte el temps en aquesta reflexió, atès que és una variable qualitativament important en qualsevol procés matemàtic. El temps fa que un determinat concepte aparega en la història amb una concreció o forma $\mathrm{i}$, en un altre moment, amb una altra diferent. El temps farà també que aquestes concrecions es mantinguen o es generalitzen en una manifestació única.

En el cas dels nombres racionals ha passat això. Ara els denominem així i en ells, s'han generalitzat els nombres fraccionaris i part de les expressions numèriques decimals, però al llarg de la història, aquesta comunió no ha existit sempre. Ni en el moment d'aparèixer, ni amb els usos que a aquestes manifestacions de situacions reals se'ls ha donat. Les diferències a l'hora d'operar i tractar els nombres fraccionaris i els decimals són tantes, que s'acostuma a anomenar el conjunt dels nombres Racionals com a «nombres decimals i fraccionaris» en l'aula de primària, amb el risc, això sí, d'introduir-hi la idea que s'està parlant de coses diferents, quan no és cert.

I és clar, semblen coses diferents; ja en la vida diària ho semblen i s'ha d'assumir que al bagatge cultural que el xiquet o la xiqueta porta a l'escola també hi són els nombres fraccionaris i decimals, col-locats en situacions i contextos diferents. Alguns exemples:

- Quan es parla de l'alçada, el pes o l'edat. Són situacions prou habituals en les converses dels majors envers els xiquets o xiquetes. En aquesta època és molt comú quantificar aquestes variables i ells i elles ho inclouen com un fet natural: «Ja fas vuitanta cinc coma cinc centímetres» o «Peses vint quilos 
i mig» o «És més alt el teu amiguet perquè te mig any més que no tu», són algunes situacions.

- Quan es parla de capacitats. No parlarem en aquest tema d'unitats de mesura, però sí que hi poden trobar-hi moltes vegades inscripcions en ampolles de quantitats en forma de fracció $3 / 41$ o de decimal 0,75 1. És molt comú, a l'hora de parlar d'algunes situacions, utilitzar els conceptes de «la meitat de...» $\mathrm{o}$ «un terç de...» de manera intuïtiva i sense que siga necessari saber de fraccions ni decimals per a comprendre-ho.

- Amb motiu del nostre sistema monetari, els decimals ocupen un lloc important en la vida quotidiana, amb totes les seues expressions: «mig euro», «20 cèntims d'euro» o si el preu està escrit «0,20 €» i totes les variants de col·locar la marca que indica decimal, siga coma o punt: «0,20€» i «0.20€». L'alumnat no està exclòs de l'atractiu dels diners i conviu habitualment amb aquestes expressions.

- Un poc més llunyà, però tal volta per ser del món dels adults és observat per ells i elles amb major interès, poden trobar a periòdics o informatius percentatges, fraccions, decimals...

Aleshores, caldrà recollir i utilitzar aquesta informació prèvia i desvetllar les connexions entre el món fraccionari i el món de les expressions decimals.

\section{Concretant...}

La pregunta que ens podem fer és: «Realment, quins elements composen el conjunt dels nombres Racionals?».

Atenent al concepte de nombre racional, aquests seran els nombres que es relacionen amb les idees de raó, fracció o quocient de dos nombres enters. Però cal concretar un poc més, almenys puntualitzar, ja que en la construcció del conjunt no apareix cap referència a les expressions decimals.

Sabem que un nombre irracional no es pot obtenir com a resultat de la divisió de dos enters qualssevol. D'acord amb això, si considerem la fracció com la representació de la divisió de dos nombres enters i observem els resultats obtinguts d'una d'aquestes divisions, podem trobar els següents tipus d'expressions:

- Una expressió decimal exacta o finita. Es produeix quan arriba un moment en el qual el residu és zero, i finalitza la quantitat de xifres decimals: $\frac{3}{5}=0,6$. Habitualment a aquestes expressions se les anomena nombres decimals. 
- Una expressió decimal infinita, que serà d'un dels dos tipus següents:

- Expressió decimal periòdica pura. S'obté quan, immediatament després de la coma, apareix una xifra o un conjunt de xifres decimals que es repeteixen constantment. Aquesta xifra o conjunt de xifres s'anomena període i es representa amb un arc a sobre de les xifres que es repeteixen: $\frac{1}{3}=$ $0,33333 \ldots=0, \widehat{3}$

- Expressió decimal periòdica mixta. Es produeix quan el període no apareix immediatament després de la coma, sinó que hi ha xifres decimals abans del període, que no es repeteixen (la quantitat de xifres entre la part entera i el període s'anomena anteperíode):

$$
\frac{1}{6}=0,16666 \ldots=0,1 \widehat{6}
$$

La conclusió que en podem extreure és que aquestes expressions decimals i les fraccions són diferents manifestacions de la mateixa cosa i com que les fraccions representen de manera més exacta el valor dels nombres racionals (les expressions decimals infinites, no poden escriure's mai en la seua totalitat), seran aquestes les encarregades de representar-los.

I automàticament hem de pensar en les equivalències, és a dir: com passar d'una manera d'expressar la mateixa cosa a l'altra? S'ha de diferenciar:

- Si volem passar de fracció a expressió decimal, cal resoldre la divisió.

- Si el que volem és passar d'expressió decimal a fracció, s'ha d'obtenir la fracció generatriu, és a dir, aquella fracció irreductible que genera l'expressió decimal. Caldrà distingir els casos de ser expressió decimal exacta, expressió decimal periòdica pura o periòdica mixta.

Aquestes qüestions es treballaran amb detall en el present tema quan es desenvolupen les capacitats per a l'educació primària.

\section{Contextualitzant...}

La següent pregunta que ens fem és «Quines seran les situacions on es necessiten aquests nombres?».

Per respondre-la, cal fer un recorregut per les diferents interpretacions que podem donar-li a una fracció, segons el context on s'estiga treballant (Llinares y Sánchez, 1988). Així, utilitzarem fraccions:

1. Quan calga representar parts d'una unitat (relació entre les parts i el tot) i les mesures d'aquesta. S'ha de distingir, segons els casos, com és aqueixa unitat, és a dir, com és allò que volem partir: 
a) Si la unitat és contínua, per exemple un pastís, en podem fer totes les parts (teòricament) que vulguem. Un cas particular d'unitat contínua, el trobem en representar fraccions o decimals en la recta numèrica.

b) Si la unitat és discreta, per exemple un paquet de galetes, es poden fer totes les parts que es vulguen, si no exigim que els elements que composen la unitat es mantinguen sencers. En cas contrari, per exemple amb ous, sols es podrà fer un nombre determinat de parts.

2. Quan es vulga expressar el quocient d'una divisió.

3. Quan es necessite representar raons numèriques en alguna de les següents situacions:

a) Proporcionalitats

b) Probabilitats

c) Percentatges

4. Quan alguna d'elles actue com operador sobre un nombre modificant-lo.

Per treballar en totes aquestes situacions s'utilitzaran les expressions fraccionàries o decimals, en funció de la idoneïtat, familiaritat o comoditat de cadascuna d'elles. A més, serà necessari dominar l'operativitat associada a ambdúes.

\section{Formalització del conjunt de nombres racionals}

\subsection{Construcció dels nombres racionals}

Una vegada presentats els nombres racionals i les connexions amb les maneres d'expressar-los (fraccions i decimals), és el moment de conèixer la construcció que Georg Cantor va donar d'aquests nombres a principis del segle Xx. És semblant a la dels nombres enters. Cal partir dels conjunts numèrics coneguts, en particular del darrer que hem treballat i elaborar una estratègia per a poder ampliar-lo.

S'ha d'arribar a poder expressar el conjunt dels nombres Racionals, $\mathbb{Q}$ (la inicial ve de quotient) com:

$$
\mathbf{Q}=\left\{\left[\frac{\mathrm{a}}{\mathrm{b}}\right] / \mathrm{a}, \mathrm{b} \in \mathrm{Z} \wedge \mathrm{b} \neq \mathbf{0}\right\}
$$

Considerem el conjunt $\mathbf{Z}^{*}=\mathbf{Z}-\{\mathbf{0}\}$ i, a partir d'aquest, el producte cartesià definit per $\mathbf{Z} \times \mathbf{Z}^{*}=\left\{(\mathbf{a}, \mathbf{b}) / \mathbf{a} \in \mathbf{Z} \wedge \mathbf{b} \in \mathbf{Z}^{*}\right\}$. Els parells de nombres seran les fraccions $\mathrm{i}$ amb l'eliminació del zero en el segon conjunt, s'observa que mai no tindrem $\mathbf{0}$ en 
la segona component. La representació gràfica d'aquest nou conjunt seria del tipus de la xarxa següent, on en l'eix horitzontal se situarien els parells de punts que no pertanyen al conjunt $\mathbf{Z} \times \mathbf{Z}^{*}$, perquè tindrien 0 a la segona component (figura 9 ).

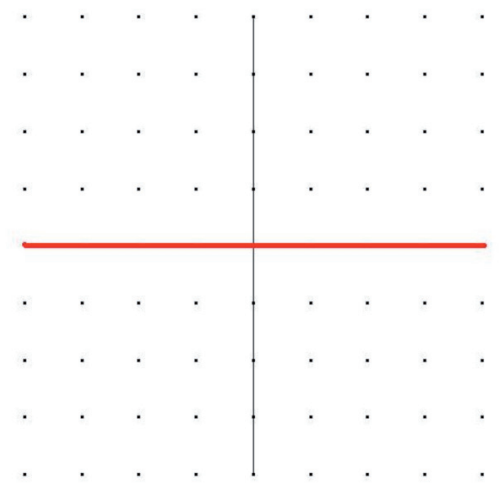

Figura 9. Representació parcial de $\mathbf{Z} \times \mathbf{Z}^{*}$

Una vegada s'ha construït el conjunt $\mathbf{Z} \times \mathbf{Z}^{*}$, cal relacionar punts del mateix. Per això s'estableix la relació $\mathbf{R}$ :

$$
\forall(\mathrm{a}, \mathrm{b}),(\mathrm{c}, \mathrm{d}) \in \mathbf{Z} \times \mathbf{Z}^{*}:(\mathrm{a}, \mathrm{b}) \mathbf{R}(\mathrm{c}, \mathrm{d}) \leftrightarrow \mathrm{a} \cdot \mathrm{d}=\mathrm{b} \cdot \mathrm{c}
$$

Aquesta és una relació binària d'equivalència, que ens diu quins dels elements d'aqueix conjunt són equivalents (estem parlant del que seran les fraccions equivalents).

La relació definida crea les classes d'equivalència:

$$
[(a, b)]=\left\{(x, y) \in Z \times Z^{*} /(x, y) R(a, b)\right\}
$$

El conjunt quocient, els elements del qual són les classes d'equivalència, és el conjunt dels nombres Racionals:

$$
\mathbf{Q}=\mathbf{Z} \times \mathbf{Z}^{*} / \mathbf{R}=\left\{[(\mathbf{a}, \mathbf{b})] /(\mathbf{a}, \mathbf{b}) \in \mathbf{Z} \times \mathbf{Z}^{*}\right\}
$$

Cada parell $(\mathbf{a}, \mathbf{b}) \in \mathbf{Z} \times \mathbf{Z} *$ es pot representar també com $\frac{\mathbf{a}}{\mathbf{b}}$, que s'anomena fracció. En aquesta representació, el nombre que s'escriu en la part de dalt rep el nom de numerador i el de la part de baix, denominador. Podem dir, per tant, que el conjunt dels nombres Racionals està format per classes d'equivalència de fraccions, definides per la relació binària que hem establert anteriorment.

És a dir, el conjunt dels nombres Racionals es pot expressar com en un principi s'ha fet:

$$
Q=\left\{\left[\frac{a}{b}\right] / a, b \in Z \wedge b \neq 0\right\}
$$


¿Com podríem representar gràficament aquestes classes d'equivalència o conjunts de fraccions equivalents? Ho veurem amb una família de fraccions equivalents, per exemple:

$$
\ldots \frac{-10}{-15}, \frac{-8}{-12}, \frac{-6}{-9}, \frac{-4}{-6}, \frac{-2}{-3}, \frac{2}{3}, \frac{4}{6}, \frac{6}{9}, \frac{8}{12}, \frac{10}{15} \ldots
$$

que representada pels parells corresponents serà:

$$
\ldots(-10,-15),(-8,-12),(-6,-9),(-4,-6),(-2,-3),(2,3),(4,6),(6,9),(8,12),(10,15) \ldots
$$

i en situar-los a la xarxa abans construïda de $\mathbf{Z} \times \mathbf{Z}^{*}$ ens permet obtenir la recta que es representa a la figura 10.

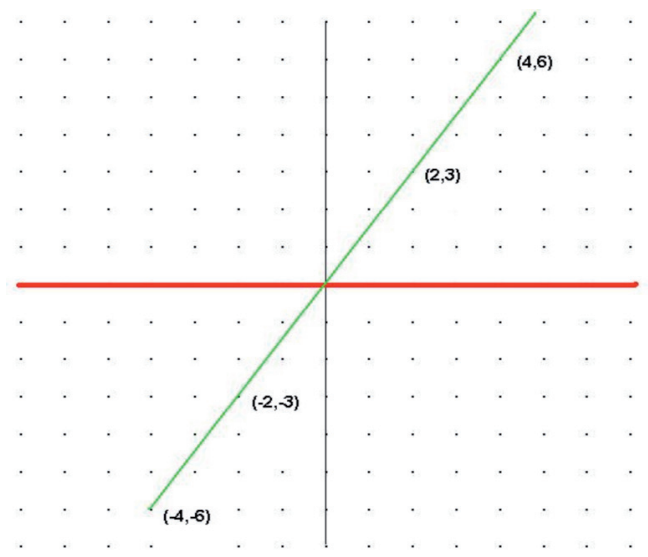

Figura10. Representació d'alguns parells de la classe d'equivalència de $(2,3)$

Gràficament, aquestes classes d'equivalència estan formades per punts que estan alineats i que es troben sobre rectes que passarien pel $(\mathbf{0 , 0})$.

Si repetirem l'exercici amb altres famílies de fraccions equivalents, s'obtindrien punts alineats sobre rectes de diferent inclinació, però que també passarien pel $\mathbf{( 0 , 0 )}$ (figura 11).

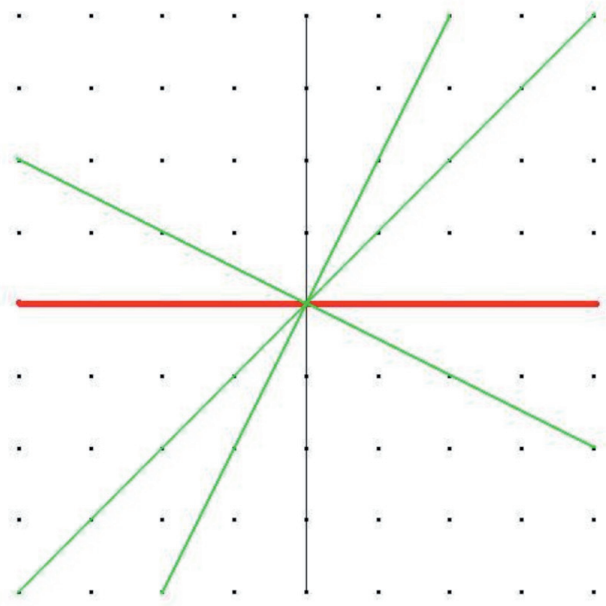

Figura 11. Representació d'algunes classes d'equivalència de $\mathbf{Z} \times \mathbf{Z}^{*}$ 
Es deixa al lector el treball d'identificar les fraccions que composen les classes d'equivalència corresponents a cadascuna de les rectes representades.

De fet, aquestes rectes tenen com expressió general $\mathbf{b} \cdot \mathbf{x}-\mathbf{a} \cdot \mathbf{y}=\mathbf{0}$ on $(\mathbf{a}, \mathbf{b})$ és la representació com a parell de la fracció $\frac{\mathbf{a}}{\mathbf{b}}$, i poden representar-se de forma explícita com: $\mathbf{y}=\frac{\mathbf{b}}{\mathbf{a}} \cdot \mathbf{x}$. Aquesta darrera expressió ens permet afirmar que les rectes treballades són de les anomenades de proporcionalitat directa.

Nota: L'única condició que se l'imposa a una fracció és que no tinga zero al denominador. Analitzem numèricament què passaria si el 0 se situés al denominador. Per exemple, si es volgués conèixer el valor del nombre racional representat per la fracció $\frac{3}{0}$, només caldria igualar a $x$ i operar: $\frac{3}{0}=x \rightarrow 3=0 \cdot x$. Quin valor per zero donaria tres? Cap. Per tant $\frac{\mathbf{3}}{\mathbf{0}}$ no representa cap nombre racional.

Aquest mateix plantejament ens porta a saber per què $(\mathbf{0 , 0 )}$ tampoc és un valor possible per representar cap nombre racional. Si s'opera: $\frac{\mathbf{0}}{\mathbf{0}}=\mathbf{x} \rightarrow \mathbf{0}=\mathbf{0} \cdot \mathbf{x}$. Quin valor per zero donaria zero? Tots, qualsevol valor. És per això que tot i pertànyer el $(\mathbf{0 , 0})$ a totes les rectes sobre les quals se situen les fraccions equivalents, no pertany a cap classe. Si no fóra així, el $\mathbf{( 0 , 0 )}$ estaria en totes les classes i de la definició de relació d'equivalència es dedueix que un element sols pot pertànyer a una de les classes, no pot formar part de més.

A l'aula de primària, es pot explicar molt senzillament que no hi ha fraccions amb denominador 0. Si s'entén el denominador de la fracció com les parts que es fan en una unitat, i el numerador com les parts que s'agafen, no podem construir cap fracció si no s'ha fet cap part.

Si s'interpreta la fracció com una divisió, l'explicació podria ser:

- $\frac{60}{0}=\ldots$ «Si avui jo he portat 60 caramels per a repartir-los, però resulta que no heu vingut ningú perquè estàveu tots malalts, puc repartir-los?». Com que no es pot fer el repartiment, aquesta divisió no té sentit.

- $\frac{\mathbf{0}}{\mathbf{0}}=\ldots$ És més estrany que es facen la pregunta d'aquesta situació, però si es dóna, caldria buscar un exemple del tipus anterior per a contestar: «No he portat caramels, però tampoc heu vingut a classe, puc repartir-los?». Aleshores, el resultat d'aquesta divisió tampoc té sentit.

De fet, el que passa en les dues situacions és que no s'hi pot aplicar el concepte de divisió. 
Conseqüències immediates de la definició de nombre racional:

1) Qualsevol fracció $\frac{\mathrm{a}}{\mathrm{b}}$ és equivalent $\mathrm{a} \frac{\mathrm{a} \cdot \mathbf{z}}{\mathrm{b} \cdot \mathrm{z}}, \forall \mathrm{z} \in \mathbf{Z}^{*}$

2) $\forall \mathrm{a} \in \mathrm{Z}^{*}: \frac{0}{\mathrm{a}}=0, \frac{\mathrm{a}}{\mathrm{a}}=1$

3) En algunes ocasions, es representarà un nombre racional per qualsevol fracció de la classe d'equivalència que el defineix. En qualsevol classe de fraccions equivalents, se'n pot trobar una els termes de la qual són primers entre sí. Aquesta fracció s'anomena fracció irreductible. La manera més adient de calcular-la és dividint els dos termes de qualsevol fracció de la classe, pel seu màxim comú divisor.

4) Donades diferents fraccions, sempre podem aconseguir-ne altres equivalents a cadascuna d'elles amb el mateix denominador. La manera més adient d'obtenir-les ha d'utilitzar com a denominador de les noves fraccions el mínim comú múltiple dels denominadors inicials $i$ modificar els anteriors numeradors per tal d'aconseguir fraccions equivalents a les primeres.

\subsection{Operacions amb nombres racionals}

\section{Addició}

$$
(+): \quad \mathbf{Q} \times \mathbf{Q} \rightarrow \mathbf{Q}
$$

S'estableix l'aplicació $\quad\left(\left[\frac{\mathbf{a}}{\mathbf{b}}\right],\left[\frac{\mathbf{c}}{\mathbf{d}}\right]\right) \rightarrow\left[\frac{\mathbf{a} \cdot \mathbf{d}+\mathbf{b} \cdot \mathbf{c}}{\mathbf{b} \cdot \mathbf{d}}\right]$ que, independentment dels representants triats per a cada nombre racional, compleix les propietats:

- Associativa.

- Commutativa.

- Element neutre $\left[\frac{0}{b}\right], \forall \mathbf{b} \in \mathbf{Z}^{*}$

- Element simètric de $\left[\frac{\mathbf{a}}{\mathbf{b}}\right]$ serà $\left[-\frac{\mathbf{a}}{\mathbf{b}}\right]$, perquè $\frac{\mathbf{a} \cdot \mathbf{b}+\mathbf{b} \cdot(-\mathbf{a})}{\mathbf{b} \cdot \mathbf{b}}$ és un element de la classe de $\frac{\mathbf{0}}{\mathbf{b}}$. A l'element simètric per l'addició de qualsevol racional se l'anomena oposat. 
Per tant, el conjunt $\mathbf{Q}$ amb l'operació que s'acaba de definir, $(\mathbf{Q},+)$, té estructura de grup abelià (vegeu l'annex).

\section{Subtracció}

Definim la subtracció de dos nombres racionals $\boldsymbol{m}$ i $\boldsymbol{s}$ com el nombre racional $\mathbf{r}=\mathbf{m}-\mathbf{s}$, de manera que $\boldsymbol{s}+\boldsymbol{r}=\boldsymbol{m}$. A nivell pràctic $\boldsymbol{m}-\boldsymbol{s}=\boldsymbol{m}+(-\boldsymbol{s})$. És a dir, restar un nombre racional és el mateix que sumar l'oposat.

Cal tenir en compte que $\forall \mathbf{z}, \mathrm{k} \in \mathbf{Z}$ :

$-(-q)=q$

$-(z+k)=-z-k$

$-(z-k)=-z+k$

\section{Multiplicació}

\section{$(\cdot): \mathbf{Q} \times \mathbf{Q} \rightarrow \mathbf{Q}$}

Es defineix l'aplicació $\quad\left(\left[\frac{\mathbf{a}}{\mathbf{b}}\right],\left[\frac{\mathbf{c}}{\mathbf{d}}\right]\right) \rightarrow\left[\frac{\mathbf{a} \cdot \mathbf{c}}{\mathbf{b} \cdot \mathbf{d}}\right]$ que, amb independència dels representants triats per a cada nombre racional, compleix les propietats:

- Associativa.

- Commutativa.

- Element neutre $\left[\frac{\mathrm{n}}{\mathrm{n}}\right], \forall \mathrm{n} \in \mathrm{Z}^{*}$

- Element simètric de $\left[\frac{\mathbf{a}}{\mathbf{b}}\right]$, amb $\mathbf{a} \neq \mathbf{0}$, serà $\left[\frac{\mathbf{b}}{\mathbf{a}}\right]$, perquè $\frac{\mathbf{a} \cdot \mathbf{b}}{\mathbf{b} \cdot \mathbf{a}}$ és un element de la classe de $\frac{\mathbf{n}}{\mathbf{n}}$. A l'element simètric per la multiplicació de qualsevol racional se l'anomena invers. En general, les fraccions $\frac{\mathbf{a}}{\mathbf{b}}$ i $\frac{\mathbf{b}}{\mathbf{a}}$ s'anomenen
inverses.

Per tant, el conjunt $\mathbf{Q}$ amb l'operació que s'acaba de definir, $(\mathbf{Q}, \cdot)$, té estructura de semigrup abelià amb element neutre (no és un grup abelià perquè $\left[\frac{0}{\mathbf{b}}\right]$ no té simètric). En canvi, $(\mathbf{Q}-\{\mathbf{0}\}, \cdot)$ sí que en té estructura de grup abelià (vegeu l'annex).

Amb la propietat distributiva de la multiplicació respecte de l'addició, $(\mathbf{Q},+, \cdot)$ és un cos commutatiu (vegeu l'annex) 


\section{Divisió}

Definim la divisió de dos nombres racionals $\mathbf{D}$ i $\mathbf{d}(\mathbf{d} \neq \mathbf{0})$ com el nombre racional $\mathbf{q}=\mathbf{D}: \mathbf{d}$, de manera que $\mathbf{d} \cdot \mathbf{q}=\mathbf{D}$. A nivell pràctic $\mathbf{D}: \mathbf{d}=\mathbf{D} \cdot \frac{\mathbf{1}}{\mathbf{d}}$. És a dir, dividir un nombre racional per un altre distint de zero és el mateix que multiplicar el primer per l'invers del segon.

\subsection{Signe a}

Per tal d'assignar signe a un nombre racional, donada una fracció $\frac{a}{b}$, aquest serà positiu si $\mathbf{a} \cdot \mathbf{b} \in \mathbf{Z}^{+}$(és a dir, el producte del numerador pel denominador és un enter positiu) i serà negatiu si $\mathbf{a} \cdot \mathbf{b} \in \mathbf{Z}^{-}$(el producte del numerador pel denominador és un enter negatiu). D'aquesta manera, tenim dividits els nombres Racionals no nuls en $Q^{+}=\left\{\left[\frac{a}{b}\right] / a \cdot b \in Z^{+}\right\}$i $Q^{-}=\left\{\left[\frac{a}{b}\right] / a \cdot b \in Z^{-}\right\}$. Per tant, tenim el conjunt $\boldsymbol{Q}$ descompost en tres subconjunts: $Q^{-}, Q^{+}$i $\{\mathbf{0}\}$, aleshores: $\mathbf{Q}=\mathbf{Q}^{-} \cup\{0\} \cup \mathbf{Q}^{+}$.

D'acord amb la definició de $\mathbf{Q}^{+} \mathbf{i} \mathbf{Q}^{-}$, és evident que, per exemple:

- $\left[\frac{-3}{2}\right]=\left[\frac{3}{-2}\right]=\left[-\frac{3}{2}\right]$, i llavors: $\frac{-3}{2}=\frac{3}{-2}=-\frac{3}{2}$

- $\left[\frac{-3}{-2}\right]=\left[\frac{3}{2}\right]$, i per això: $\frac{-3}{-2}=\frac{3}{2}$

\subsection{Immersió dels enters en els racionals}

El conjunt dels nombres enters és un subconjunt dels nombres racionals. Per tal de formalitzar aquesta inclusió definim la següent aplicació:

$\mathbf{f}: \mathbf{Z} \rightarrow \mathbf{Q}$

$\mathbf{z} \rightarrow \mathbf{f}(\mathbf{z})=\left[\frac{\mathbf{z}}{1}\right]$ és a dir, considerem cada enter com a un racional re-

presentat per una fracció que té l'enter com a numerador i la unitat positiva com a denominador. Aquesta aplicació compleix les següents propietats:

- $\mathbf{f}$ és injectiva (les imatges de dos elements originals diferents són diferents).

- $\forall x, y \in Z: f(x+y)=f(x)+f(y)$

- $\forall x, y \in Z: f(x \cdot y)=f(x) \cdot f(y)$ 
- $\mathbf{f}(\mathbf{0})=\left[\frac{0}{1}\right]$ que és l'element neutre de l'addició.

- $\mathbf{f}(1)=\left[\frac{1}{1}\right]$ que és l'element neutre de la multiplicació.

Així doncs, com que l'aplicació que acabem de definir és injectiva i conserva les operacions dels nombres enters, es pot identificar cada nombre enter amb la imatge d'aquest i considerar que el conjunt dels enters és part dels racionals.

\subsection{Ordre a $Q$}

El conjunt dels nombres Racionals és un conjunt totalment ordenat i això vol dir que no existeix cap dubte a l'hora de saber si un nombre racional és major o menor que un altre. La formalització amb fraccions seria:

$$
\left[\frac{a}{b}\right] \leq\left[\frac{c}{d}\right] \quad \text { sii } \quad a \cdot d \leq b \cdot c
$$

Aquesta relació, així definida, verifica les propietats reflexiva, antisimètrica, transitiva i connexa. És, per tant, una relació d'ordre total i fa que els nombres racionals estiguen totalment ordenats. A més, aquesta ordenació conserva el seu sentit amb l'addició i amb la multiplicació per racionals no negatius:

- $\forall \mathrm{x}, \mathrm{y}, \mathrm{z} \in \mathrm{Q} \mathrm{amb} \mathrm{x} \leq \mathrm{y} \Rightarrow \mathrm{x}+\mathrm{z} \leq \mathrm{y}+\mathrm{z}$

- $\forall \mathrm{x}, \mathrm{y}, \mathrm{z} \in \mathrm{Q} a \mathrm{amb} \mathrm{x} \leq \mathrm{y}, \mathrm{z} \geq 0 \Rightarrow \mathrm{x} \cdot \mathrm{z} \leq \mathrm{y} \cdot \mathrm{z}$

En el cas de la multiplicació per racionals negatius, s'inverteix el sentit de l'ordenació:

\section{- $\forall x, y, z \in Q a m b x \leq y, z<0 \Rightarrow x \cdot z \geq y \cdot z$}

Si expressem aquesta relació d'ordre amb nombres racionals qualssevol $\mathbf{q}_{\mathbf{1}}$ i $\mathbf{q}_{\mathbf{2}}$, i no amb parells de nombres enters (fraccions), tindrem que: $q_{1} \leq q_{2}$ sii $q_{1}-q_{2} \leq \mathbf{0}$

L'anterior relació d'ordre dels nombres racionals definida mitjançant classes d'equivalència dona lloc a altra relació d'ordre total entre fraccions, és a dir, en $\mathbf{Z} \times \mathbf{Z}^{*}$, que es defineix de manera anàloga:

$$
\frac{a}{b} \leq \frac{c}{d} \quad \text { sii } \quad a \cdot d \leq b \cdot c
$$

A nivell operatiu, ordenarem fraccions - per tant, nombres racionals- d'acord amb algun dels següents casos: 
- Fraccions amb el mateix denominador. Per ordenar-les tindrem en compte els numeradors, que són nombres enters.

- Fraccions amb el mateix numerador. Les ordenarem atenent als denominadors, que també són nombres enters.

- Fraccions amb diferents numerador i denominador. Habitualment les transformarem en fraccions equivalents a les inicials, amb el mateix denominador, i per conèixer el seu ordre aplicarem el primer dels casos anteriors.

Com a resum de totes les propietats expressades per al conjunt dels nombres

Racionals, direm que $(\mathbf{Q},+, \cdot, \leq)$ és un cos commutatiu totalment ordenat (vegeu l'annex).

\section{Els nombres racionals a l'aula de primària}

\subsection{Algunes consideracions}

La idea de fracció té sentit en quantitat de situacions a priori diferents (comentades al punt 2), però no podem pensar que la relació automàtica d'aquestes amb les fraccions es donarà sense revisar-ne moltes d'aquelles. És a dir, si identifiquem una situació concreta en la qual el concepte de fracció té sentit i a partir d'aquesta s'estudia tot allò relacionat amb el concepte de fracció (les relacions d'equivalència $\mathrm{i}$ ordre, operacions $\mathrm{i}$ algorismes...), ¿hem de pensar que en altres situacions susceptibles de ser tractades amb fraccions, el xiquet o la xiqueta tindran clar que tot aquest mecanisme es pot aplicar? Doncs, no sempre. Per tant, s'ha d'insistir en presentar diverses situacions fins que les connexions d'equivalència entre els diferents contextos i la concreció simbòlica de fracció estiga clara (Llinares y Sánchez, 1988).

Serà, doncs, un nou repte per al docent de l'aula de primària plantejar processos d'ensenyament i aprenentatge de les fraccions, des de diferents perspectives i interpretacions possibles, per a ajudar a aconseguir una comprensió conceptual i operativa de la idea de fracció, sense crear compartiments separats o llacunes inconnexes.

Molts autors han estudiat l'estructura cognitiva que permetrà els xiquets i les xiquetes de l'escola assolir les habilitats necessàries per a poder comprendre les relacions part-tot. Aquestes habilitats, que l'alumnat hauria d'incorporar, es concreten en les que els permetran entendre:

1. Que un tot sempre es pot dividir en parts.

2. Que una unitat es podrà dividir en el nombre de parts demanat. 
3. Que les subdivisions que fem han de cobrir totalment la unitat.

4. Que el nombre de parts que volem fer pot no coincidir amb el nombre de talls necessaris.

5. Que les parts han de ser iguals (no s'ha de confondre aquesta igualtat amb la identitat de forma, color o textura...).

6. Que una part separada pot tornar a considerar-se com a una nova unitat i tornar a ser dividida.

7. Que la unitat es conserva encara que es dividisca.

8. El control simbòlic de les fraccions.

9. Les relacions part-tot, en contextos continus i discrets.

10. Que existeixen fraccions menors que la unitat, iguals a la unitat i majors que aquesta.

Treballar algebraicament les fraccions abans de tenir la idea mental clara del que signifiquen i del que es vol aconseguir amb la relació part-tot o fer-ho molt ràpidament, es constata com una gran dificultat afegida al procés d'aprenentatge de les fraccions. Aquesta dificultat és vital tenir-la present, per a intentar establir ponts entre la realitat i l'operativitat de les fraccions, moltes vegades convertida en quelcom sense sentit per a l'alumnat.

\subsection{Quadre de capacitats}

El treball en educació primària referent al tema de nombres racionals, té com a objectiu contribuir a què l'alumnat assolisca les capacitats que s'expressen en el següent quadre resum, la finalitat de les quals es concreta en afavorir el desenvolupament de la seua competència matemàtica i representar una ajuda per a la resta de competències de l'Educació primària.

L'ordre d'aquestes capacitats és seqüencial, és a dir, progressiu, i d'intensitat de dificultat creixent, excepte la capacitat que es refereix a la resolució i invenció de problemes que està present en tot el treball que desenvolupa les restants capacitats:

\begin{tabular}{|l|l|}
\hline \multicolumn{1}{|c|}{ Respecte de fraccions } & Respecte de decimals \\
\hline $\begin{array}{l}\text { 1. Conèixer les diferents interpretacions } \\
\text { de les fraccions, utilitzant mètodes ma- } \\
\text { nipulatius, gràfics i numèrics. }\end{array}$ & \\
\hline 2. & \\
\hline
\end{tabular}

2. Comprovar i reconèixer que una dècima, una centèsima, una mil·lèsima... s'obtenen dividint respectivament la unitat en 10, 100, 1.000... parts iguals. Fraccions decimals i nombres decimals.

3. Escriure i llegir fraccions decimals en forma d'expressions decimals exactes i a l'inrevés

5. Ordenar fraccions i nombres decimals.

4. Comprovar la conservació del valor d'un nombre decimal, independentment dels zeros afegits a la dreta de la seua expressió decimal. 


\begin{tabular}{|l|l|}
\hline $\begin{array}{l}\text { 6. Sumar i restar fraccions amb igual de- } \\
\text { nominador. }\end{array}$ & 7. Sumar i restar nombres decimals. \\
\hline $\begin{array}{l}\text { 8. Comprovar que s'obté el mateix resultat sumant o restant quantitats expressades en } \\
\text { forma de fracció decimal que representades com a nombre decimal. }\end{array}$ \\
\hline & $\begin{array}{l}\text { 9. Multiplicar i dividir nombres decimals } \\
\text { per naturals. }\end{array}$ \\
\hline $\begin{array}{l}\text { 10. Reconèixer l'equivalència de fraccions } \\
\text { en situacions reals i analíticament. Ob- } \\
\text { tenir la fracció irreductible d'una famí- } \\
\text { lia de fraccions equivalents. }\end{array}$ \\
\hline $\begin{array}{l}\text { 11. Sumar i restar fraccions amb diferent } \\
\text { denominador. Multiplicar i dividir } \\
\text { fraccions. }\end{array}$ & 12. Multiplicar i dividir nombres decimals. \\
\hline 13. Introduir la proporcionalitat directa. Regla de tres simple. \\
\hline 14. Obtenir la fracció generatriu que correspon a qualsevol expressió decimal i viceversa. \\
\hline $\begin{array}{l}\text { 15. Aplicar els coneixements sobre fraccions i expressions decimals per a resoldre i } \\
\text { inventar problemes. }\end{array}$ \\
\hline
\end{tabular}

\subsection{Desenvolupament de les capacitats}

\section{Conèixer les diferents interpretacions de les fraccions, utilitzant mètodes manipulatius, gràfics i numèrics}

Les situacions que els permetran conèixer les diferents interpretacions de les fraccions són les presentades al principi del tema com els contextos on és usual la utilització de fraccions (punt 2).

Com que els nombres enters no s'introdueixen fins el final de l'etapa, no hi haurà nombres negatius pràcticament en tota l'Educació primària. Els que s'utilitzen són positius i es fa innecessari el signe. La definició formal de les fraccions és amb nombres enters per al numerador i denominador, però quan s'introdueixen en l'escola, sempre es fa amb nombres naturals.

El primer concepte que s'ha de treballar és el d'unitat. Considerarem com a unitat allò que volem partir en parts iguals que la recobriran. També s'anomena «tot», per contraposició a «parts».

Donat que en $3 r$ de primària es comença a dividir, els xiquets i xiquetes ja coneixen les situacions de la vida quotidiana esmentades al principi del tema i en l'aula de primària ja s'ha parlat de mig litre, el doble, el triple... s'introduirà en $4 \mathrm{t}$ curs el concepte de fracció.

S'ha de començar per situacions reals i quotidianes on la unitat és contínua (manipulant amb paper, cartolina, cordes, pizzes, pastissos...). Per exemple, a partir d'una situació com: «Per a fer un berenar pel natalici de Maria hem de comprar al 
supermercat pizzes per calfar-les al microones i traure-les a la taula tallades en tres porcions iguals. Necessitem saber quanta pizza vol cadascú per calcular la quantitat de pizzes que cal comprar». Per a treballar amb l'alumnat podem representar cada pizza amb un cartró (dels que serveixen com a base de les pizzes) tallat en tres parts iguals i fer-ho servir com si fora la pizza de veritat (figura 12).

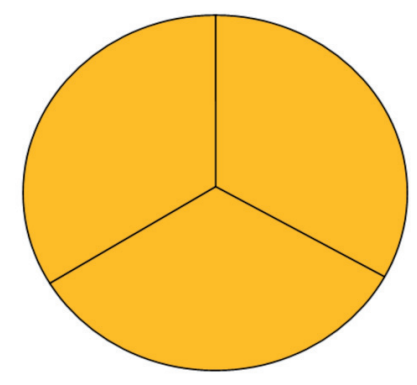

Figura 12. Representació d'una pizza dividida en tres parts iguals

A partir d'aquest plantejament poden aparèixer diferents possibilitats segons la quantitat de pizza que vol menjar cadascú:

1. Qui berenarà menys d'una pizza.

2. Qui prendrà una pizza sencera.

3. Qui menjarà més d'una pizza.

En tots els casos l'alumnat ha de verbalitzar quanta pizza vol prendre i escriureho en un paper per a donar-li'l al docent. El procés per arribar a la representació numèrica de les fraccions pot ser en cada cas com segueix:

1. Qui berenarà menys d'una pizza: «D'una pizza tallada en tres parts iguals, Joana vol dues parts».

Caldrà incidir en que la unitat, el tot, està partida en tres porcions iguals.

Demanem a Joana que verbalitze i escriga quanta pizza berenarà. Al fer aquest treball podem trobar expressions del tipus: «vull dos trossos dels tres que té la pizza», «dues parts de tres que té la pizza», «dues porcions de tres», «dues de tres». No és necessari passar, en el primer moment, a la representació simbòlica de la fracció. És bo que l'alumnat escriga, parle sobre les seues expressions, tractant de reduir-les, fins que semble normal estalviar temps i espai escrivint a la pissarra, al quadern (una frase per cadascú és molt) i es pense en fer un canvi. Aleshores, espontàniament o per suggeriment del mestre o la mestra, ha de sorgir la demanda d'escriure menys. Aqueix és el moment d'aprofitar per a introduir la representació numèrica de la fracció. Serà com un simbolisme per a estalviar.

En front de la recerca d'una expressió numèrica adequada l'alumnat es troba amb un dubte: els nombres que coneix, els naturals, no li serveixen per a representar aquestes quantitats. Hem d'introduir un nou tipus de nombres i una nova manera 
de representar que Joana vol dos trossos d'una pizza que està partida en tres parts iguals. Si no hi ha cap xiquet o xiqueta que ja ho sàpiga i ho diga, traslladarem a nombres qualssevol les expressions verbals anteriors i escriurem $\frac{2}{3}$ comentant que aquesta expressió s'anomena fracció, que a dalt es collloca el nombre de parts que agafem i a sota el nombre de parts iguals que s'hi fan en la unitat, en la pizza en aquest cas. Al nombre de dalt li direm numerador i al de sota denominador.

Ja està introduïda la nova simbologia. Es fa necessari aprendre a llegir aquestes noves expressions de la manera més clara i ràpida possible. A partir d'alguns exemples de fraccions i de les propostes dels xiquets s'ha d'arribar a la lectura més comuna: s'anomena el numerador com a cardinal i el denominador com a ordinal (tres quarts, dos cinquens, un sisè, tres dècims, un onzè, dos dotzens), amb les excepcions dels denominadors 2 i 3, que es lligen com a mitjos i terços. Aleshores en aquest cas: dos terços.

Si l'assignatura s'imparteix en castellà, cal notar les diferències: «en las fracciones cuyo denominador sea mayor o igual que 11, se leerá éste añadiendo la terminación - avo al nombre del cardinal (tres onceavos, cuatro veinteavos,...)».

2. Qui prendrà la pizza sencera: «D’una pizza tallada en tres parts iguals, Pere vol les tres parts».

Quan demanem a Pere que verbalitze quanta pizza es vol menjar, trobarem: «vull tres trossos dels tres que té una pizza» o també «vull una pizza sencera».

Per a la representació numèrica de la fracció que expressa quanta pizza vol menjar Pere, s'ha d'utilitzar la notació introduïda al cas anterior: «Tres terços de pizza $\frac{\mathbf{3}}{\mathbf{3}}$ », però també cal remarcar «pizza sencera $=\mathbf{1}$ », perquè serà la connexió entre la unitat i la pizza trossejada. Ha de quedar clara la idea que menjar-se tres trossos és menjar-se tota la pizza, i que una unitat completa, es representa per $\frac{3}{3}$ o per $\mathbf{1}$. Així doncs $\frac{3}{3}=\mathbf{1}$.

En general, les situacions d'aquest tipus es representen per fraccions on el numerador i el denominador són iguals, $\frac{\mathbf{a}}{\mathbf{a}}$, i que s'anomenen fraccions unitat.

3. Qui menjarà més d'una pizza: «D’una pizza tallada en tres parts iguals, Pau se'n vol menjar quatre trossos».

Sol-licitem a Pau que ens verbalitze quanta pizza es vol menjar: «vull menjar-me quatre trossos com els que eixen quan es parteix la pizza en tres parts iguals»o d'altra manera «vull menjar-me una pizza sencera i un tros d'altra que en té tres» (figura 13). 

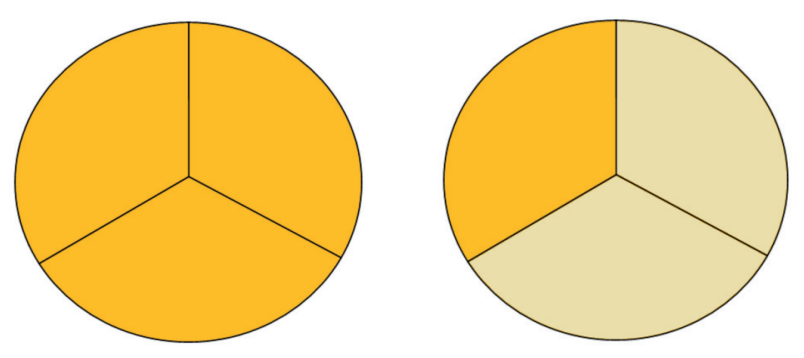

Figura 13. Representació de la selecció d'una pizza sencera i una part d'una altra

De manera anàloga als casos anteriors, procedim a continuació a buscar la representació numèrica de la fracció que expressa quanta pizza vol menjar-se Pau.

Com per a berenar quatre trossos fan falta dues pizzes, un error molt comú és posar al denominador les parts de les dues unitats i, per tant, expressar la situació anterior per $\frac{4}{6}$. Si entre les dues pizzes hi ha ara sis porcions, sembla lògic; però, clar, aquesta fracció no correspon a la situació original, de partida; correspon a una situació on la pizza estiguera trossejada en sis parts:

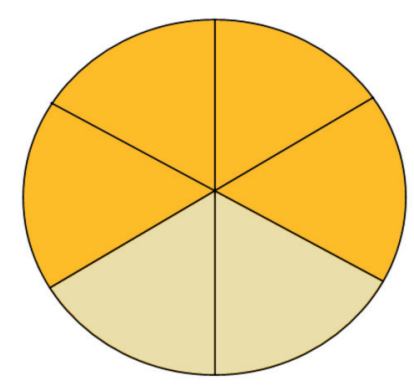

Figura 14. Representació d'una pizza dividida en 6 parts i destacades 4

Ells i elles haurien d'intentar resoldre el dubte, per tal de no posar la fracció anterior. Hi poden eixir moltes respostes, rescatarem les vàlides:

- Posar 1 i $\frac{1}{3}$, que és certa i que analíticament es representa per $1+\frac{1}{3}$. Podem aprofitar aquesta resposta per a introduir la notació següent: $1 \frac{1}{3}$ que rep el nom de nombre mixt $i$ es llegeix un $i$ un terç, un enter i un terç o una unitat $\mathrm{i}$ un terç.

- Escriure $\frac{4}{3}$, que és la representació numèrica associada al concepte general de fracció $i$ al significat dels termes d'aquesta. Cal incidir en què les parts de la unitat es mantenen (tres), però que per menjar més d'una pizza n'agafem més d'una unitat. Aleshores, sempre que hi posem una fracció amb un numerador que siga major que el denominador, agafarem més d'una unitat, «més d'una pizza». 
Després de veure aquestes dues maneres de representar la situació, es decidirà utilitzar la segona per la semblança que té amb les altres fraccions, sabent que en algunes ocasions ens podrem trobar amb expressions de nombres mixtes.

En aquest moment, i pel fet d'haver trobat dos tipus de fraccions no unitàries qualitativament diferents $\left(\frac{2}{3} \mathrm{i} \frac{4}{3}\right)$, hem de distingir-les anomenant-les de manera distinta. Així, es denominaran fraccions pròpies aquelles en les quals el numerador és un enter menor que el denominador (sempre són menors que la unitat: «Joana vol menjar menys d'una pizza»), i fraccions impròpies quan el numerador és major que el denominador (sempre són majors que la unitat: «Pau es vol menjar més d'una pizza»).

Una vegada presentat el concepte de fracció com a relació entre les parts i el tot mitjançant situacions de tipus manipulatiu amb objectes concrets per cada exemple (bé siga la pizza, bé siga el pastís...), cal abandonar la presència física de la unitat i concentrar l'atenció en les representacions gràfiques d'aquesta. El treball, a partir dels dibuixos, tindrà com a objectiu trobar una forma d'expressió més esquemàtica que done resposta a totes les situacions reals: la recta numèrica.

Com que estem treballant només amb fraccions no negatives, la recta numèrica serà realment una semirecta amb origen en el 0 i creixerà cap a la dreta (figura 15).

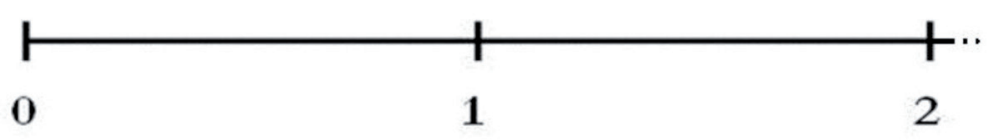

Figura 15. Representació de la semirecta numèrica positiva

Així, si representem les fraccions dels exemples anteriors obtenim el que es mostra a la figura 16.

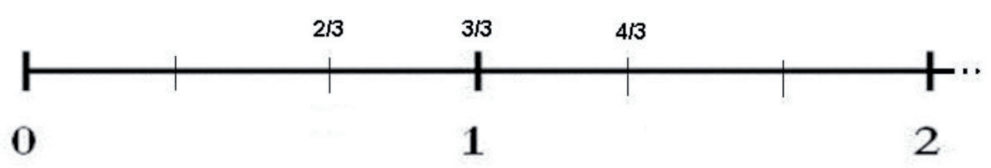

Figura 16. Representació d'algunes fraccions en la semirecta numèrica

Mitjançant aquest exemple i d'altres, ha de quedar clar que una fracció pròpia sempre se situarà en aquesta semirecta a l'esquerra de l'1, una fracció unitat a l'1 i una fracció impròpia a la dreta de l'1.

Una vegada introduïdes les fraccions amb unitats de tipus continu, cal treballar-les també amb les de tipus discret, en les quals la unitat està composada per diferents elements separats. Probablement no seran una novetat en la seua vida, perquè ja les han utilitzades algunes vegades potser sense ser massa conscients, més aviat 
ho treballarem per tal d'analitzar les diferències amb situacions de les modalitats anteriors. Quan les unitats són discretes trobarem ocasions en les quals el nombre de parts coincideix amb el nombre d'elements que composen la unitat i casos en els que el nombre de parts el divideix exactament.

La situació de partida pot ser semblant a les proposades per les unitats continues. En el primer cas, per exemple, a partir d'una situació com: «Per a preparar un berenar pel natalici de Quim volem comprar al supermercat uns quants paquets de vuit galetes de xocolata». Cal saber quina part del paquet de galetes vol cada membre de l'alumnat per a poder calcular la quantitat de paquets a comprar (el nombre d'elements de la unitat és 8, com es veu a la figura 17).

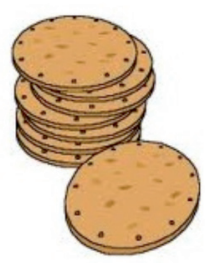

Figura 17. Representació d'un paquet de 8 galetes

A partir d'aquest plantejament poden aparèixer diferents possibilitats de menjar galetes:

1. Qui berenarà menys d'un paquet

2. Qui prendrà un paquet sencer

3. Qui menjarà més d'un paquet

En tots els casos l'alumnat ha de verbalitzar quina part del paquet de galetes vol prendre i arribar a escriure-ho en un paper per a donar-li'l al docent. El procés fins a la representació numèrica de les fraccions pot ser en cada cas com segueix:

1. Qui vol menys d'un paquet: «Carla es vol menjar cinc galetes. Quina part del paquet vol menjar-se Carla?».

Caldrà incidir que la unitat, el tot, està composada per vuit elements. Demanem a Carla que verbalitze quant vol menjar del paquet: «vull menjar cinc galetes d'un paquet que en té vuit». La representació gràfica seria:

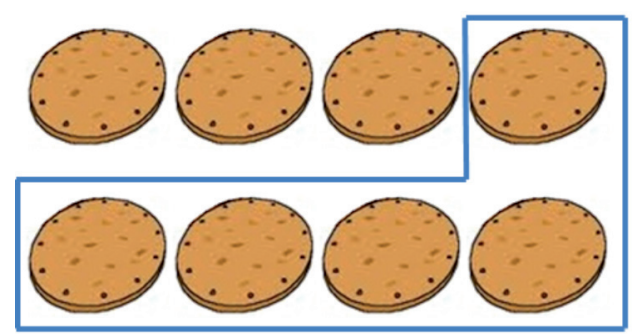

Figura 18. Representació de la selecció de 5 galetes d'un paquet de 8 
Com que s'haurà fet un treball previ en un context continu, se'ls demanarà la representació numèrica d'una fracció que indique quina part del paquet de galetes es vol menjar Carla. Recordarem el significat dels termes de la fracció i, aleshores, han d'escriure $\frac{\mathbf{5}}{\mathbf{8}}$. És convenient repassar la lectura de les fraccions.

2. Qui prendrà un paquet sencer: «Antoni vol menjar-se les vuit galetes. Quina part del paquet es vol menjar Antoni?».

Demanem a Antoni que verbalitze quant vol menjar del paquet: «vull menjar-me vuit galetes d'un paquet que en té vuit» o també «vull menjar un paquet complet». Per a la representació numèrica de la fracció que expressa quantes galetes s'ha menjat Antoni, s'ha de fer memòria de les fraccions unitat i utilitzarem $\frac{\mathbf{8}}{\mathbf{8}}$, per a representar aquesta situació, però també cal remarcar que «paquet sencer $=\mathbf{1}$ », per $\operatorname{tant} \frac{8}{8}=1$.

3. Qui menjarà més d'un paquet: Per exemple «Laia es vol menjar deu galetes. Quina part del paquet vol menjar-se Laia?».

Demanem a Laia que verbalitze quant es vol menjar del paquet: «vull menjar-me deu galetes com les d'un paquet de vuit»o «vull menjar-me un paquet complet $\mathrm{i}$ dues galetes d'un altre paquet» (figura 19).

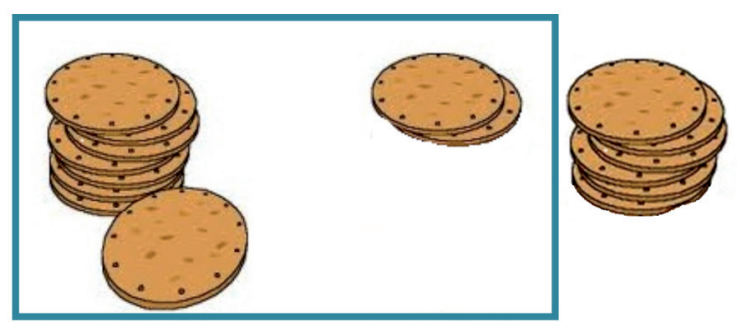

Figura 19. Representació de la selecció d'un paquet sencer i dues galetes d'un altre

Es planteja el dubte de com expressar-ho en forma de fracció. De la mateixa manera que en el cas continu, un error molt comú és posar en el denominador les parts de les dues unitats i, per tant, representar la situació anterior per $\frac{\mathbf{1 0}}{\mathbf{1 6}}$. Si entre els dos paquets hi ha $\mathbf{1 6}$ galetes, sembla lògic; però clar, aquesta fracció no correspon a la situació de partida, correspondria a una situació on el paquet tingués 16 galetes.

L'alumnat haurà d'intentar resoldre el dubte, per tal de no posar la fracció anterior i prenent com a base el treball fet amb unitats continues, arribar a les expressions 1 i $\frac{2}{8}$ o $1 \frac{2}{8}$ o finalment $\frac{10}{8}$

De manera anàloga, es treballen els casos en els quals el nombre de parts divideix al nombre d'elements que composen la unitat. Per exemple, a partir d'una situació com: «Per a un berenar pel natalici de Lledó volem comprar al supermercat pa- 
quets de vuit galetes que estan envasades en bosses de 2 galetes», necessitem saber quants paquets hem de comprar.

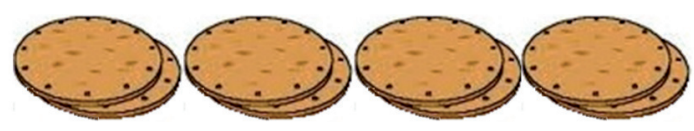

Figura 20. Representació d'un paquet de 8 galetes, embossades de 2 en 2

Ara la unitat està organitzada en 4 parts iguals. Aleshores podrem tenir les següents possibilitats de menjar galetes:

1. Qui berenarà menys d'un paquet

2. Qui prendrà un paquet sencer

3. Qui menjarà més d'un paquet

Novament, aprofitarem aquestes situacions per a reconduir l'activitat fins a la representació numèrica de les fraccions:

1. Qui berenarà menys d'un paquet: «Andreu vol berenar tres bosses de galetes. Quina part del paquet vol berenar Andreu?».

Caldrà incidir que la unitat, el tot, està partida en 4 parts iguals. Demanem a Andreu que ens verbalitze quant vol menjar-se del paquet: «vull menjar-me tres bosses de les quatre que en té un paquet». La representació gràfica d'aquesta situació es veu a la figura 21.

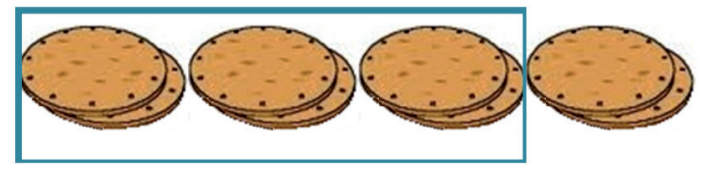

Figura 21. Representació de la selecció de 3 bosses d'un paquet de 4

Com que s'haurà fet un treball previ en context continu i discret de la primera de les possibilitats, se'ls demanarà directament la representació d'una fracció que indique quina part del paquet de galetes vol berenar Andreu. D'acord amb el significat dels termes de la fracció, han d'escriure $\frac{\mathbf{3}}{\mathbf{4}}$

2. Qui prendrà un paquet sencer: «Roser vol les quatre bosses. Quant es menja Roser del paquet?».

Demanem a Roser que verbalitze quant es vol menjar del paquet: «vull menjar-me les galetes de les quatre bosses d'un paquet» o també «vull un paquet sencer».

Per a la representació numèrica de la fracció que expressa quant es vol menjar Roser, es farà memòria de les fraccions unitat i utilitzaran una d'aquestes, $\frac{4}{4}$, per a representar la situació, però també cal remarcar que «paquet sencer $=1$ », per tant $\frac{4}{4}=1$ 
3. Qui menjarà més d'un paquet: «Quim vol menjar-se 5 bosses de galetes. Quina part del paquet es vol menjar Quim?».

Demanem a Quim que verbalitze quant vol menjar del paquet: «vull menjar-me cinc bosses» $\mathrm{o}$ «vull menjar-me un paquet complet i una bosseta d'un altre paquet». La representació gràfica d'aquesta situació es troba a la figura 22.

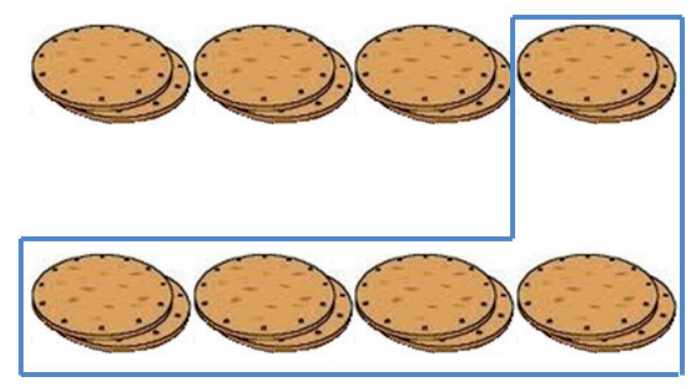

Figura 22. Representació de la selecció d'un paquet sencer i una bossa d'un altre

De la mateixa manera que en els anteriors cassos de fraccions impròpies, un error molt comú és posar al denominador les parts de les dues unitats i, per tant, expressar la situació anterior per $\frac{\mathbf{5}}{\mathbf{8}}$. Com entre els dos paquets hi ha $\mathbf{8}$ bossetes, sembla lògic; però clar, aquesta fracció no correspon a la situació original, de partida, correspondria a una situació on el paquet tinguera 8 bossetes.

Prenent com a base el treball anterior, arribaran a les expressions 1 i $\frac{1}{4}$ o $1 \frac{1}{4}$ o finalment $\frac{5}{4}$

En els dos tipus de situacions anteriors, galetes soltes en el paquet o en bosses de dues, s'ha treballat igual que en el cas continu: fraccions pròpies, unitat i impròpies.

Seguint amb les interpretacions de les fraccions presentades en el punt 2 d'aquest tema i situant-nos en 5é i 6é cursos de primària, treballarem la resta de situacions on necessitarem també les fraccions.

Les farem servir per a representar el quocient d'una divisió; és a dir, una fracció serà una altra manera d'expressar el resultat d'una divisió. Per exemple, «una mestra té tres litres de suc de taronja per fer un berenar i vol repartir-los equitativament entre les 7 taules en les que ha organitzat l'alumnat. Quant de suc li correspondrà a cada taula?». Per respondre a aquesta pregunta, hauran de fer la divisió $3 \mid \underline{7}$ o bé utilitzar la fracció $\frac{3}{7}$ per expressar el quocient d'aquesta operació.

També utilitzarem les fraccions quan calga representar raons entre dos nombres. En aquest cas, podem trobar situacions de proporcionalitats, probabilitats i percentatges. En qualssevol dels casos, les fraccions seran les representacions de les relacions numèriques que s'estableixen entre els nombres que apareixen en les situacions. 
Així, en el cas de la proporcionalitat, utilitzarem les fraccions per a representar la relació entre dues quantitats, que de vegades es referiran a un total i a una de les seues parts i, en altres ocasions, a dues parts d'un tot. Per exemple, s'ha de representar per $\frac{4}{10}$ la relació entre el nombre d'infants, 4, i el nombre total de persones, 10 , que acudeixen a un dinar familiar de Nadal, i per $\frac{4}{6}$ la relació entre el nombre d'infants i d'adults en el mateix dinar.

En el cas d'una probabilitat de successos equiprobables, usarem les fraccions per representar la relació entre el nombre de cassos favorables i el de casos possibles de que ocórrega un succés qualsevol. Per exemple, es representarà per $\frac{4}{10}$ la probabilitat de que siga infant una persona triada a l'atzar de les $\mathbf{1 0}$ que acudeixen al dinar familiar o per $\frac{\mathbf{6}}{\mathbf{1 0}}$ la de que siga adult.

Quan calga representar percentatges, utilitzarem també fraccions que, en aquest cas, sempre tindran un 100 en el seu denominador. Es tracta ara d'expressar relacions entre un nombre determinat de parts d'un tot i el 100, que és el nombre total de parts iguals que es consideren en aquest tot. Per exemple i seguint amb el menjar familiar de Nadal, representarem per $\frac{\mathbf{4 0}}{\mathbf{1 0 0}}$ el percentatge que suposa la quantitat d'infants que acudeixen al dinar. Aquesta darrera fracció es pot substituir per l'expressió, $40 \%$, que quotidianament s'usa per a expressar els percentatges.

Finalment, utilitzarem les fraccions com a operadors quan aquestes actuen sobre un nombre i el modifiquen. Per exemple, si volem calcular quants quilòmetres s'han recorregut quan s'han fet els $\frac{\mathbf{2}}{\mathbf{5}}$ d'un camí de $\mathbf{6 0} \mathbf{~ k m}$, caldrà esbrinar quant és una cinquena part de $\mathbf{6 0} \mathbf{~ k m}$ i multiplicar aquest nombre per 2, obtenint com a resultat $\mathbf{2 4} \mathbf{~ k m}$. En general, quan una fracció actua com a operador sobre un nombre el transforma en un altre que és el resultat de calcular el valor de la part del nombre que indica la fracció.

Resulta evident que calcular el valor d'un percentatge d'una determinada quantitat consisteix en fer actuar com a operador a la fracció que representa l'esmentat percentatge sobre la quantitat elegida. Així, per a calcular el 40 \% de les 10 persones que acudeixen al dinar de Nadal, hem de fer actuar a la fracció $\frac{40}{100}$ com a operador sobre 10, que és la quantitat total de persones. Haurem d'esbrinar quant és la centèsima part de 10 i multiplicar aquest nombre per 40, obtenint com a resultat 4 infants.

Els cursos proposats per a treballar aquestes darreres interpretacions de les fraccions són els dos últims de primària, perquè la noció de fracció com a part-tot ja ha d'estar quasi totalment assolida i perquè ara les utilitzem com una eina per a resoldre altres situacions problemàtiques. 


\section{Comprovar i reconèixer que una dècima, una centèsima, una mil·lèsima... s'obtenen dividint respectivament la unitat en $10,100,1.000 \ldots$ parts iguals. Fraccions decimals i nombres decimals}

En aquesta capacitat posarem una especial atenció en les fraccions que tenen com a denominadors diferents potències de 10 . Seran les anomenades fraccions decimals, que ens serviran per a representar els nombres racionals coneguts com nombres decimals.

Iniciarem aquest treball a $4 \mathrm{t}$ de primària (amb la dècima i la centèsima) i el continuarem en 5é i 6é (amb la mil·lèsima, i la resta d'unitats decimals si s'escau).

Si dividim en deu parts iguals una unitat, representada per exemple per un paper que hem de retallar en tires, cadascuna de les parts serà una dècima (figura 23). La transcripció simbòlica d'aquesta en forma fraccionaria, $\frac{1}{\mathbf{1 0}}$, no oferirà cap problema a l'alumnat pel que ja s'ha treballat en la capacitat 1 .

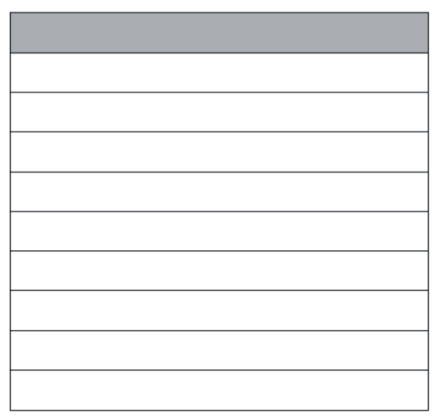

Figura 23. Representació gràfica d'una dècima

Si ara necessitem trossos de paper més petits i dividim cada dècima en deu parts iguals, obtindrem cent parts iguals en la unitat, cadascuna de les quals serà una centèsima (figura 24). La forma fraccionària de la transcripció simbòlica d'aquesta, $\frac{1}{100}$, tampoc oferirà cap problema a l'alumnat per la mateixa raó anterior.



Figura 24. Representació gràfica d'una centèsima 
Anàlogament si dividim cada centèsima en deu parts iguals, obtindrem mil trossets iguals en la unitat, cadascun dels quals serà una mil·lèsima. L'escriptura de la fracció que la representa, $\frac{1}{\mathbf{1 . 0 0 0}}$, de nou no presentarà cap problema per l'alumnat pel que han après en la primera capacitat.

De manera semblant als casos anteriors, es podrien construir els següents ordres d'unitats decimals (deumil·lèsima, centmil·lèsima...) que corresponen a les fraccions $\frac{1}{10.000}, \frac{1}{100.000} \ldots$

A partir d'aquestes unitats decimals es treballaran també les fraccions amb numeradors diferents de l'u, mantenint en els denominadors la unitat seguida de zeros. Per exemple $\frac{5}{10}, \frac{23}{100}, \frac{453}{100}$, representaran, respectivament, cinc dècimes, vint-itres centèsimes i quatre-centes cinquanta-tres centèsimes.

Poden aparèixer en el treball d'aquesta capacitat qüestions sobre l'equivalència de $\frac{10}{100}$ i $\frac{1}{10}$, per exemple. Si es dóna el cas s'explicaria aquesta amb representacions adequades. Si no es dóna esperarem a treballar-ho en la capacitat 10.

En general, totes les fraccions que tenen en el denominador una potència de $\mathbf{1 0}$ s'anomenen fraccions decimals. El subconjunt de $\mathbb{Q}$, generat per aquestes fraccions és el conjunt de nombres racionals decimals, o simplement nombres decimals, $\mathrm{i}$ es representa per $\mathbb{D}$. Formalment, aquest conjunt és: $\mathbf{D}=\left\{\left[\frac{\mathbf{a}}{10^{\mathbf{n}}}\right] / \mathbf{a} \in \mathbf{Z} \wedge \mathbf{n} \in \mathbf{N}\right\}$.

\section{Escriure i llegir fraccions decimals en forma d'expressions decimals exactes i a l'inrevés}

En aquesta capacitat treballarem per primera vegada la connexió entre la manera d'expressar una quantitat amb una fracció i amb una expressió decimal.

A partir de la representació material (pastís, corda, cinta, reglets...) o gràfica d'una dècima, una centèsima, una mil·lèsima part..., i les seues transcripcions simbòliques, cal plantejar-se si aquestes podrien escriure's també utilitzant el sistema de numeració decimal que ja coneixen per aprofitar els seus avantatges representatius i operatoris. Es tracta de pensar com es poden representar parts menors que la unitat, sabent que les unitats d'ordre superior s'escriuen cap a l'esquerra d'aquesta.

En la introducció de $\frac{1}{10}, \frac{1}{100}, \frac{1}{1.000}$, hem vist com dividint successivament cada unitat decimal en deu parts iguals obtenim la unitat del següent ordre d'unitats decimals. En aquest moment, es fa necessari distingir els ordres d'unitats que estan coneixent ara dels que coneixien ja per als naturals. En aquests nombres, les unitats de $1 \mathrm{r}$ ordre s'anomenen unitats; les de $2 \mathrm{n}$ ordre, desenes; les de 
$3 r$ ordre, centenes; les de $4 \mathrm{t}$ ordre, unitats de miler... i creixen de deu en deu cap a l'esquerra. En el cas dels decimals, les unitats de 1r ordre, s'anomenen dècimes; les de $2 \mathrm{n}$ ordre, centèsimes; les de $3 \mathrm{r}$ ordre, mil·lèsimes... i decreixen de deu en deu cap a la dreta.

La transició d'unes expressions a altres es pot realitzar amb l'ajuda dels àbacs, situant un nou àbac a la dreta del que representa els nombres naturals per indicar, d'esquerra a dreta, les xifres decimals i assenyalar d'alguna manera en quin punt se separen els dos tipus de xifres (amb una goma elàstica, un tros de cinta adhesiva, un llaç...). A diferència del que passa a la part sencera del nombre, cal tenir en compte que, com s'ha esmentat anteriorment, les posicions de les unitats decimals estan ordenades en sentit invers al creixement del seu valor; així, les dècimes, que són unitats decimals de primer ordre, tenen un valor superior a les centèsimes, que són de segon ordre. Per exemple, al nombre 315'286, el 2 representa unitats decimals de primer ordre i té un valor superior al 8 que representa unitats decimals de segon ordre, mentre que no passa el mateix per al 5 i l'1 de la part sencera.

Veiem ara com s'obté l'expressió decimal d'una dècima part de la unitat, $\frac{\mathbf{1}}{\mathbf{1 0}}$, que és la unitat decimal de primer ordre. Per obtenir la nova representació de la dècima observaran que no hi ha cap unitat sencera; així, cal començar l'expressió numèrica amb un 0 al lloc de les unitats. En intentar escriure la quantitat de dècimes, sorgirà el dubte d'on es col'loca l'1. No el podem posar a l'esquerra del 0 , perquè això representaria una desena; caldrà, doncs, posar-lo a la dreta: 01. Aquesta expressió representa la quantitat d'una unitat sencera i no el que realment es vol representar. Per a resoldre aquest problema s'ha d'incorporar l'ús de la coma entre el 0 i l'1, amb el significat mencionat anteriorment. Així, l'expressió a la que arribarem és 0,1 i es llegirà de la mateixa manera que es llegeix la fracció de la qual prové, una dècima, o també: zero coma un.

Vegem com escriure mitjançant el SND una centèsima part, la unitat decimal de segon ordre, que fins ara representàvem per la fracció $\frac{1}{\mathbf{1 0 0}}$. Obtindrem les xifres que formen l'expressió decimal de la centèsima reflexionant sobre el fet que no en tenim cap unitat sencera, i per tant posarem 0 al lloc de les unitats. Com que tampoc tenim cap dècima completa, haurem de posar un altre 0 al seu lloc. Pel que ja saben escriuran: 0,0. En observar que tenen 1 centèsima, es preguntaran, «on es col·loca l'1?». D'acord amb el criteri d'escriptura de les expressions numèriques dels ordres d'unitats decimals, que s'ha esmentat anteriorment, caldrà posar aquest 1 a la dreta del zero de les dècimes: 0,01.

Ja tenim la nova expressió decimal. Es llegirà de la mateixa manera que es llegeix la fracció de la qual prové, una centèsima, o també: zero coma zero un.

De manera semblant arribarem a escriure mitjançant el SND la mil·lèsima, que és la unitat decimal de tercer ordre. És a dir, el que representa $\frac{1}{\mathbf{1 . 0 0 0}}$ s'expressarà també com 0,001 i es llegirà com una mil·lèsima, o també: zero coma zero, zero, un. 
Cal assumir que les fraccions on aparega l' 1 al numerador i la unitat seguida de zeros al denominador, es tradueixen per $0,000 \ldots 1$, segons els zeros del denominador, i sempre se n'obtindrà un nombre finit de xifres decimals.

Després d'haver introduït cadascuna de les fraccions anteriors i seguint un procediment anàleg, es treballarà en tots els casos amb fraccions del mateix tipus però

amb numeradors diferents de la unitat, per exemple , $\frac{2}{10}, \frac{5}{100}, \frac{13}{100}$, amb la conclusió que totes les fraccions que tenen denominadors d'aquest estil produeixen expressions amb un nombre finit de xifres decimals: 0,$2 ; 0,05 ; 0,13$, respectivament.

Anàlogament, es procedeix quan es tracta de fraccions impròpies, per exemple $\frac{23}{10}$, $\frac{135}{100} \ldots$ En aquestes fraccions, han d'observar que hi ha unitats senceres i parts menors que la unitat; així, seguint el procediment anterior, han d'obtenir les següents expressions decimals 2,3 i 1,35 .

Desenvolupem el cas de $\frac{23}{10}$. Si treballem amb els àbacs, tenim vint-i-tres boles a la vareta de les dècimes. D'acord amb la manera de treballar amb aquest material, si transformem cada grup de deu d'aquestes boles en una bola de la vareta següent cap a l'esquerra, obtindrem 2 boles en la vareta de les unitats i en quedaran 3 en la de les dècimes.

Per tenir l'expressió decimal que representa aquesta quantitat sols han d'escriure el nombre de boles que correspon a cada vareta, tenint en compte el que ja saben sobre com es formen les expressions decimals. Així, escriuran: 2,3.

Es llegirà de la mateixa manera que es llegeix el nombre mixt $2 \frac{3}{10}$ corresponent a la fracció impròpia de la qual prové, dos unitats i tres dècims o dècimes, o també: dos coma tres.

Anàlogament es treballaran les altres fraccions decimals i la manera de trobar les seues expressions decimals.

Quan estiga assolida l'estructura d'aquestes expressions decimals, es pot treballar la manera ràpida de trobar-les, que consistirà en escriure el numerador de la fracció, amb una coma situada en la posició necessària perquè hi haja tantes xifres decimals com zeros acompanyen a la unitat en el denominador (si cal, s'afegeixen zeros a l'esquerra de les xifres que composaven el numerador).

Al llarg d'aquesta capacitat hem comprovat que totes les expressions decimals que hem treballat en ella i que corresponen a fraccions decimals, tenen un nombre finit de xifres decimals. Per aquesta raó s'anomenen expressions decimals exactes i són les que s'associen amb els nombres decimals. 
Una qüestió molt important per a completar l'adquisició d'aquesta capacitat és verbalitzar correctament les diferents representacions numèriques que es treballen i que es desenvolupen a continuació:

1. Fraccions pròpies, per exemple $\frac{\mathbf{7}}{\mathbf{1 0}}$. Podem llegir la fracció de diverses maneres: «7 parts de 10», «set dècimes parts», «set dècims»... I 1'expressió decimal corresponent 0,7 com: «zero coma set», «zero unitats, set dècimes», 0 «set dècimes».

2. Fraccions impròpies, per exemple $\frac{\mathbf{7 3}}{\mathbf{1 0}}$. De manera anàloga al cas anterior llegirem: «73 parts de 10», etc. L'expressió decimal 7,3 es pot llegir: «set coma tres», «set unitats i tres dècimes»o «setanta-tres dècimes».

Per a finalitzar, cal insistir en llegir correctament expressions com 6,98 (sis unitats noranta-vuit centèsimes) i 6,098 (sis unitats noranta-vuit mil-lèsimes), per a evitar la confusió. Per a aprofundir en aquestes qüestions aprofitarem situacions que es plantegen relacionades amb els sistemes d'unitats de mesura i amb el sistema monetari.

Completarem el treball d'aquesta capacitat estudiant la manera d'obtenir fraccions decimals a partir de les expressions decimals exactes corresponents.

Podem utilitzar qualsevol dels exemples anteriors per a trobar el procediment que converteix una expressió decimal exacta en una fracció decimal, el numerador de la qual estarà composat per les xifres del nombre sense la coma i el denominador serà la unitat seguida de tants zeros com xifres decimals hi haja a l'expressió decimal exacta. La posició de l'ultima xifra decimal de la dreta ens informa del seu ordre i, per tant, de la quantitat de parts que haurem de fer en la unitat per escriure l'expressió decimal exacta en forma de fracció. Per exemple:

$$
0,05=\frac{\mathbf{5}}{\mathbf{1 0 0}} \quad 3,27=\frac{\mathbf{3 2 7}}{\mathbf{1 0 0}} \quad 2,3=\frac{\mathbf{2 3}}{\mathbf{1 0}}
$$

Tot aquest treball de conversió de fraccions en expressions decimals i a l'inrevés, es justifica per a poder operar amb nombres decimals, utilitzant indistintament fraccions decimals o expressions decimals exactes segons convinga. 


\section{Comprovar la conservació del valor d'un nombre decimal, independentment dels zeros afegits a la dreta de la seua expressió decimal}

Treballarem aquesta capacitat a partir de $4 \mathrm{t}$ curs de primària. Començarem amb nombres decimals que deriven de fraccions pròpies.

Una situació quotidiana per ells i elles, que posa de manifest la necessitat d'adquirir aquesta capacitat podria estar relacionada amb una activitat de mesura. Per exemple, dos grups diferents de xiquets i xiquetes mesuren la mateixa corda utilitzant com a unitat el decímetre en un grup i el centímetre en l'altre, i han d'expressar el resultat en metres per sumar-lo a la longitud d'una altra corda que està expressada en aquesta unitat. Si els resultats de les mesures són 7 decímetres i 70 centímetres, respectivament, s'obtenen així les expressions $0,7 \mathrm{~m}$ i 0,70 m. Com que s'ha mesurat el mateix objecte, la igualtat del valor de les expressions és immediata: $0,7=0,70$.

Aquest fet que acabem de comprovar hauria de generalitzar-se per qualssevol expressions decimals exactes treballant amb altres materials, per exemple: els proporcionem dues cartolines quadrades de la mateixa superfície. Dins de l'activitat que s'estiga realitzant a l'aula, l'alumnat necessita dividir una cartolina en 10 parts iguals i l'altra en 100 parts iguals, de les quals n'han d'agafar 7 i 70, respectivament. La representació gràfica d'aquesta situació seria:
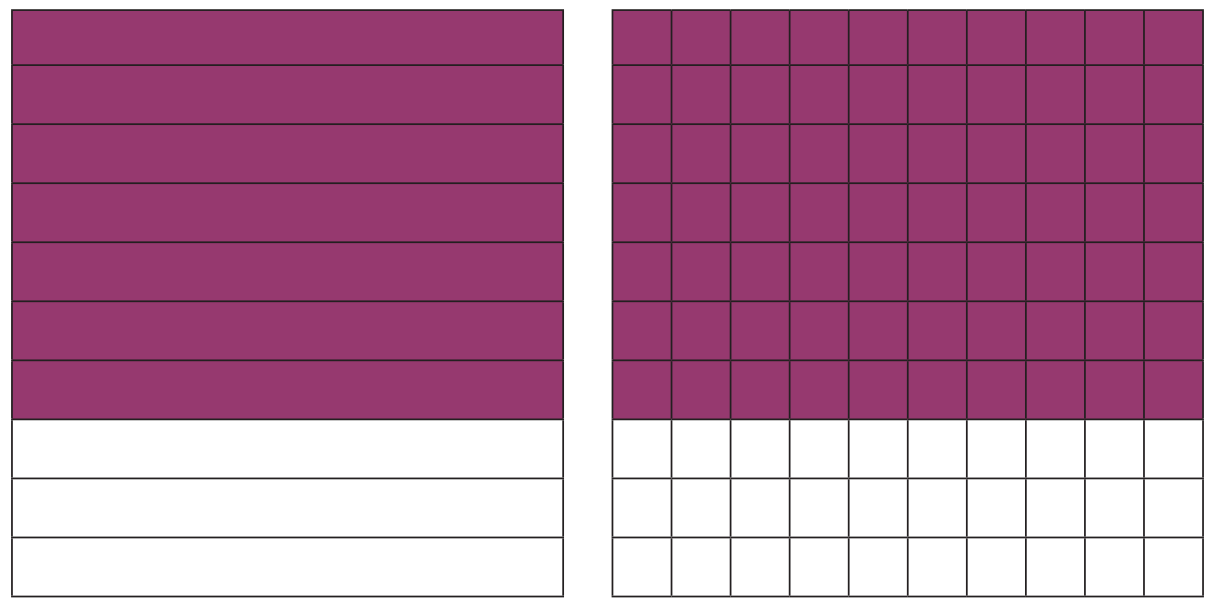

Figura 25. Representació gràfica de 7 dècimes i 70 centèsimes

Immediatament, s'observa que els dos grups han agafat la mateixa quantitat de cartolina. Si expressem les fraccions associades a aquestes quantitats obtindrem: $\frac{7}{\mathbf{1 0}} \mathrm{i}$ $\frac{\mathbf{7 0}}{\mathbf{1 0 0}}$. Que es representen per $0,7 \mathrm{i} 0,70 \mathrm{amb}$ nombres decimals, per tant: $0,7=0, \mathbf{1 0}$.

La conclusió ha de ser que són expressions decimals diferents de la mateixa quantitat, aleshores tenen el mateix valor i, per tant, podríem traure els zeros de la dreta. 
En aquestes situacions s'observen també equivalències entre dues fraccions, sense haver treballat específicament aquest concepte. Caldrà reprendre després tota aquesta informació per a utilitzar-la en el moment adient.

Es pot fer també el treball amb els àbacs, on el fet d'afegir zeros a la dreta en l'expressió decimal suposa ampliar columnes a la dreta d'ells per referir-se als ordres d'unitats que corresponen als zeros, però açò no implica situar cap bola en aquestes; per tant, la representació del nombre inicial i del que obtenim afegint zeros a la seua dreta és la mateixa, és a dir, «els àbacs queden igual» i en conseqüència tenen el mateix valor.

Amb fraccions impròpies, la situació és molt semblant, però amb part sencera no nul·la en el nombre decimal. Es reprendrà el que es va veure a 4t i s'ampliarà a 5é de primària. Si cal, s'utilitzarà material real o representacions gràfiques com a ajuda.

Caldrà automatitzar i treballar amb llapis i paper aquesta capacitat, amb exercicis del tipus següent que demanen relacionar una expressió de cada columna amb altres que representen la mateixa quantitat:

$\begin{array}{ccc}\frac{523}{100} & \mathbf{5 2 , 3} & \mathbf{0 , 5 2 3 0} \\ \frac{523}{10} & \mathbf{5 , 2 3} & \mathbf{0 , 0 5 2 3 0 0} \\ \frac{523}{10000} & \mathbf{0 , 5 2 3} & \mathbf{5 2 , 3 0} \\ \frac{5230}{100000} & \mathbf{0 , 0 5 2 3} & \mathbf{5 , 2 3 0 0}\end{array}$

Tanmateix, convé realitzar exercicis de lectura d'aquests nombres decimals per tal de comprovar les diferents maneres de llegir la mateixa quantitat.

Una aplicació immediata de la conservació del valor dels nombres decimals, independentment dels zeros que s'afegisquen a la dreta, s'utilitza per a facilitar l'operativitat amb aquests nombres. 


\section{Ordenar fraccions i nombres decimals}

El conjunt dels nombres Racionals, com es va veure al punt 3.5 d'aquest tema, és un conjunt totalment ordenat $\mathrm{i}$ això vol dir que no existeix cap dubte a l'hora de saber si un nombre racional és major o menor que un altre.

Com que aquests nombres racionals poden estar expressats amb fraccions o amb expressions decimals, distingirem les dues possibilitats:

1. Si són fraccions les que es volen ordenar, cal considerar tres casos que es treballaran seqüencialment a partir de $4 \mathrm{t}$ curs:

- Fraccions amb el mateix denominador. Per exemple, amb l'ajuda de dues cordes iguals, es vol comparar les fraccions $\frac{2}{5}$ i $\frac{3}{5}$. Per fer-ho s'assenyalen en ambdues cordes marques que les divideixen en cinquenes parts i es talla de cadascuna d'elles un dels trossos corresponents a les fraccions que es vol ordenar. Aquesta situació és molt intuïtiva i la contestació serà encertada a partir de la comparació directa del material. En al cas de l'exemple, es comprova que la fracció amb numerador més petit és menor que l'altra.

Per tal de generalitzar aquest fet, sense el suport directe de material o d'una situació real, podem utilitzar com ajuda la representació de les fraccions a la recta numèrica. Per representar-hi les fraccions, dividim el segment entre el 0 i l'1 en cinc parts iguals i escrivim les fraccions on corresponga:

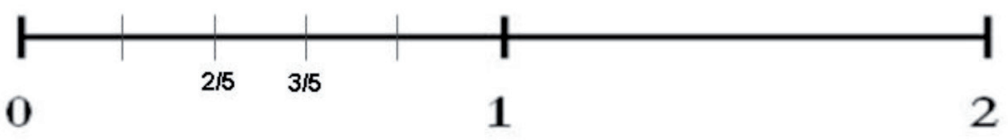

Figura 26. Representació de $\frac{2}{5}$ i $\frac{3}{5}$ a la recta numèrica

Com que l'ordenació a la recta numèrica s'ha assolit amb els nombres Naturals, és clar que la fracció situada a l'esquerra és la menor.

Posteriorment al treball amb materials o representacions gràfiques i la corresponent verbalització, cal fer el pas següent en l'abstracció, que és la representació simbòlica d'aquesta relació d'ordre, utilitzant els signes coneguts per als nombres Naturals: $\frac{2}{5}<\frac{3}{5}$

Una vegada s'han comprovat situacions paregudes en diferents casos, cal donar la norma general: «Quan dues fraccions tenen el mateix denominador, és menor la que té el numerador més menut».

- Fraccions amb el mateix numerador. Anàlogament al cas anterior i a partir d'una situació problemàtica real, agafar de dues cordes iguals dos trossos, de longituds $\frac{1}{2}$ i $\frac{1}{3}$ de cadascuna, es vol saber si la fracció $\frac{1}{2}$ és menor que $\frac{1}{3}$ o no ho és. A partir de la comparació directa dels trossos de corda, arriben a 
la conclusió que $\frac{1}{3}$ és menor que $\frac{1}{2}$. En aquest cas concret es comprova que la fracció amb denominador més gran és menor que no l'altra.

Per a generalitzar aquest fet, sense el suport directe de material o situació real, utilitzarem com ajuda la recta numèrica. Per tal de representar-hi les fraccions, dividim el segment entre el 0 i l'1 en tres i en dues parts iguals i escrivim les fraccions on corresponga. La dificultat afegida és que el nombre de parts que s'ha de fer no és igual per a les dues fraccions. Caldrà indicar les divisions amb marques diferents:

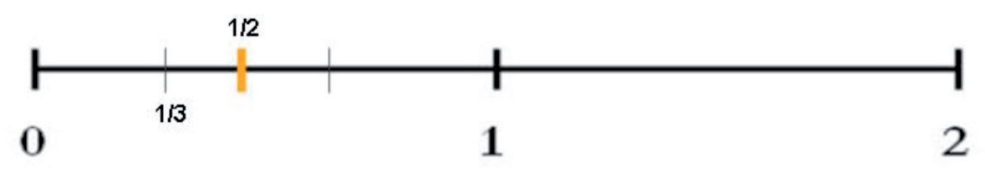

Figura 27. Representació de $\frac{1}{3}$ i $\frac{1}{2}$ a la recta numèrica

Novament, com que l'ordenació a la recta numèrica s'ha assolit amb els nombres Naturals, la fracció situada a l'esquerra és la menor.

Finalment cal arribar a la representació simbòlica d'aquesta relació d'ordre, utilitzant els signes coneguts: $\frac{1}{3}<\frac{1}{2}$

Una vegada s'han comprovat situacions semblants en diferents casos, cal donar la norma general: "Quan dues fraccions tenen el mateix numerador, és menor la que té el denominador més gran».

- Fraccions amb diferent numerador $i$ denominador. De la mateixa manera, caldrà partir d'una situació problemàtica real, agafar de dues cordes iguals dos trossos de longituds $\frac{3}{5}$ i $\frac{1}{2}$ de cadascuna, es vol saber si la fracció $\frac{1}{2}$ és menor o no que $\frac{3}{5}$. A partir de la comparació directa dels trossos de corda, arriben a la conclusió que $\frac{1}{2}$ és menor que $\frac{3}{5}$.

Després d'analitzar més exemples, no es troba una norma general per a ordenar aquests tipus de fraccions. Per tal de trobar-la ens ajudem de la recta numèrica i representem l'exemple anterior:

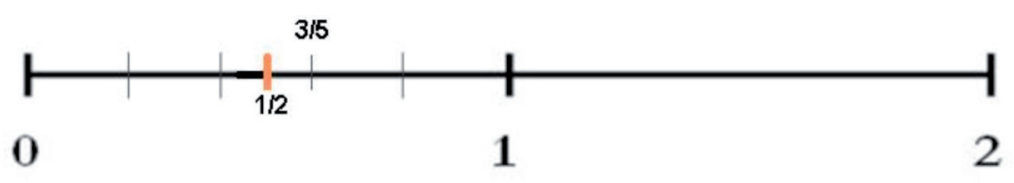

Figura 28. Representació de $\frac{1}{2}$ i $\frac{3}{5}$ a la recta numèrica 
S'hi observa, en tots els casos, que la recta numèrica tampoc ens ajuda a trobar una norma general, per no haver una relació directa entre l'ordre dels numeradors i denominadors i l'ordre de les fraccions.

Per resoldre aquest problema, se'ls preguntarà si podem usar alguna de les normes que ja sabem. Els ajudarem a què arriben a concloure que han d'utilitzar la més simple i intuïtiva, que és la que ordena les fraccions amb denominadors iguals.

Com que es treballarà l'ordenació de fraccions amb diferent numerador $\mathrm{i}$ denominador, després d'haver vist la reducció de fraccions a altres equivalents a elles amb igual denominador per tal de sumar-les o restar-les, faran servir la mateixa tècnica per a convertir les fraccions inicials en fraccions equivalents a aquestes amb el mateix denominador. Només caldrà ordenar pels nous numeradors les fraccions obtingudes i, a partir d'aquestes, ordenar les fraccions inicials; és a dir, com que $\frac{1}{2}=\frac{5}{10} \mathrm{i} \frac{3}{5}=\frac{6}{10}$, i s'acompleix que $\frac{5}{10}<\frac{6}{10}$ aleshores $\frac{1}{2}<\frac{3}{5}$

2. Si són nombres decimals representats per les seues expressions decimals exactes, el treball començaria en 5é curs de primària. S'ha de relacionar l'ordenació d'aquestes expressions amb la dels nombres naturals que, intuïtivament, no és de la mateixa manera.

Per exemple, en els naturals queda clar que 7 és menor que 66, i s'ha de ser conscient que, per a l'alumnat, passar d'aquesta situació elemental a que 0'66 és menor que 0'7 no és evident. Aquest treball d'ordenació d'expressions decimals necessita d'una fase manipulativa (per exemple, mesurar 7 dm d'una corda i $66 \mathrm{~cm}$ de la mateixa i expressar els resultats en metres) i de representació gràfica (amb quadrats iguals), perquè al veure la situació següent no hi ha cap dubte (figura 29).
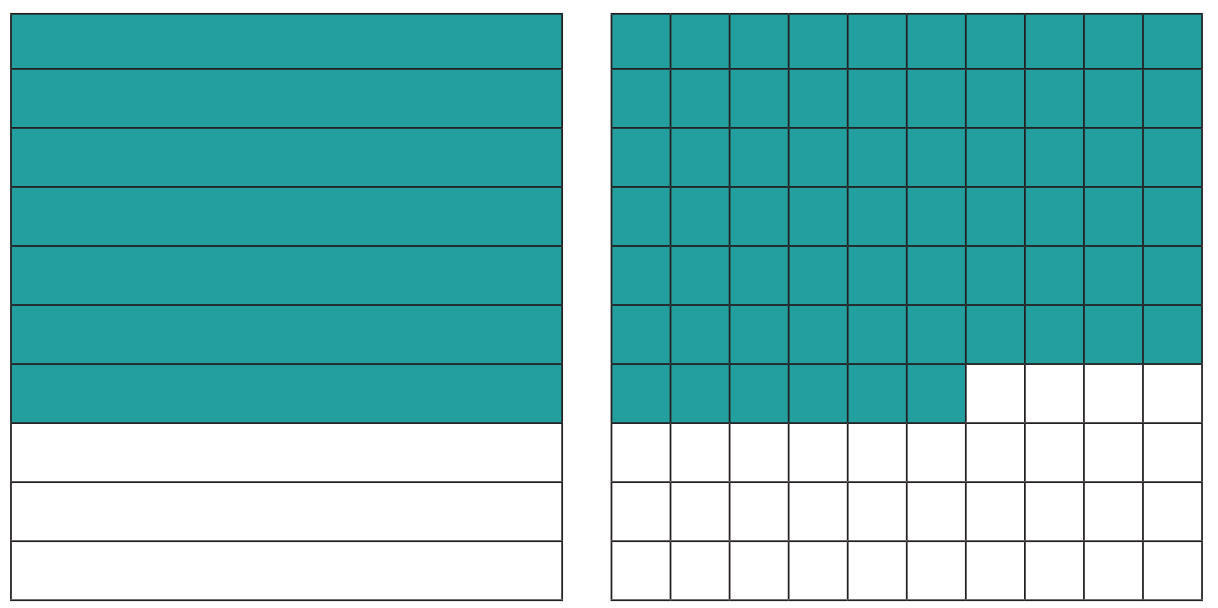

Figura 29. Representació de 7 dècimes i 66 centèsimes 
Novament, després del treball amb materials o representacions gràfiques i la corresponent verbalització, cal fer el pas cap a la representació simbòlica d'aquesta relació d'ordre: $\mathbf{0 , 6 6}<\mathbf{0 , 7}$.

Els dubtes en l'ordenació d'expressions decimals apareixen quan se les vol ordenar sense l'ajuda de materials o representacions gràfiques.

Per a resoldre aquests dubtes les expressions decimals s'han d'ordenar per passos, utilitzant les normes d'ordenació conegudes per als nombres Naturals. Primer s'ordenen per la part sencera, és a dir, la part anterior a la coma. Si aquesta és diferent, ja tenim la justificació per ordenar les expressions.

Si les parts senceres són iguals, cal ordenar-les segons les xifres decimals, començant per les dècimes. Si aquestes són diferents ja tindrem criteri per ordenar les expressions decimals. En cas contrari, es passaria a comparar les centèsimes, mil·lèsimes...

Cal observar que hi ha una errada molt comuna en l'alumnat i és pensar que si hi ha més xifres decimals el nombre és major: per exemple, pensar que el nombre 136'652312 és major que 136'65232, equivocació que se soluciona correctament aplicant el criteri anterior.

Nota: Per ordenar expressions decimals no exactes de nombres racionals, s'utilitza el mateix criteri que s'ha exposat en la darrera capacitat.

\section{Sumar i restar fraccions amb igual denominador}

En 5é de primària, serà quan es començarà a sumar fraccions. Al mercat, a casa, amb menjars,..., hi ha moltes situacions que poden implicar una addició de parts. En el nivell gràfic o manipulatiu es presenten poques dificultats, serà en el moment de passar a la fase simbòlica, quan podem trobar-ne més.

Distingirem els següents casos:

1. Fracció pròpia més fracció pròpia, amb una altra fracció pròpia com a resultat. Per exemple: «Un xiquet es menja 3 porcions i un altre 2 d'una pastilla de xocolata dividida en 8 porcions iguals. Quina part de la pastilla s'ha menjat cadascú i quanta s'han menjat entre els dos?». El que es busca és la suma de les fraccions $\frac{3}{8}$ i $\frac{2}{8}$ que són les que expressen la part de pastilla que s'ha menjat cada xiquet.

En la situació real no hi ha cap problema per a comprovar que s'han menjat $\mathbf{5}$ porcions de les $\mathbf{8}$ que hi havia, és a dir $\frac{\mathbf{5}}{\mathbf{8}}$. Simplement, el que han fet és sumar les porcions que s'han menjat cadascú i expressar-ho respecte de la unitat. 
En la representació gràfica, cal tindre cura de representar sempre la unitat, i sobre aquesta les porcions de cada xiquet (figura 30).

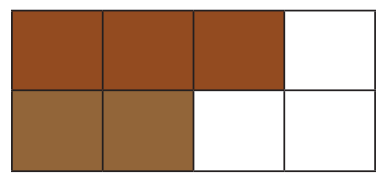

Figura 30. Representació de l'addició de $\frac{3}{8}$ i $\frac{2}{8}$

Queda clar que s'han menjat 5 de les $\mathbf{8}$ porcions, és a dir, la fracció que s'ha obtingut com a resultat és $\frac{\mathbf{5}}{\mathbf{8}}$

Tant en la situació real com en la representació gràfica es comprova que el numerador de la fracció resultant és la suma dels numeradors de les fraccions inicials i que el denominador és el mateix d'aquestes.

De manera simultània al treball amb materials o representacions gràfiques i la corresponent verbalització, farem la representació simbòlica de l'addició:

$$
\frac{3}{8}+\frac{2}{8}=\frac{3+2}{8}=\frac{5}{8}
$$

És necessari insistir amb més exemples associats a la resolució de situacions problemàtiques per a identificar clarament el que significa sumar fraccions amb el mateix denominador i per a evitar que, en el treball posterior d'addició en la fase simbòlica, ens trobem com a resultat: $\frac{\mathbf{5}}{\mathbf{1 6}}$

2. Fracció pròpia més fracció pròpia, amb una fracció impròpia com a resultat. Per exemple, «Una xiqueta es menja 3 porcions i una altra 6 d'unes pastilles de xocolata dividides cadascuna en 8 porcions iguals. Quina part de pastilla s'ha menjat cadascuna i quanta se n'han menjat entre les dues?». El que es busca és la suma de les fraccions $\frac{\mathbf{3}}{\mathbf{8}}$ i $\frac{\mathbf{6}}{\mathbf{8}}$ que, com en l'exemple anterior, són les que expressen la part de pastilla que s'ha menjat cada xiqueta.

En la situació real no hi ha cap problema per a comprovar que s'han menjat 9 porcions de xocolata com cadascuna de les $\mathbf{8}$ que hi ha en una pastilla. L'expressió d'aquest resultat com a $\frac{\mathbf{9}}{\mathbf{8}}$ no significarà cap problema, tenint en compte que s'ha treballat abans les fraccions impròpies. Simplement, el que han fet és sumar les porcions que s'han menjat cadascuna i expressar-ho respecte de la unitat.

En la representació gràfica s'ha de tindre cura de representar sempre la unitat i, sobre aquesta, les porcions de cada xiqueta. Els demanem que representen les fraccions inicials i el resultat i, clar, hi ha una dificultat, que no n'hi ha prou amb una unitat només: 

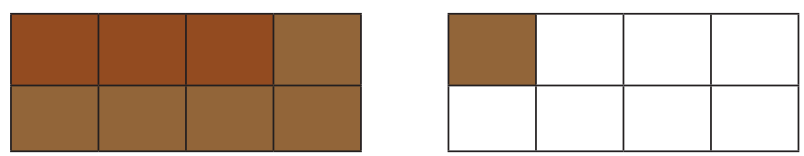

Figura 31. Representació de l'addició de $\frac{3}{8}$ i $\frac{6}{8}$

Queda clar que s'han menjat 9 de les 8 parts, és a dir, la fracció que s'ha obtingut com a resultat és $\frac{9}{8}$, que també es pot expressar com $1 \frac{1}{8}$, si utilitzem nombres mixtes com hem vist en la capacitat 1 .

Anàlogament al cas anterior, es comprova que el numerador de la fracció resultant és la suma dels numeradors de les fraccions inicials i que el denominador és el mateix d'aquestes.

De manera simultània al treball amb materials o representacions gràfiques i la corresponent verbalització, hem de fer la representació simbòlica de l'addició:

$$
\frac{3}{8}+\frac{6}{8}=\frac{3+6}{8}=\frac{9}{8}=1 \frac{1}{8}
$$

És necessari insistir amb més exemples associats a la resolució de situacions problemàtiques per a identificar clarament el que significa sumar fraccions amb el mateix denominador, obtenint una fracció impròpia com a resultat $\mathrm{i}$ per a evitar que, en el treball posterior d'addició en la fase simbòlica, ens trobem que expressen com a solució: $\frac{9}{16}$

Amb situacions semblants, treballarem totes les possibilitats de l'addició de fraccions amb el mateix denominador, utilitzant, per a expressar els resultats, tant fraccions pròpies, com impròpies o nombres mixtes.

Com a regla general, la suma de dues fraccions amb el mateix denominador és una altra fracció que té com a numerador la suma dels numeradors de les fraccions inicials i com a denominador el mateix que tenien aquestes fraccions.

També en 5é de primària es començarà amb la subtracció de fraccions. Com que les fraccions que es treballen en primària són sempre positives, totes les subtraccions de fraccions que es plantegen tindran el minuend major o igual que el subtrahend.

Consistirà, en una primera fase, en buscar una situació quotidiana que connecte la vida real amb el treball que volem realitzar. Per exemple: "Un xiquet agafa sis porcions d'una pastilla de xocolata dividida en 8 parts iguals. Si se'n menja quatre d'aquestes porcions, quina part de pastilla li queda?». El que es busca és la

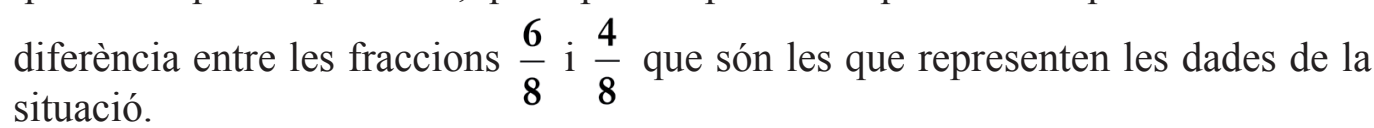


En la situació real no hi ha cap problema per a comprovar que li queden $\mathbf{2}$ porcions de les 8 que hi havia, és a dir $\frac{2}{8}$. Simplement, el que han fet és restar les porcions que agafa i les que es menja i expressar-ho respecte de la unitat.

En la representació gràfica, s'ha de tindre cura de representar sempre la unitat i, a sobre d'aquesta, les porcions agafades (figura 32).

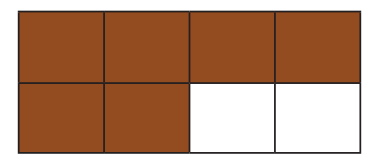

Figura 32. Representació de $\frac{6}{8}$

llevant-ne, a continuació, les parts menjades (figura 33).

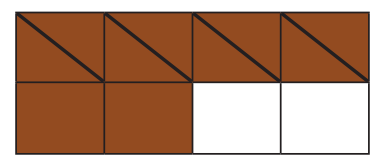

Figura 33. Representació de la subtracció $\frac{6}{8}$ menys $\frac{4}{8}$

És clar que li queden $\mathbf{2}$ de les $\mathbf{8}$ porcions de la unitat, és a dir, la fracció que s'ha obtingut com a resultat és $\frac{2}{8}$

Tant en la situació real com en la representació gràfica es comprova que el numerador de la fracció resultant és la diferència entre els numeradors de les fraccions inicials i que el denominador és el mateix d'aquestes.

De manera simultània al treball amb representacions materials o gràfiques i la corresponent verbalització, hem de fer la representació simbòlica de la subtracció:

$$
\frac{6}{8}-\frac{4}{8}=\frac{6-4}{8}=\frac{2}{8}
$$

És necessari insistir amb més exemples, associats a la resolució de situacions problemàtiques, per a identificar clarament el que significa restar fraccions amb el mateix denominador i per a evitar que, en el treball posterior de subtracció en la fase simbòlica, ens trobem com a resultat : $\frac{2}{\mathbf{0}}$

En general, tant en fraccions pròpies com impròpies, el procediment és semblant a l'addició i, per tant, la regla general és: la diferència entre dues fraccions amb el mateix denominador és altra fracció que té com a numerador la diferència entre els numeradors anteriors $i$ com a denominador el mateix que tenien les fraccions inicials. 


\section{Sumar i restar nombres decimals}

A partir de 5é curs de primària i de manera progressiva, es treballarà l'addició $i$ subtracció de nombres decimals. En un principi, aquestes operacions no tenen cap dificultat, per semblar-se molt a l'addició i subtracció de nombres naturals. Utilitzarem situacions reals que podrien estar relacionades amb activitats de mesura $i$ del sistema monetari i distingirem els següents casos:

1. Sumands amb la mateixa quantitat de xifres decimals. Sumar sense portar-ne en aquestes xifres. Per exemple: «Per a preparar una festa en classe hem gastat 35,24 $€$ en una tenda i 9,32 € en una altra. Quants diners hem gastat en total?».

Per a respondre a aquesta pregunta cal fer una addició de nombres decimals. $S$ 'ha de tenir cura en situar en columna els dos nombres decimals, de manera que es facen coincidir verticalment les comes. Aquesta qüestió resulta senzilla si recorden la posició on se situaven els nombres naturals per sumar. Una vegada disposats d'aquesta manera, es procedeix a sumar començant per la dreta i seguint els mateixos passos que utilitzaven per a sumar els nombres naturals, és a dir:

sense oblidar situar la coma al lloc corresponent del resultat.

2. Sumands amb la mateixa quantitat de xifres decimals. Sumar portant-ne a aquestes xifres de manera progressiva. Per exemple: «Per a preparar una festa en classe hem gastat 35,24 $€$ en una tenda i 9,92 $€$ en una altra. Quants diners hem gastat en total?».

En aquest cas poden sorgir dificultats per a comprendre l'operació:

Aleshores, caldria treure àbacs i representar amb ells els sumands i comprovar que, de la mateixa manera que ocorre amb els nombres naturals, cada vegada que s'ajunten 10 unitats d'un ordre es forma una unitat d'ordre immediat superior, és a dir, les 11 dècimes que obtenim en sumar 9 i 2 dècimes dels sumands generen 1 unitat natural de primer ordre, que portem, i una dècima que deixem al lloc que li escau. 
De manera anàloga, treballarem addicions portant-ne en altres ordres d'unitats en les xifres decimals.

3. Sumands amb diferents quantitats de xifres decimals. Per exemple: «Necessitem comprar corda per a cobrir dos costats del pati del col-legi. Si un costat mesura 35,24 $\mathrm{m}$ i altre 9,9 m, quanta corda hem de comprar?».

En aquest cas l'addició serà:

$$
\begin{aligned}
& 35,24 \\
& +9,9 \\
& \hline 45,14
\end{aligned}
$$

i l'automatització en la resolució vindrà quan, aplicant el que ja saben, tinguen clar que s'han de fer coincidir en columna les comes dels sumands $i$ que han de sumar per columnes començant per la dreta. Si hi ha cap problema, poden emplenar amb zeros els buits de les xifres decimals dels sumands que en tinguen menys, segons han vist a la capacitat 4 .

En tots els casos, és necessari insistir amb més exemples associats a la resolució de situacions problemàtiques per a identificar clarament el que significa sumar nombres decimals i aconseguir l'automatització d'aquesta operació.

Respecte de la subtracció, repetirem els passos anteriors. En primer lloc, restarem nombres, amb la mateixa quantitat de xifres decimals, sense portar-ne. En segon lloc, portant-ne de manera progressiva en les xifres decimals i, per últim, restarem termes amb diferents quantitats de xifres decimals. En tots els casos, la referència ha de ser la subtracció de nombres naturals i, quan resten portant-ne, utilitzaran l'algorisme estàndard d'aquesta operació.

En 6é de primària, haurien de resoldre aquestes dues operacions sense la necessitat d'emplenar amb zeros els buits en les expressions decimals.

Caldrà comprovar, amb exemples, que l'addició de nombres decimals compleix les propietats commutativa i associativa.

\section{Comprovar que s'obté el mateix resultat sumant o restant quantitats expressades en forma de fracció decimal que representades com a nombre decimal}

També en 5é i 6é de primària, hem d'utilitzar el que han aprés en relació a obtenir la fracció decimal corresponent a un nombre decimal, per tal de comprovar, i si escau rectificar, les operacions fetes amb nombres decimals. Per exemple, si estem calculant $53,37+22,51$, poden fer-ho sumant els nombres decimals o convertint-los en fraccions decimals i sumant-les: 


$$
\frac{+22,51}{75,88} \quad 53,37+22,51=\frac{5337}{100}+\frac{2251}{100}=\frac{7588}{100}=75,88
$$

Si la relació d'equivalència entre les fraccions encara no l'han treballada, farem la comprovació sempre que les fraccions tinguen el mateix denominador; és a dir, sempre que els nombres decimals tinguen la mateixa quantitat de xifres decimals. Una vegada es treballen les capacitats $10 \mathrm{i} 11$, podrem reprendre aquest punt i fer les comprovacions per a sumands amb qualsevol quantitat de xifres decimals.

Es procedeix anàlogament en el cas de la subtracció.

\section{Multiplicar i dividir nombres decimals per naturals}

A partir de 5é curs de primària, es comença a multiplicar i dividir nombres decimals per naturals.

\section{Multiplicació}

Començarem amb aquesta operació i, com en els casos anteriors, partirem d'una situació real, per exemple: «Si per a fer un joc hem de donar 1,25 m de cinta a cada xiquet $i$ tenim la classe organitzada en grups de 3 xiquets $i$ xiquetes, quants metres de cinta necessitem comprar per a cada grup?».

Han de relacionar aquesta situació amb els coneixements que tenen sobre la multiplicació de naturals per arribar a plantejar com a solució del problema la següent operació:

\section{1,25 \\ $\times 3$}

A partir d'aquesta i amb el que saben, intentaran resoldre-la. Ha d'estar ben clar: es multiplica igual que si els dos factors foren nombres naturals i una vegada multipliquem per les dècimes ho anotem al resultat, situant la coma al lloc corresponent del producte.

\section{1,25 \\ $\times 3$ \\ 3,75}

Es comprova amb més situacions d'aquest tipus i passem després a la multiplicació d'un nombre decimal (en un primer moment només d'una xifra decimal) per un nombre natural de dues xifres, per exemple: «L'alumnat de la nostra classe està agrupat en 13 parelles per a organitzar una festa al col-legi. Si cada parella pot 
portar 2,5 1 de suc de taronja, quants litres tindrem en total?». Treballarem amb l'algorisme de llapis i paper explorant possibilitats:

\section{2,5 \\ $\times 13$}

Inicialment i per la semblança que hi ha amb els nombres naturals, sembla lògic que es multiplique per $3 \mathrm{i}$, pel que sabem de la multiplicació anterior, obtindrem el resultat de manera senzilla:

\section{2,5 \\ $\times 13$ \\ 7,5}

Per donar el següent pas cal recordar que no multipliquem per 1, en realitat ho estem fent per 10. És a dir, no multiplicarem 1 per 5 dècimes, sinó 10 per 5 dècimes i 10 per 2 unitats. Com ja saben que 10 dècimes fan una unitat i que 10 unitats fan una desena, obtindran 5 unitats i 2 desenes com a resultat parcial. Aleshores, com després han de sumar, igual que a la multiplicació de nombres naturals, cal situar aquest resultat al seu lloc, $i$ és per això que el desplacen cap a l'esquerra per alinear els ordres d'unitats corresponents dels productes parcials:

\section{2,5 \\ $\times 13$ \\ 7,5}

25

32,5

Es resolen més situacions d'aquest tipus i s'augmenta la dificultat de les operacions amb més xifres decimals al multiplicand, per exemple, «Si cadascuna de les 13 parelles aporta $3,76 €$ per a comprar el que fa falta per a la festa, quants euros tenim en total?». En aquest cas, la multiplicació serà:

$\begin{array}{r}3,76 \\ \times \quad 13 \\ \hline 11,28 \\ 37,6 \\ \hline 48,88\end{array}$

És important recordar l'operació anterior i el funcionament del sistema de numeració pels nombres decimals, per a tenir clar que el resultat de multiplicar l'1 de les desenes per 6 centèsimes donarà 6 dècimes com a resultat i que haurem 
d'escriure-les al lloc adient. Anàlogament, passarà amb el 7 de les dècimes i el 3 de les unitats.

Cal notar que no desapareixen les comes dels productes parcials de l'algorisme i és bo que no desapareguen fins que no estiga automatitzada l'operació. Podrà estar-ho quan se n'adonen que la quantitat de xifres decimals del producte coincideix amb el nombre de xifres decimals del multiplicand. A partir d'aquest moment aplicarem, com a regla general, resoldre l'operació sense escriure les comes dels productes parcials $i$ situant la coma en el producte final separant tantes xifres decimals com hi ha al multiplicand.

Augmentem la dificultat de les multiplicacions considerant nombres decimals i nombres naturals amb més xifres fins que estiga assolida completament aquesta operació i es faça servir de manera automàtica la regla general descrita abans.

\section{Divisió}

D'acord amb l'enunciat d'aquesta capacitat, es treballarà la divisió només quan el divisor siga un nombre natural. Per exemple: «Hem de repartir, en parts iguals, una corda de 42,56 m entre 5 grups de xiquets, quants metres li corresponen a cada grup?». La divisió que resol aquest problema segueix un procediment semblant a la que es fa amb nombres naturals, per exemple:

\section{$42,56 \mid 5$ \\ 0258}

Quan s'arriba a la coma del dividend, és a dir, quan es baixa la xifra de les dècimes, vol dir que ja s'ha acabat de dividir la part entera. Ha de quedar clar que també ha finalitzat la part entera del quocient i, per això, hem de posar la coma al lloc corresponent i continuar la divisió:



Cal notar també que, quan dividim amb decimals, no s'atura el procés fins que arribem a obtenir de residu zero, o fins que la persona que opere ho desitge. Per tant, no esperarem a posar la coma al quocient al final de l'algorisme, perquè no sabrem exactament el lloc de col·locació ja que el quocient pot tenir més xifres decimals que el dividend: 


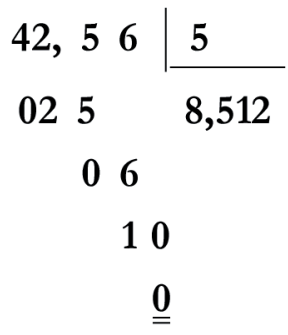

Augmentem la dificultat de les divisions considerant nombres decimals i nombres naturals amb més xifres fins que estiga assolida completament aquesta operació i s'aplique de manera automàtica la regla general d'anotar la coma al quocient quan s'opera la xifra de les dècimes del dividend.

\section{Reconèixer l'equivalència de fraccions en situacions reals $i$ analíticament. Obtenir la fracció irreductible d'una família de fraccions equivalents}

La idea d'equivalència és un concepte ampli, general i fonamental en els diferents camps científics i en la vida diària. Molt a sovint, relacionem situacions, sons, conceptes genèrics, per equivalències. Quan alguna cosa equival a una altra, té el mateix valor per alguna característica, encara que no es manifeste igual per a les altres.

Es treballarà el concepte d'equivalència aplicada a les fraccions a partir de $4 \mathrm{t}$ de primària. Ha de treballar-se de manera manipulativa. Per exemple, a partir d'una situació d'aula en la que «es reparteixen cartolines iguals amb els fraccionaments que es mostren en la figura 34 per tal que els xiquets i xiquetes retallen la part ombrejada amb motiu de fer un mural. Se'ls fan les següents preguntes: Quina part de cartolina ha utilitzat cada grup? Quin dels tres grups ha utilitzat més cartolina?».
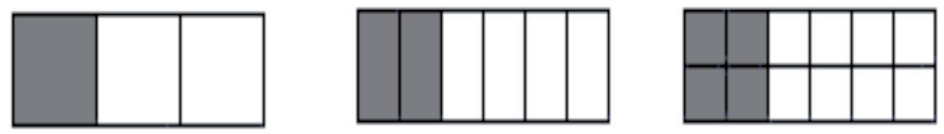

Figura 34. Representació de $\frac{1}{3}, \frac{2}{6}$ i $\frac{4}{12}$

Per respondre a la primera pregunta, els xiquets expressen numèricament les fraccions $\frac{1}{3}, \frac{2}{6}$ i $\frac{4}{12}$ i al comparar els trossos de cartolina que ha utilitzat cada grup, se n'adonen que són iguals i, per tant, els tres grups han utilitzat la mateixa quantitat de cartolina. 
Caldrà que reflexionen al voltant del fet que hi ha tres expressions fraccionàries per tal d'indicar la mateixa quantitat $i$, com a conseqüència d'aquesta reflexió, expressaran:

$$
\frac{1}{3}=\frac{2}{6}=\frac{4}{12}
$$

On les igualtats no volen dir que les fraccions siguen iguals, sinó que representen la mateixa porció de la unitat. Es continua treballant el concepte d'equivalència amb aquesta o unes altres situacions (en contextos discrets i continus) que generen conjunts de fraccions que representen la mateixa quantitat. El següent pas serà introduir el nom de la relació que existeix entre aquestes fraccions, anomenant-les fraccions equivalents.

Continuant amb el treball, els podem plantejar les preguntes següents: «Sempre caldrà disposar d'un material amb el qual es puguen construir fraccions equivalents o comprovar si ho són fraccions donades? Podem trobar cap tipus de relació numèrica entre els termes de les fraccions equivalents?». A partir de la comparació entre els numeradors i els denominadors de les diferents fraccions de cada família de fraccions equivalents estudiades en els exemples anteriors, els ajudarem a deduir que podem trobar una fracció equivalent a una altra multiplicant els dos termes d'aquesta per un mateix nombre (és a dir, multiplicant-la per una fracció unitat), el que s'anomena amplificar fraccions; o dividint-los, i aleshores s'anomenarà simplificar fraccions.

Per exemple: $\frac{1}{3}=\frac{1}{3} \times \frac{2}{2}=\frac{2}{6}$ i $\frac{1}{3}=\frac{1}{3} \times \frac{4}{4}=\frac{4}{12}$

Una vegada estiga clar aquest procediment, l'utilitzarem per tal de trobar fraccions equivalents a una altra donada.

Quan en el procés de simplificació d'una fracció obtinguem una altra equivalent a aquesta que no es pot simplificar més (perquè els seus termes són primers entre sí), l'anomenarem fracció irreductible de la família de fraccions equivalents a la primera. Una manera ràpida de trobar aquesta fracció es treballarà junt amb la divisibilitat de nombres naturals, amb la finalitat que l'alumnat descobrisca que dividint els dos termes de la fracció inicial pel màxim comú divisor d'aquests s'obté l'esmentada fracció irreductible. En l'exemple que s'està treballant, aquesta és $\frac{1}{3}$

Quan el que es vol fer és comprovar si dues fraccions són equivalents, podem utilitzar diferents procediments:

1. Cercar un nombre tal que en multiplicar o dividir per ell els dos termes d'una fracció done com a resultat, respectivament, els termes de l'altra.

2. Convertir les fraccions en altres equivalents a elles amb el mateix denominador i comparar-les, comprovant si són o no iguals. 
3. Trobar la fracció irreductible de cadascuna d'elles. Quan aquestes irreductibles coincidisquen, les fraccions de les quals provenen seran equivalents. En cas d'arribar a fraccions irreductibles que no siguen iguals, les fraccions inicials no seran equivalents.

Podem relacionar el concepte i el càlcul intuïtiu de fraccions equivalents treballats fins ara amb la definició formal de la relació d'equivalència (vegeu 3.1) que ens permet construir el conjunt dels nombres racionals. D'acord amb aquesta relació, dues fraccions $\frac{\mathbf{a}}{\mathbf{b}} \mathrm{i} \frac{\mathbf{c}}{\mathbf{d}}$ són equivalents sii $\mathbf{a} \cdot \mathbf{d}=\mathbf{b} \cdot \mathbf{c}$. Es pot comprovar amb els alumnes de 6é de primària aquest fet, com a complement del que s'ha treballat referent a les fraccions equivalents.

La importància d'aquesta capacitat radica en la necessitat de trobar fraccions amb el mateix denominador equivalents a altres donades, per tal d'ordenar i sumar o restar les fraccions originals. Tanmateix, usarem la simplificació de fraccions per tal d'expressar els resultats de situacions problemàtiques de la manera més senzilla possible.

Nota: Quan al dividir el numerador entre el denominador d'una fracció s'obtinga una expressió decimal exacta o una expressió periòdica amb poques xifres en l'anteperíode i en el període, es poden usar aquests resultats per tal de saber si dues o més fraccions són o no equivalents. Així, quan les expressions decimals coincidisquen, les fraccions seran equivalents.

\section{Sumar i restar fraccions amb diferent denominador. Multiplicar i dividir fraccions}

Aquestes operacions es treballen en 6é de primària, quan ja es té un domini del que significa el concepte de fracció, de l'equivalència de fraccions i de l'addició i subtracció de fraccions amb el mateix denominador.

\section{Addició}

Partint d'una situació real, per exemple: «L'alumnat d'una aula està organitzat en 2 grups que disposen de cartolines iguals per tal de fer un mural. Un dels grups talla la cartolina en tres parts iguals i n'utilitza una, un altre grup necessita partir-la en quatre parts iguals, de les quals ens farà servir tres. Necessiten saber quina part de cartolina els ha sobrat conjuntament als dos grups per tal de poder utilitzar-la en una altra part de mural».

La representació gràfica d'aquesta situació es troba a la figura 35. 


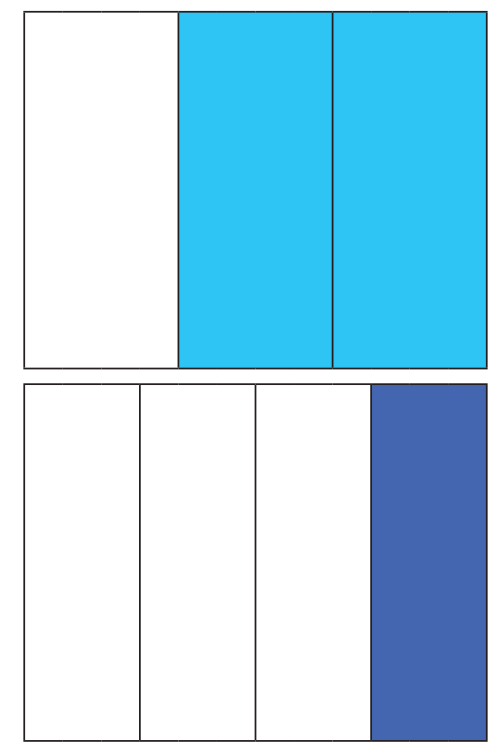

Figura 35. Representació de $\frac{2}{3}$ i $\frac{1}{4}$

Els xiquets i les xiquetes expressen numèricament les fraccions que representen el que els ha sobrat a cada grup: $\frac{2}{3} \mathrm{i} \frac{1}{4}$, i identifiquen l'addició com l'operació que resol el seu dubte. Per tant, cal sumar aquestes dues fraccions: $\frac{2}{3}+\frac{1}{4}$

Es troben amb el problema que el denominador de les fraccions sumands no coincideixen i, per tant, no saben com fer l'operació.

Els suggerim que, abans de resoldre l'operació numèrica, utilitzen els trossos de cartolina. Els uneixen i els comparen amb una cartolina sencera (cartolina unitat). Però es troben amb el problema de no saber expressar numèricament el que tenen davant, perquè no saben en quantes parts haurien de dividir aquesta unitat per tal de poder fer-ho.

Després de comentar entre ells la situació en la qual es troben, pensen que és convenient disposar d'una unitat fraccionada. Marquen les divisions a sobre d'una cartolina per a fraccionar-la en terços, o en quarts (al ser els denominadors de les fraccions a sumar). Els trossos de cartolina que els havien sobrat els superposen units a sobre de les cartolines marcades, sense poder expressar el resultat, en cap dels dos casos, per no coincidir amb ninguna divisió marcada (figura 36). 

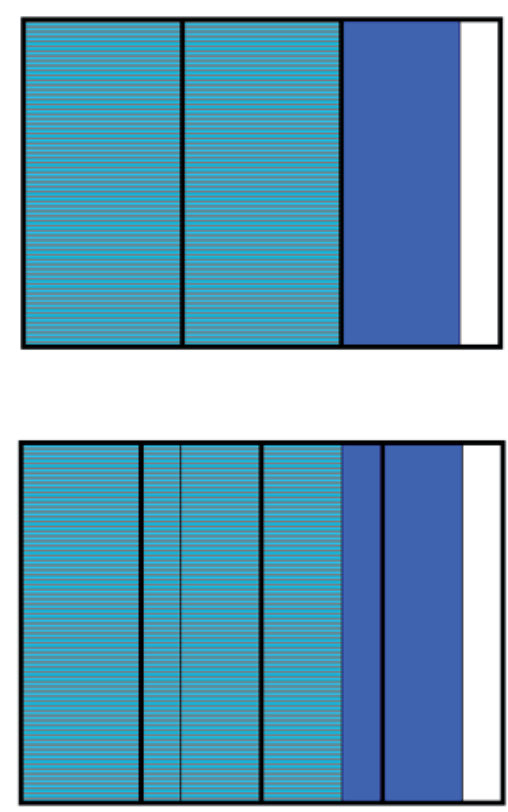

Figura 36. Representació de $\frac{2}{3}$ i $\frac{1}{4} \begin{gathered}\text { sobre dues cartolines, una dividida en terços i l'altra } \\ \text { en quarts }\end{gathered}$

Continuen pensant en diferents maneres de fraccionar la cartolina unitat, per exemple sisenes parts, vuitenes parts..., fins que arriben a la divisió en 12 parts iguals, que és la que els permet expressar numèricament el resultat per haver trobat una marca en la unitat que coincideix amb un dels extrems dels dos trossos units (figura 37).



Figura 37. Representació de $\frac{2}{3}$ i $\frac{1}{4}$ sobre una cartolina dividida en dotzenes parts

La marca és la que fa 11, és a dir el resultat és $\frac{\mathbf{1 1}}{\mathbf{1 2}}$. Per tant el resultat ja el saben:

$$
\frac{2}{3}+\frac{1}{4}=\frac{11}{12}
$$

Els podem preguntar si el procediment per a sumar fraccions amb diferent denominador sempre ha de fer-se manipulativament o podem buscar un algorisme que ens proporcione la solució numèrica.

En la recerca d'aquest algorisme i a partir de la superposició dels trossos sobre la cartolina dividida en 12 parts, observen que les fraccions originals $\frac{2}{3}$ i $\frac{1}{4}$ poden 
expressar-se com $\frac{8}{12}$ i $\frac{3}{12}$, i descobreixen la relació d'equivalència que existeix entre aquestes, perquè expressen, respectivament, la mateixa porció de cartolina. Aleshores cal descobrir la relació numèrica entre les fraccions originals i les equivalents, $i$ troben que: $\frac{2}{3} \times \frac{4}{4}=\frac{8}{12} \mathrm{i} \frac{1}{4} \times \frac{3}{3}=\frac{3}{12}$

Com que han aconseguit fraccions amb el mateix denominador i aquestes sí que saben sumar-les, arriben numèricament al resultat que ja coneixien:

$$
\frac{2}{3}+\frac{1}{4}=\frac{8}{12}+\frac{3}{12}=\frac{11}{12}
$$

És necessari insistir amb més exemples associats a la resolució de situacions problemàtiques per a identificar clarament el que significa sumar fraccions amb diferent denominador i, per tant, arribar a la conclusió que l'algorisme que els permet sumar les fraccions originals consisteix en convertir-les en altres equivalents a aquestes amb el mateix denominador per tal de poder aplicar l'addició de fraccions que ja coneixen.

Únicament quedarà per veure com trobar aquestes fraccions equivalents per tal que no siga una dificultat en cada ocasió.

En un primer moment, i treballant amb denominadors menuts, el procediment per a trobar les fraccions equivalents es resol multiplicant els dos termes de cada fracció pel denominador de l'altra. Per exemple $\frac{3}{4}+\frac{1}{6}=\frac{3 \times 6}{4 \times 6}+\frac{1 \times 4}{6 \times 4}=\frac{18}{24}+\frac{4}{24}=\frac{22}{24}$

Quan hi ha més de dues fraccions o els denominadors són molt grans i com que entre 5é i 6é curs de primària és on es treballa la divisibilitat dels nombres naturals, caldrà descobrir que el mínim comú múltiple $(\mathrm{mcm})$ dels denominadors serà el denominador de les noves fraccions equivalents, per ser el menor valor que alhora és múltiple de tots els denominadors. Podem agafar l'exemple anterior i utilitzar el mcm $(4,6)=12$ com a denominador comú: $\frac{3}{4}+\frac{1}{6}=\frac{9}{12}+\frac{2}{12}=\frac{11}{12}$, i observar que els termes de les fraccions són menors que els del procediment anterior. Com a cas particular d'aquest mètode, quan un dels denominadors és múltiple de l'altre o altres, serà aquest el que s'usarà com a denominador comú. Per exemple, en el cas de $\frac{2}{3}$ i $\frac{1}{6}$ serà 6 el denominador comú a les dues fraccions, així:

$$
\frac{2}{3}+\frac{1}{6}=\frac{4}{6}+\frac{1}{6}=\frac{5}{6}
$$


Caldrà comprovar amb exemples numèrics que l'addició de fraccions compleix les propietats commutativa $\mathrm{i}$ associativa.

\section{Subtracció}

Respecte de la subtracció de fraccions amb diferent denominador, es parteix del treball previ de l'addició i, per tant, tot el que s'ha fet en relació als denominadors, s'hereta de manera natural. Aleshores, una vegada tindrem les fraccions equivalents amb el mateix denominador, cal procedir d'acord amb la capacitat 6 .

Multiplicació

Començarem multiplicant una fracció per un nombre natural. Partint d'una situació real, per exemple: «A classe es disposa de vàries cordes d'igual llargària per a lligar uns paquets. Necessitem $\frac{3}{5}$ d'una corda per a cada paquet. Si hem de lligar 4 paquets, quanta corda utilitzarem?».

Es tornarà a la base del que suposa una multiplicació per nombres naturals, addició de sumands iguals. Cal reprendre aquesta idea des del principi, per tal d'utilitzar el mateix mecanisme amb les fraccions.

En aquest cas, l'operació que han de realitzar és $\frac{\mathbf{3}}{\mathbf{5}} \times 4$ i, a partir de la idea de multiplicació com una addició repetida, fan la següent operació:

$$
\frac{3}{5} \times 4=\frac{3}{5}+\frac{3}{5}+\frac{3}{5}+\frac{3}{5}=
$$

Com que saben sumar fraccions amb igual denominador, doncs arribem al resultat:

$$
=\frac{3+3+3+3}{5}=\frac{3 \times 4}{5}=\frac{12}{5}
$$

I enllaçant el primer i els darrers termes de la cadena d'igualtats s'obté:

$$
\frac{3}{5} \times 4=\frac{3 \times 4}{5}=\frac{12}{5}
$$

És a dir, per lligar els 4 paquets, es necessiten $\frac{12}{5}$ de corda.

La regla sembla que pot estar clara ràpidament (si fóra necessari es comprovaria amb més exemples): per a multiplicar una fracció per un nombre natural, cal multiplicar el numerador de la fracció per aquest nombre $i$ deixar el mateix denominador.

Quan es tracte de multiplicar dues fraccions, partirem també d'una situació real, per exemple: «Per tal de fer un berenar, hem comprat en una pastisseria $\frac{\mathbf{3}}{\mathbf{4}}$ d'un bescuit dividit en quarts. Com que les racions són massa grans dividim el que hem 
comprat en cinquenes parts. En acabar el berenar, observem que sols s'han menjat $\frac{2}{5}$ parts del bescuit que teníem. Quina part del bescuit sencer hem gastat en el berenar?».

Per ajudar l'alumnat a entendre el procediment de la multiplicació de fraccions s'utilitzarà la interpretació geomètrica, a partir de l'àrea d'un rectangle els costats del qual tenen com a longitud les dues fraccions que hem de multiplicar.

Com que no coneixen l'operació que resol aquesta situació, ens ajudarem de la representació gràfica de les dades per arribar a trobar-la. Així, al començament dibuixarem el bescuit sencer dividit en quatre parts iguals, ombrejarem els $\frac{3}{4}$ que hem comprat, els dividirem en cinquenes parts i assenyalarem els $\frac{2}{5}$ de $\frac{3}{4}$ que ens
hem menjat (figura 38 ).
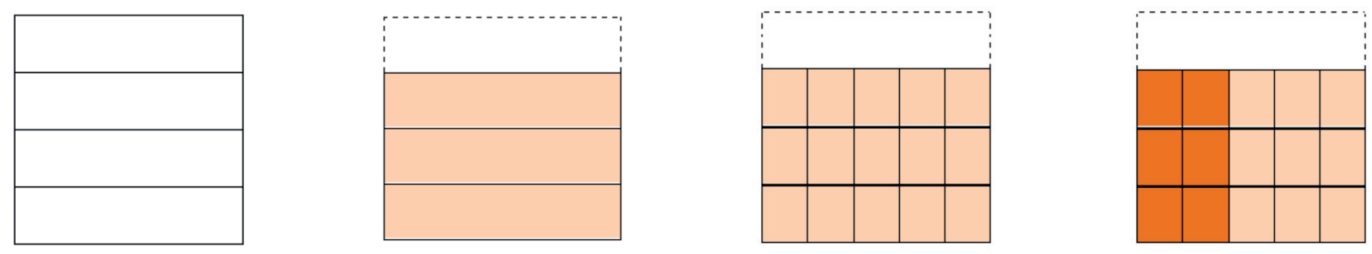

Figura 38. Representació de les successives divisions del bescuit fins arribar a $\frac{2}{5}$ de $\frac{3}{4}$

Per a contestar a la pregunta plantejada en la situació problemàtica caldrà expressar numèricament les parts del bescuit que s'han menjat en el berenar com a parts del bescuit sencer. Per aconseguir-ho dividirem en cinquenes parts la unitat que prèviament havien dividit en quartes parts i assenyalarem en fosc les parts que s'han menjat (figura 39).

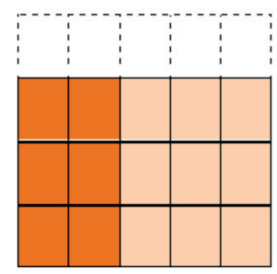

Figura 39. Representació, com a fracció de la unitat, del bescuit que s'ha menjat

Com s'observa en el dibuix, el bescuit consumit en el berenar representa els $\frac{\mathbf{6}}{\mathbf{2 0}}$ del bescuit sencer. Aquest valor és l'àrea del rectangle que té com a longituds dels costats $\frac{2}{5} \mathrm{i} \frac{3}{4}$, que com saben es calcula multiplicant-les: $\frac{2}{5} \times \frac{3}{4}$. Aleshores ja es poden igualar les dues expressions: $\frac{2}{5} \times \frac{3}{4}=\frac{6}{20}$ 
El pas següent és adonar-se què ha passat numèricament, que és on es volia arribar. Observant la igualtat anterior l'alumnat descobreix que la multiplicació de fraccions en aquest cas es pot resoldre de la següent manera:

$$
\frac{2}{5} \times \frac{3}{4}=\frac{6}{20}=\frac{2 \times 3}{5 \times 4}
$$

És necessari insistir amb més exemples associats a la resolució de situacions problemàtiques per a identificar clarament el que significa multiplicar fraccions $i$, per tant, arribar a la conclusió que el producte de fraccions és una altra fracció el numerador i denominador de la qual es calculen multiplicant, respectivament, els numeradors $i$ denominadors de les fraccions inicials.

El treball s'ha de completar estudiant la relació de la multiplicació de fraccions amb expressions on aparega una fracció «de» qualsevol altre nombre, interpretant-la com una multiplicació de la fracció pel nombre corresponent. En aquest cas la fracció està actuant com a operador sobre el nombre com es pot veure en els exemples següents:

- «Hem recorregut els $\frac{\mathbf{2}}{\mathbf{5}}$ d'un camí que té $\mathbf{6 0} \mathrm{km}$. Quants kilòmetres hem recorregut?» En aquest cas, $\frac{\mathbf{2}}{\mathbf{5}}$ de $\mathbf{6}$ s'haurà de calcular esbrinant quant és una cinquena part de 60, per posteriorment agafar-ne dues d'aquestes. Més endavant se n'adonaran que aquests càlculs són els que corresponen a l'operació $\frac{2}{5} \times 60$

- «Un poble ha produiit les $\frac{2}{7}$ parts de tot el vi de la comarca que són 30001 . Al llarg de l'any es venen, en aquest poble, les $\frac{3}{5}$ parts de la seua producció. Quants litres de vi s'han venut al poble?». En aquest cas, aplicant el que s'ha treballat a l'exemple anterior, calcularan $\frac{2}{7}$ de 3000 , realitzant l'operació $\frac{2}{7} \times 3000$. Posteriorment per a calcular $\frac{3}{5}$ de $\frac{2}{7} \times 3000$ aplicaran de nou el mateix procediment, n'obtenint $\frac{3}{5} \times \frac{2}{7} \times 3000$

Un cas particular de situacions amb expressions on aparega una fracció «de» qualsevol altre nombre, seran aquelles en les quals s'ha de calcular el percentatge d'una quantitat (simbolitzat per \% i representat per una fracció que té el percentatge al numerador i un 100 al denominador).

Per exemple: «En una peça de roba que val $50 €$, ens fan un descompte del $15 \%$. Quants euros ens descompten?». En aquest cas «el $15 \%$ de 50» es tradueix pel 
« $\frac{15}{100}$ de $50 » \mathrm{i}$, per tant, a partir dels casos anteriorment estudiats, el càlcul serà $\frac{15}{100} \times 50$

Un altre cas particular serà relacionar les parts que es fan d'un total amb el percentatge que suposen aqueixes parts del total. Per exemple: «S'han venut els $\frac{3}{5}$ de les entrades d'un camp de futbol. Quin percentatge d'entrades s'ha venut?» En aquest cas es tracta de trobar una fracció equivalent a $\frac{3}{5}$ que tinga com a denominador 100 , és a dir $\frac{60}{100}$ i expressar-la com a percentatge: $60 \%$.

Cal notar que el nombre decimal corresponent a $\frac{3}{5}$ és $\mathbf{0 , 6}$ i que també es pot calcular el percentatge multiplicant-lo per 100: $0,6 \times 100=60$, aleshores el percentatge és $60 \%$.

Comprovarem amb exemples que la multiplicació de fraccions compleix les propietats commutativa, associativa i distributiva, respecte de l'addició.

\section{Divisió}

Abans de començar amb el treball de la divisió, l'alumnat ha de saber què són les fraccions inverses. A partir d'una fracció donada, per exemple $\frac{\mathbf{5}}{\mathbf{7}}$, que entenem com 5 parts d'una unitat dividida en 7 parts, la inversa d'aquesta serà la fracció amb els termes canviats de posició, és a dir: $\frac{7}{5}$, en la que es representa que hem agafat 7 parts d'una unitat dividida en 5 .

A partir de l'observació d'alguns exemples de fraccions inverses, han de ser conscients que la inversa d'una fracció pròpia és impròpia i a l'inrevés i també que al multiplicar una fracció per la seua inversa, s'obté com a resultat una fracció unitat. En aquest cas: $\frac{5}{7} \times \frac{7}{5}=\frac{5 \times 7}{7 \times 5}=\frac{35}{35}=1$

Encara que les situacions on poden aparèixer les divisions de fraccions no són molt habituals, cal fer l'esforç per trobar-ne i presentar aquesta operació a partir d'una d'aquestes, per tal de iustificar-la. Per exemple: «En un joc que volem organitzar al pati, que mesura $\frac{3}{10}$ de $\mathrm{km}$ de llarg, cal col-locar un con cada $\frac{2}{45}$ de $\mathrm{km}$. Quants cons hem de posar si ja hem col-locat el primer al principi del pati?». 
Pels coneixements que tenen de les operacions amb nombres naturals en situacions semblants a aquesta, arribarien a decidir que han de calcular la divisió $\frac{3}{10}: \frac{2}{45}$.

Cal recuperar, en aquest moment, tot el que han aprés de la divisió de nombres naturals. I han de recordar que resoldre la divisió és trobar el factor que li falta a una multiplicació de la que es coneix l'altre factor i el resultat. La qüestió és buscar eixe factor, és a dir, el quocient. Numèricament la situació és aquesta:

$$
\frac{3}{10}: \frac{2}{45}=\mathrm{q} \Longleftrightarrow \frac{3}{10}=\frac{2}{45} \times \mathrm{q}
$$

Ells i elles encara no saben resoldre cap equació, no saben aïllar la incògnita que en aquest moment seria el quocient, però podem guiar el raonament per tal que pensen què poden fer, per a aconseguir que quede sol el quocient a un costat de la igualtat, tenint en compte que tot el que se li faça al terme de la dreta se li haurà de fer al de l'esquerra, per tal de garantir que es mantinga la igualtat.

L'alumnat sap que si es multipliquen dues fraccions inverses, s'obté com a resultat 1. Aleshores, per tal d'aïllar el quocient, se'ls pregunta quina seria la fracció que multiplicada per $\frac{2}{45}$ donaria 1 , trobant com a resposta que la fracció seria $\frac{45}{2}$.

La situació aleshores és:

$$
\frac{3}{10} \times \frac{45}{2}=\frac{2}{45} \times \frac{45}{2} \times q \square \frac{3}{10} \times \frac{45}{2}=1 \times q=q
$$

Per tant, s'ha transformat la divisió de fraccions que no se sabia calcular en una multiplicació que sí se sap calcular:

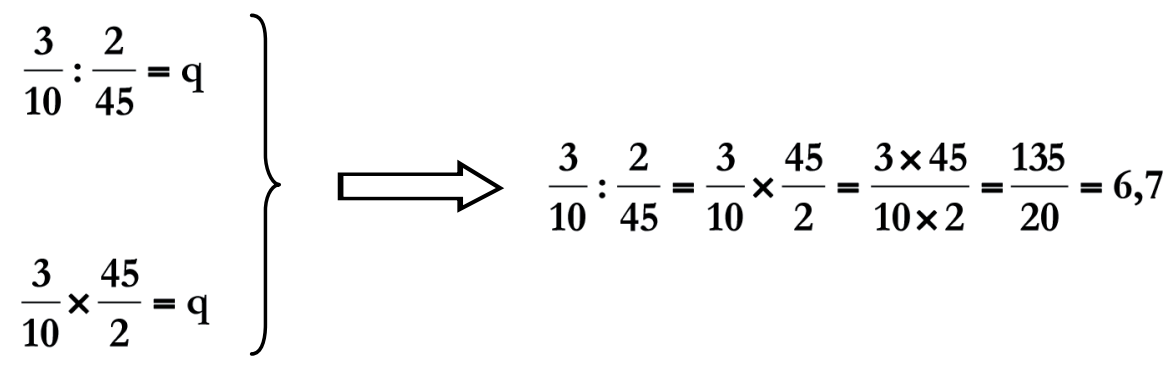

Podem finalment concloure que es posaran 6 cons (i quedarà un tros de pati).

S'insistirà amb més exemples associats a la divisió de fraccions, per a arribar a la conclusió que el resultat de dividir dues fraccions s'obté multiplicant la primera fracció per la inversa de la segona.

A l'hora d'operar i per a evitar que hagen d'escriure de nou les fraccions invertint la segona, es pot introduir la multiplicació en creu dels termes de les fraccions com la manera més usual de resoldre la divisió. Així $\frac{3}{10}: \frac{2}{45}=\frac{3 \times 45}{10 \times 2}$ 


\section{Multiplicar i dividir nombres decimals}

En l'últim curs de primària completarem el càlcul amb nombres decimals, treballant la multiplicació i la divisió d'aquests nombres entre sí.

\section{Multiplicació}

Busquem una situació on siga necessari multiplicar dos nombres decimals, per exemple: «Per folrar un moble de l'aula, volem esbrinar quanta superfície de tela hi ha en una peça de 3,7 m de llarg, per 0,75 m d'amplada». Pel que ja han estudiat en 5 é i 6é curs de primària relacionat amb la mesura i la geometria, saben que l'operació que cal fer és:

\section{3,7 \\ $\times 0,75$}

però encara no coneixen el procediment per calcular-la. Saben multiplicar un decimal per un nombre natural, però no dos nombres decimals; aleshores cal recórrer al que han aprés en la capacitat 3 , que consisteix en passar les expressions decimals a les corresponents fraccions decimals i operar amb aquestes:

$$
\left.\begin{array}{r}
3,7=\frac{37}{10} \\
0,75=\frac{75}{100}
\end{array}\right\} 3,7 \times 0,75=\frac{37}{10} \times \frac{75}{100}=\frac{37 \times 75}{10 \times 100}=\frac{2775}{1000}=2,775
$$

Hem obtingut un nombre amb tres xifres decimals, 2,775, com a resposta a quanta superfície de tela disposem per folrar el moble. La justificació del nombre de xifres decimals del resultat, que és la suma de les quantitats d'aquestes xifres que tenen els factors, ve donada pel denominador de la fracció resultat, 1000 en aquest cas. Seguint la cadena d'igualtats cap a l'esquerra, es veu que aquest 1000 és el resultat de la multiplicació de 10 x 100, que són respectivament els denominadors associats a una i dues xifres decimals dels factors.

Si volem resoldre la multiplicació sense recórrer a la transformació dels factors en fraccions, demanarem a l'alumnat que en aquest tipus d'exercicis observen com s'obté el numerador de la fracció resultat, en aquest cas multiplicant 37 i 75, que són els nombres naturals corresponent a les expressions decimals que hem de multiplicar.

Aleshores d'acord amb el que acabem de veure en els dos paràgrafs anteriors, farem l'operació de la següent manera:

$$
\begin{array}{r}
3,7 \\
\times 0,75 \\
\hline 185 \\
259 \\
\hline 2,775
\end{array}
$$


S'insistirà amb més exemples associats a la multiplicació de nombres decimals per a arribar a la conclusió que: «la multiplicació de dos nombres decimals es resol multiplicant-los sense tenir en compte les comes i col-locant la coma en el resultat obtingut separant tantes xifres decimals com en tenen entre els dos factors junts».

Novament, cal comprovar amb exemples que la multiplicació de nombres decimals compleix les propietats commutativa, associativa i distributiva respecte de l'addició.

\section{Divisió}

Per tal de dividir nombres decimals, es recorre al mateix procediment que a l'inici de la multiplicació. Cal observar què passa amb les fraccions i, aleshores, treure la conclusió per als nombres decimals, analitzant diferents casos, segons la quantitat de xifres decimals que tinguen els termes de la divisió.

La situació inicial pot ser semblant a la utilitzada per a dividir fraccions. Per exemple: «L'alumnat de 6é de primària ha de preparar per a Carnestoltes unes disfresses de bruixes que necessiten cadascuna 2,5 $\mathrm{m}$ de tela negra per a la seua confecció. La mare d'una xiqueta ha dut a l'aula una peça de tela comprada en un mercat ambulant que mesura 12,7 m. Quantes disfresses es podran elaborar amb ella?». Després de comentar amb l'alumnat els diferents procediments que proposen per a obtenir la solució, hauran de tenir clar que cal fer la divisió:

\section{$12,7 \quad 2,5$}

Com que no saben fer-la, expressarem els nombres amb fraccions i tindrem:

$$
\left.\begin{array}{r}
12,7=\frac{127}{10} \\
2,5=\frac{25}{10}
\end{array}\right\} 12,7: 2,5=\frac{127}{10}: \frac{25}{10}=\frac{127 \times 10}{10 \times 25}=\frac{1270}{250}=\frac{127}{25}=5,08
$$

S'observa que s'ha passat d'una divisió de nombres decimals a una de nombres naturals, $12,7 \mid \underline{2,5} \Rightarrow 127 \quad 25$, multiplicant els nombres inicials per la unitat seguida de tants zeros com han estat necessaris per transformar-los.

Amb situacions problemàtiques anàlogues, es treballaria el cas en el qual el dividend tinga menys xifres decimals que el divisor, per exemple: 
Per a resoldre aquesta divisió passem a fraccions:

$$
\left.\begin{array}{rl}
325,7 & =\frac{3.257}{10} \\
2,83 & =\frac{283}{100}
\end{array}\right\} 325,7: 2,83=\frac{3.257}{10}: \frac{283}{100}=\frac{3.257 \times 100}{10 \times 283}=\frac{325.700}{2.830}=\frac{32.570}{283}=115,08833 \ldots
$$

Aleshores, la transformació de la divisió, en aquest cas, és:

\begin{tabular}{l|l|l|l}
325,7 & 283
\end{tabular}$\quad$ on també s'ha obtingut una divisió de nombres naturals.

Quan el dividend tinga més xifres decimals que el divisor, podem trobar, per exemple, la següent divisió:

$$
325,75 \quad 2,8
$$

Novament, passem a fraccions:

$$
\left.\begin{array}{rl}
325,75 & =\frac{32.575}{100} \\
2,8 & =\frac{28}{10}
\end{array}\right\} 325,75: 2,8=\frac{32.575}{100}: \frac{28}{10}=\frac{32.575 \times 10}{100 \times 28}=\frac{325.750}{2.800}=\frac{32.575}{280}=116,3392 \ldots
$$

Igual que en els casos anteriors, la divisió de nombres decimals es transformaria en una de nombres naturals: $325,75|\underline{2,8} \Rightarrow 32575| \underline{280}$. Cal notar que la presència d'un zero en les unitats del divisor, pot allargar els càlculs. Si es vol evitar açò, es pot multiplicar només per 10 i no per 100 els dos nombres decimals, i així quedaria la divisió $3257,5 \quad 28$ on s'han eliminat les xifres decimals del divisor, però no totes les del dividend, obtenint una divisió que saben calcular.

S'insistirà amb més exemples associats a la divisió de nombres decimals en tots els casos d'aquesta per a arribar a la conclusió que, com a norma general, «la divisió de dos nombres decimals es resol multiplicant-los pel mateix nombre, que serà la unitat seguida de tants zeros com siga necessari, per tal de convertir ambdós en nombres naturals i efectuant la divisió d'aquests». 


\section{Introduir la proporcionalitat directa. Regla de tres simple}

Com es va comentar al punt 2 del present tema, es poden trobar fraccions en diferents situacions quotidianes. Ens interessen ara aquelles on les fraccions s'interpreten com una raó entre dues quantitats i, en particular, les que es refereixen al treball amb proporcionalitats. Les relacionades amb la probabilitat no són objecte d'aquesta publicació.

L'alumnat de 6é curs de primària podrà entrar en contacte amb aquesta interpretació de les fraccions quan es troben en una situació en la què les quantitats creixen o decreixen mantenint una relació constant entre elles, anomenada raó de proporcionalitat. Per exemple, si entre els ingredients d'una recepta de cuina sabem que fan falta $50 \mathrm{~g}$ de mel per tal de fer un pastís per 4 persones, es vol saber quanta en farà falta per a 8 o 16 persones. Es comenta amb l'alumnat cóm esbrinar-ho i per tal de visualitzar les relacions numèriques caldria arribar a emprar una taula com la següent:

\begin{tabular}{|c|c|c|c|}
\hline Nombre de persones & 4 & 8 & 16 \\
\hline Quantitat de mel & 50 & $?$ & $?$ \\
\hline
\end{tabular}

En observar que el nombre de persones de cada columna duplica el de la columna anterior, pensaran que el càlcul necessari per tal d'obtenir les quantitats de mel de les caselles buides és també duplicar l'anterior per aconseguir així que es mantinga la dolçor del pastís. Una vegada fets els càlculs, la taula quedarà:

\begin{tabular}{|c|c|c|c|}
\hline Nombre de persones & 4 & 8 & 16 \\
\hline Quantitat de mel & 50 & 100 & 200 \\
\hline
\end{tabular}

En la que es pot comprovar que les relacions entre el parell de nombres de cada columna es representen per les fraccions $\frac{4}{50}, \frac{8}{100}, \frac{16}{200}$, que són equivalents entre sí i que tenen com a fracció irreductible $\frac{2}{25}$. A aquesta expressió se l'anomena constant de proporcionalitat entre les quantitats anteriors i podem dir que el nombre de persones i la quantitat de mel es troben en relació de proporcionalitat directa o, el que és el mateix, són directament proporcionals.

Si es donara el cas que foren 12 les persones per a les que hem de fer el pastís, en demanar-los que esbrinaren la quantitat de mel necessària amb ajuda de la taula, podrien inserir una nova columna entre el 8 i el 16:

\begin{tabular}{|c|c|c|c|c|}
\hline Nombre de persones & 4 & 8 & $\mathbf{1 2}$ & 16 \\
\hline Quantitat de mel & 50 & 100 & $?$ & 200 \\
\hline
\end{tabular}

Sembla lògic pensar que si el 12 s'obté sumant els valors anteriors $4+8$, per tal d'obtenir la quantitat de mel, caldrà seguir el mateix procediment: $50+100$. És a dir: 


\begin{tabular}{|c|c|c|c|c|}
\hline Nombre de persones & 4 & 8 & $\mathbf{1 2}$ & 16 \\
\hline Quantitat de mel & 50 & 100 & $\mathbf{1 5 0}$ & 200 \\
\hline
\end{tabular}

Per saber si el resultat obtingut és correcte, expressaran la raó entre el nombre de persones (12) i la quantitat de mel (150), és a dir $\frac{12}{150}$ i comprovaran que és una fracció equivalent a $\frac{2}{25}$, que és la constant de proporcionalitat d'aquesta situació problemàtica.

Si en aquesta mateixa situació haguérem de fer el pastís per 5 persones, l'alumnat hauria d'esbrinar quanta mel faria falta en aquest cas. Ara no poden treure la quantitat de manera tant intuïtiva com en els casos de la taula. Després de reflexionar la manera d'obtenir-la els ajudarem a descobrir la necessitat de conèixer la quantitat de mel per persona i multiplicar-la després per les 5 persones, en aquest cas. Així, els càlculs haurien de ser $50: 4=12,5$ grams de mel per persona i 12,5 x $5=62,5$ grams de mel per a les 5 persones.

Aquestes i altres situacions semblants es poden resoldre utilitzant el que habitualment s'anomena «Regla de tres simple», que no és més que una altra manera de presentar l'ús de la proporcionalitat. Així, per exemple, en la situació anterior si es vol esbrinar quanta mel fa falta per fer el pastís per 12 persones, ajudarem a l'alumnat a fer el raonament següent: si per 4 persones calen $50 \mathrm{~g}$ de mel, per 12 persones farà falta una quantitat desconeguda que cal trobar i que anomenarem «X». Com ja s'ha esmentat, la relació entre 4 i 50 s'ha de mantenir entre 12 i $\mathbf{x}$, perquè el pastís mantinga la dolçor. Aquesta proporcionalitat es pot representar amb el format:

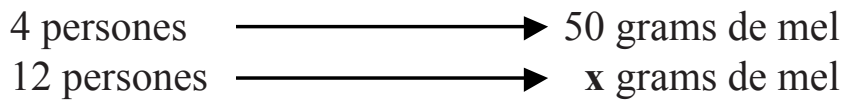

Per calcular $\mathbf{x}$ l'alumnat necessita els conceptes de proporcionalitat i d'equivalència de fraccions. Pel primer saben que: $\frac{4}{50}=\frac{12}{x}$ i pel segon: $4 \cdot x=12 \cdot 50$. En aquest moment els podem preguntar com obtenir el valor de $\mathbf{x}$ i si no se'ls acudeix, els suggerirem la utilització de la idea de divisió exacta per identificar $12.50 \mathrm{com}$ un dividend, 4 com un divisor i $x$ com un quocient. Aleshores $x=\frac{12 \cdot 50}{4}$. Resolent aquesta operació, obtindran que $\mathbf{x}=\mathbf{1 5 0}$ grams, que és la quantitat de mel que cal per fer el pastís per 12 persones.

Com que aquests dos procediments són equivalents per tal de trobar la solució en situacions d'aquests tipus, podran utilitzar qualsevol dels dos indistintament. 


\section{Obtenir la fracció generatriu que correspon a qualsevol expressió decimal i viceversa}

La correspondència entre fraccions decimals i nombres decimals s'ha treballat anteriorment en el desenvolupament de la capacitat 3. Per tal de completar les relacions que existeixen entre fraccions i expressions decimals en general, ens quedaria treballar en l'últim curs de l'etapa la relació entre expressions decimals periòdiques i fraccions no decimals. Caldrà trobar la fracció generatriu d'una expressió decimal periòdica i viceversa.

Obtindrem, doncs, les fraccions generatrius d'expressions decimals periòdiques pures o mixtes, que no són més que les fraccions irreductibles que generen les esmentades expressions decimals. Aquests càlculs són necessaris per a eliminar la gran dificultat d'operativitat que envolta les expressions decimals periòdiques, però de vegades el procés de trobar aquestes fraccions, els ha semblat als alumnes un seguit de passos foscos, sense molta utilitat, que serveix només per això, per a obtenir-les i no pas per a utilitzar-les amb posterioritat.

Cal insistir en què les expressions decimals periòdiques poden aparèixer de vegades en situacions de la vida quotidiana (adaptacions de les quantitats d'ingredients de receptes de cuina a diferents nombres de comensals, variacions en la borsa, valors estadístics de variables contínues en successos aleatoris...). Com que no podem expressar les infinites xifres decimals d'aquestes quantitats, per operar amb elles les convertim en expressions decimals exactes bé per truncament o bé per arrodoniment. Això provoca sempre una pèrdua d'informació i per tal d'evitar-la necessitem saber quines són les fraccions que generen les expressions decimals periòdiques. Així, en operar amb les fraccions, estarem realitzant els càlculs amb les quantitats exactes. En qualsevol cas, en l'últim curs de primària, els xiquets ja haurien de tenir el suficient grau d'abstracció com per a entendre aquestes qüestions i la justificació de les mateixes, per tant, convé donar eines per a calcular-les amb el que saben, però d'una manera senzilla.

Partirem, en primer lloc, d'una expressió periòdica pura, 1,53 per exemple, i volem saber la fracció generatriu d'aquesta, que anomenarem $\mathbf{x}$ fins que la trobem. És a dir $\mathbf{x}=\mathbf{1 , 5 3}$. La major dificultat per tal de trobar la fracció que es busca està en el període de l'expressió.

Hem d'intentar trobar un procediment que ens garantisca l'eliminació del període. Per tal d'això, buscarem una altra expressió i una operació, el resultat de la qual no siga ja periòdic. Observarem, amb exemples numèrics, que si una expressió periòdica s'opera amb un altre nombre amb l'addició, multiplicació o divisió, no desapareix el període. L'única operació que el fa desaparèixer és una subtracció en la qual l'altre terme té el mateix període que aquest.

Per tal d'aconseguir una subtracció d'aquest tipus, convertirem la nostra igualtat en altra que conserve el període i que actuarà com a minuend. La manera d'obtenir-la serà multiplicar la igualtat per la unitat seguida de tants zeros com xifres 
tinga el període. És a dir, $100 \cdot \mathbf{x}=153, \widehat{53}$. El subtrahend serà la igualtat inicial $i$ la subtracció serà:

$$
\begin{aligned}
& 100 \cdot x=153, \widetilde{53} \\
& -\quad x=1, \overparen{53} \\
& \hline 99 \cdot x=152
\end{aligned}
$$

Com que la $\mathbf{x}$ és un factor es pot expressar també com el resultat d'una divisió:

$$
x=\frac{152}{99}
$$

D'aquesta manera ja hem trobat la fracció generatriu que buscàvem: $1, \widehat{53}=\frac{152}{99}$ Potser que aquesta obtenció de la fracció generatriu no resulte intuïtiva pels xiquets i xiquetes. En aquest cas podem proposar-los una activitat amb la calculadora que consisteix en obtenir les fraccions que han generat les següents expressions decimals, sense donar cap informació més:

$$
\begin{aligned}
& 0,111111111111111 \ldots \\
& 0,2222222222222 \ldots \\
& 0,333333333333333 \ldots \\
& \ldots . . \\
& 0,888888888888888 . .
\end{aligned}
$$

És a dir, han de fer proves de divisions per tal d'aconseguir que els resultats siguen aquests amb infinites xifres decimals periòdiques. Al final de la sessió, de ben segur que la majoria haurà aconseguit trobar les fraccions que les han produït, $\frac{1}{9}, \frac{2}{9}, \frac{3}{9} \ldots \frac{8}{9}$, si més no, fraccions equivalents a aquestes que haurem de simplificar, per tal d'obtenir-les.

Es repeteix l'experiment, però ara amb diverses xifres al període:

\section{$0,454545454 \ldots$ \\ 0,678678678 ...}

I els resultats, trobats de manera semblant als casos anteriors, seran: $\frac{45}{99}, \frac{678}{999} \ldots$

Això, és molt important haver-ho aconseguit (serà una fracció amb tants nous al denominador com xifres estiguen al numerador, és a dir, com xifres tinga el període), perquè el treball difícil ja està fet, saben passar a fracció qualsevol expressió decimal periòdica pura, però amb part entera nul·la. Si la pregunta ara és trobar la fracció generatriu de $\mathbf{1 , 5 3 5 3 5 3 5 3} \ldots$, de l'exemple inicial, o de qualsevol altra expressió decimal periòdica pura però amb part entera no nul·la, caldrà només separar les dues parts de l'expressió i aplicar el que ja saben:

$$
1+0,5353535353 \ldots=1+\frac{53}{99}=\frac{152}{99}
$$


Una vegada s'ha treballat suficientment, es pot sintetitzar amb una regla que, si més no, enfosqueix el procediment i fa oblidar, en moltes ocasions, la lògica del que s'està fent i, per tant, condemnada a l'oblit o a la barreja: La fracció generatriu d'una expressió decimal periòdica pura, té com a numerador el resultat de restar el nombre natural format per la part entera seguit del periode, menys el nombre natural format sols per la part entera, $i$ com a denominador un nombre format per tants nous com xifres hi estiguen al periode. Que no és més que una drecera per a obtenir el resultat anterior, sense saber què s'està fent.

Si el nombre és periòdic mixt, per exemple 1,32 $\overline{5}$, es continuarà anomenant $\mathbf{x}$ a la fracció que es busca: $\mathbf{x}=1,325$ i el procediment ara constarà de dos passos, el primer convertirà l'expressió periòdica mixta en una periòdica pura multiplicant la igualtat per la unitat seguida de tants zeros com xifres tinga l'anteperíode $100 \cdot x=132,5$ i el segon pas serà aplicar a aquesta nova igualtat el procediment vist abans per les expressions periòdiques pures, és a dir $1.000 \cdot x=1.325$ ' 5 . Els termes de la subtracció seran ara aquestes dues darreres igualtats:

$$
\begin{aligned}
1.000 \cdot x & =1325, \overline{5} \\
-100 \cdot x & =132, \overline{5} \\
\hline 900 \cdot x & =1193
\end{aligned} \Rightarrow x=\frac{1193}{900}
$$

La fracció generatriu que buscàvem és: $1,325=\frac{1193}{900}$

En un intent de trobar una manera més intuïtiva de fer aquests càlculs, podem introduir una reflexió sobre un altre procediment per a obtenir la fracció generatriu d'una expressió decimal periòdica mixta.

D'una banda, ja saben obtenir la fracció generatriu d'una expressió decimal periòdica pura i, d'altra, una expressió periòdica mixta es diferencia de la pura en què hi ha un nombre finit de xifres decimals que no es repeteixen i que sempre estan entre la coma i el període, és a dir, l'anteperíode. Doncs el que podem fer és descompondre l'expressió decimal periòdica mixta com a suma d'una expressió decimal exacta i d'una periòdica mixta més senzilla i fer els càlculs amb aquestes.

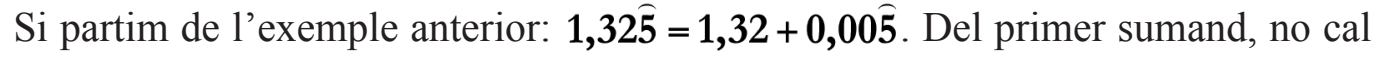
preocupar-se, ja se sap convertir a fracció decimal: $1,32=\frac{132}{100}$

Per a trobar l'expressió generatriu del segon sumand, cal multiplicar-lo per la unitat seguida de tants zeros com zeros tinga l'anteperíode, en aquest cas $\mathbf{1 0 0}$, per tant: $\mathbf{1 0 0} \times \mathbf{0 , 0 0 5}=\mathbf{0 , 5}$. Ara ja saben obtenir la fracció generatriu: $\mathbf{0 , 5}=\frac{\mathbf{5}}{\mathbf{9}}$. Finalment cal desfer el canvi inicial, si havíem multiplicat per 100, dividirem per $\mathbf{1 0 0}$ :

$$
\frac{0, \widehat{5}}{100}=\frac{\frac{5}{9}}{100} \rightarrow 0,00 \overline{5}=\frac{5}{900}
$$


Per tal de trobar la fracció generatriu definitiva, faltarà només sumar les dues fraccions obtingudes: $1,325=1,32+0,005=\frac{132}{100}+\frac{5}{900}=\frac{1.188}{900}+\frac{5}{900}=\frac{1.193}{900}$.

De manera anàloga al cas de les expressions decimals periòdiques pures, $\mathrm{i}$ amb les mateixes reticències d'abans, es pot sintetitzar aquest càlcul amb la regla següent: La fracció generatriu d'una expressió decimal periòdica mixta, té com a numerador el resultat de restar el nombre natural format per la part entera seguida de l'anteperiode $i$ del periode, menys el nombre natural format per la part entera seguida de l'anteperiode, i com a denominador un nombre format per tants nous com xifres tinga el període i tants zeros com xifres tinga l'anteperiode.

En qualssevol dels casos treballats fins ací, si la fracció que s'obté pels procediments descrits no fos irreductible, caldrà simplificar-la fins a què ho siga per arribar així a la fracció generatriu buscada.

Com a complement del càlcul de la fracció generatriu de qualsevol expressió decimal podem treballar també amb els xiquets el càlcul de l'expressió decimal que correspon a qualsevol fracció. Sabem que el procediment per a trobar aquesta expressió és resoldre la divisió indicada en la fracció.

Això ho saben fer, però com que podria ocórrer que la divisió es fera molt llarga, per tal de saber amb exactitud si la part decimal és exacta, periòdica pura o mixta, es fa necessari, abans de realitzar la divisió, saber com serà l'expressió decimal. Aquest coneixement a priori ens evitarà errors o càlculs innecessaris.

Per a donar resposta a aquest dubte proposarem als xiquets que calculen diferents expressions decimals a partir d'algunes fraccions irreductibles donades per nosaltres, amb la finalitat d'observar després els resultats i traure conclusions.

Així, calcularan les expressions decimals de: 3/2, 2/5, 3/7, 4/11, 5/6, 28/15, obtenint 1,$5 ; 0,4 ; 0,428571428571 \ldots ; 0,3636 \ldots ; 0,8333 \ldots ; 1,8666 \ldots$ respectivament. Treballarem més exemples semblants amb altres fraccions irreductibles; també farem servir la calculadora a més del càlcul amb llapis i paper, per tal de comprovar que, de vegades, el resultat que proporciona la màquina no correspon al mateix tipus d'expressió decimal (quan el nombre de xifres decimals és molt gran).

Els demanarem que reflexionen sobre les fraccions i que es fixen en els denominadors per a intentar treure les primeres conclusions al voltant de les relacions que pot haver entre aquests i les diferents expressions decimals que obtenim.

La nostra intenció és arribar, amb les ajudes que necessiten, al descobriment de la necessitat de conèixer les fraccions irreductibles de les donades i, observant els factors primers del denominador d'aquestes, saber quin tipus d'expressió decimal obtindrem d'acord amb els següents casos:

- Si els factors primers són sols 2 i/o 5, les expressions decimals corresponents seran exactes. 
- Si els factors primers són diferents de 2 i 5, les expressions decimals corresponents seran periòdiques pures.

- Si els factors primers combinen 2 i/o 5, amb altres factors primers les expressions decimals corresponents seran periòdiques mixtes.

Una vegada està construït el pont entre expressions decimals i fraccions, les dades dels problemes es poden expressar numèricament segons convinga. Tota l'equivalència d'operativitat entre fraccions $i$ expressions decimals queda, per tant, connectada.

\section{Aplicar els coneixements sobre fraccions i expressions decimals per a resoldre $\mathrm{i}$ inventar problemes}

És en situacions reals on cobra especial sentit el treball fet amb fraccions i decimals, perquè realment és la realitat la que origina interrogants la resposta dels quals passarà per saber, en aquest cas, treballar amb aquests nombres.

Malgrat que la resolució i invenció de problemes apareix de vegades com la última part del treball amb nombres, estem practicant-les des del principi, perquè presentem els conceptes corresponents de manera contextualitzada, a partir de situacions reals que han de resoldre's.

Exercitarem la resolució de problemes prenent com a orientació les quatre fases de Polya (comprendre el problema, elaborar un pla, executar el pla i examinar la solució obtinguda) i reflexionant amb l'alumnat sobre la importància, desenvolupament i utilitat de cadascuna d'elles.

Quan es troben resolent els problemes, hem d'aprofitar els errors que puguen sorgir per reflexionar amb els nens sobre ells i, com a conseqüència, potenciar noves situacions d'aprenentatge a partir de la reflexió. És molt important diferenciar entre els errors de càlcul i els errors de raonament, donat que exigeixen mètodes diferents pel seu tractament.

Desenvoluparem el treball corresponent a aquesta capacitat en els tres darrers cursos de primària, respectant en cadascun d'ells els nivells cognitius de l'alumnat respecte de fraccions i decimals.

L'alumnat ha de treballar també la invenció de problemes relacionats amb aquests conceptes. El que es pretén és comprovar si són capaços de generar situacions que es resolguen amb ells. El treball d'inventar problemes serà posterior al de resoldre'ls. No els demanarem mai que inventen un problema d'un tipus que encara no s'haja resolt.

Cada vegada que els proposem la invenció d'un tipus nou de problemes recorrerem els passos següents, que es presenten seqüenciats per la seua dificultat, independentment del curs en què ens trobem: 
- Amb ajudes:

- Els donarem els nombres, el context i/o les operacions que intervenen en la situació.

- Els donarem els nombres i/o les operacions, però no el context.

- Sense ajudes: els donarem sols els tipus de nombres i/o les operacions que han d'aparèixer en la situació problemàtica.

Després d'inventar les situacions problemàtiques, les intercanvien amb els companys per tal que cap xiquet o xiqueta resolga les que ha inventat, amb la finalitat de potenciar la seua capacitat tant de redacció com d'expressió matemàtica, que implicarà l'exigència de claredat $i$ de totalitat en dades $i$ incògnites. 


\section{TEMA 3}

\section{Magnituds i mesura}

En aquest tema es treballa la construcció dels conceptes de Magnitud i Mesura. El primer, a partir del conjunt quocient obtingut mitjançant una relació d'equivalència definida en el conjunt de tots els elements que tenen una determinada característica o propietat. El segon, a partir d'una aplicació entre el conjunt quocient anterior i el dels nombres reals no negatius. Comença el tema amb una referència històrica sobre aquests conceptes, continua amb la seua formalització i finalitza amb un extens tractament didàctic dels corresponents continguts en l'aula de primària.

\section{Introducció}

\subsection{Històrica}

En física, magnitud és quelcom susceptible de ser quantificat, és a dir, de ser mesurat, de ser ponderat. Algunes magnituds poden ser directament apreciables pels nostres sentits, com la longitud, la massa, la superfície. Unes altres no ho són i necessiten mètodes indirectes per ser mesurades (acceleració, energia...).

La noció de magnitud està inevitablement relacionada amb la de mesura. Es denominen magnituds certes propietats o aspectes observables d'un sistema físic que poden ser expressades en forma numèrica, aleshores s'anomenen magnituds escalars, o mitjançant un vector, $i$ en aquest cas s'anomenen magnituds vectorials. El gust per l'art, tanmateix, no és una magnitud, perquè no és possible elaborar una escala ni molt menys un aparell que determine quantes vegades un ésser humà té més gust per l'art que no pas un altre.

Mesurar és relacionar una quantitat d'una magnitud amb una altra o altres quantitats d'aquella que es consideren patrons universalment acceptats. El fet de mesurar exigeix, doncs, tenir en compte quatre variables: una magnitud, una quantitat d'aquesta, una unitat relacionada amb elles i un nombre, que és el resultat de la comparació de la quantitat amb la unitat escollida a l'efecte.

Antigament es triaven moltes unitats de referència per a mesurar un mateix tipus de magnitud. Una unitat menuda per a quantitats menudes de la magnitud, i una de gran per a les grans, tractant que els nombres que resultaven de comparar les quantitats de magnitud a mesurar amb la unitat d'aquesta, foren senzills, de dues o tres xifres enteres i tal volta una decimal o dues. Així, la massa de pedres precioses es mesurava en quirats (també anomenats quirats mètrics), unitat derivada de la 
massa de les llavors d'un arbre àrab que s'ha normalitzat com 0,2 $\mathrm{g}$ i, per exemple, quantitats grans com les collites es mesuraven en tones. No s'ha de confondre aquest significat de la paraula quirat amb un altre molt utilitzat en joieria $i$ que es refereix a la fracció màssica d'or en un aliatge multiplicada per 24.

Aquesta primera manera de mesurar és clar que no és útil, perquè cada zona pot triar la seua manera particular de fer-ho. Concretament, al nostre país, la fanecada és una unitat de superfície dels camps de cultiu, que en la actualitat encara s'usa. Equival a $833,3 \mathrm{~m}^{2}$. És l'extensió de terra estimada que es pot sembrar amb una faneca de gra; conté quatre quartons (unitat de mesura de la terra agrícola a Mallorca) i equival a la dotzena part d'una hectàrea (unitat de mesura de superfícies al sI).

Una segona opció és adoptar una única unitat i usar-la amb els seus múltiples i submúltiples, per exemple, el metre, el quilòmetre, el mil·límetre, intentant així que el nombre que resulta de la mesura siga còmode.

La tercera de les opcions és triar només una unitat i acceptar que el nombre que resulte de mesurar la magnitud no siga senzill. Per exemple, el diàmetre d'una agulla és $8,5 \times 10^{-5} \mathrm{~m}$ i el de la Terra és $1,27 \times 10^{7} \mathrm{~m}$.

Al llarg de la història, aquest tema ha evolucionat notablement. Per diverses raons, la primera i més important, perquè la necessitat de mesurar està present en les nostres vides de manera quotidiana i habitual. No es pot fugir d'aquest fet.

\section{El Sistema Internacional d'unitats}

El primer conjunt d'unitats concebut com un sistema estable fou el Sistema Mètric Decimal, creat a França amb la Revolució Francesa a finals del segle XVIII. Antoine de Lavoisier va dir d'aquest:

$[\ldots]$ no res més gran ni més sublim ha eixit de les mans de l'home que el sistema mètric decimal.

En 1881, es va adoptar en el Congrés Internacional dels Electricistes, celebrat a París, el Sistema Cegesimal (cGS, inicials de centímetre, gram, segon), proposat pel matemàtic alemany Karl Gauss.

Basat en el primer, l'any 1901, el físic i enginyer italià Giovanni Giorgi proposà el sistema MKS (inicials de metre, quilogram, segon), adoptat oficialment en 1935, el qual va donar lloc després de ser ampliat, al Sistema Internacional (1960).

Actualment, arreu del món, la norma és utilitzar el Sistema Internacional (sI) d'unitats, encara que als Estats Units d'Amèrica es continua en procés de transició, des que al 1875 s'hi adoptara formalment el Sistema Mètric Decimal.

El si és el resultat del treball de diverses organitzacions internacionals durant més d'un segle, amb el qual s'ha aconseguit un sistema d'unitats de mesura comú per a totes les àrees de la ciència $i$ la tecnologia. 
Cada estat estableix adopcions i exclusions legals de caràcter formatiu o industrial. A Espanya, la Llei de Pesos i Mesures, de 8 de juliol de 1892; la Llei 88/1976, de 8 de novembre; el Reial decret 1317/1989, de 27 d'octubre i la correcció d'errades d'aquest, i la Norma unE 82100:1996 són les normatives que es consideren. Però, com que és estrany que es penalitze per no complir-les, es comú veure aparells destinats a mesurar la pressió graduats en $\mathrm{kg} / \mathrm{cm}^{2}$ en lloc de bars i, per exemple, característiques de calderes i refrigeradors amb mesures en calories i frigories, respectivament.

A més d'homogeneïtzar les transaccions científiques, tècniques i comercials, un dels majors avantatges d'un sistema coherent d'unitats, com el si, és que facilita la comparació de valors dispars d'una mateixa magnitud (per exemple distàncies microscòpiques i astronòmiques) i les relacions entre les diferents magnituds.

En la nomenclatura científica, els símbols emprats per les unitats no són abreviatures ortogràfiques, són només símbols. En general, estan formats per lletres simples o, excepcionalment, parelles o trios.

Les normes per a la correcta utilització de magnituds, unitats i símbols científics, les proposen les associacions científiques internacionals ${ }^{1}$ (en aquest cas l'Oficina Internacional de Peses i Mesures) i les adopten les administracions de cada Estat, amb la finalitat de facilitar els intercanvis d'informació i les transaccions materials (particularment entre organismes i empreses multinacionals).

El si està constituït per dues classes d'unitats: fonamentals i derivades. A una magnitud particular només li correspon un conjunt d'unitats d'aquest sistema. La Conferència General de Pesos i Mesures, ${ }^{1}$ a més, ha admès l'ús d'altres unitats que, sense pertànyer al sı, són importants i àmpliament utilitzades arreu del món.

Alguns exemples d'aquests tipus d'unitats són els que figuren als quadres següents:

\section{UNITATS FONAMENTALS}

\begin{tabular}{|c|c|c|}
\hline MAGNITUD & NOM & SÍMBOL \\
\hline longitud & metre & $\mathrm{m}$ \\
\hline massa & quilogram & $\mathrm{kg}$ \\
\hline temps & segon & $\mathrm{s}$ \\
\hline intensitat de corrent elèctrica & ampere & $\mathrm{A}$ \\
\hline temperatura termodinàmica & kelvin & $\mathrm{K}$ \\
\hline quantitat de substància & mol & $\mathrm{mol}$ \\
\hline intensitat lluminosa & candela & $\mathrm{cd}$ \\
\hline
\end{tabular}

1. La informació actualitzada al respecte de les unitats, de les seues relacions i de les normes d'ús es pot trobar en la pàgina web del Bureau International des Poids et Mesures, http://www.bipm.org/. 


\section{ALGUNES UNITATS DERIVADES}

\begin{tabular}{|c|c|c|}
\hline \multicolumn{3}{|c|}{ Sense nom especial } \\
\hline MAGNITUD & NOM & SÍMBOL \\
\hline superfície & metre quadrat & $\mathrm{m}^{2}$ \\
\hline volum & metre cúbic & $\mathrm{m}^{3}$ \\
\hline velocitat & metre per segon & $\mathrm{m} / \mathrm{s}$ \\
\hline acceleració & metre per segon al quadrat & $\mathrm{m} / \mathrm{s}^{2}$ \\
\hline \multicolumn{2}{|c|}{ Amb nom o símbol especial } \\
\hline angle pla & radian & $\mathrm{rad}$ \\
\hline angle sòlid & estereoradian & $\mathrm{sr}$ \\
\hline freqüència & hertz & $\mathrm{Hz}$ \\
\hline força & newton & $\mathrm{N}$ \\
\hline potència & watt & $\mathrm{W}$ \\
\hline resistència elèctrica & ohm & $\Omega$ \\
\hline
\end{tabular}

UNITATS ACCEPTADES QUE NO PERTANYEN AL SI

\begin{tabular}{|c|c|c|}
\hline MAGNITUD & NOM & SÍMBOL \\
\hline massa & tona & $\mathrm{t}$ \\
\hline temps & minut, hora & min, $\mathrm{h}$ \\
\hline temperatura & grau Celsius & ${ }^{\circ} \mathrm{C}$ \\
\hline volum & litre & L o l \\
\hline
\end{tabular}

\section{Prefixos al SI}

Per tal de no haver d'utilitzar nombres massa grans o massa menuts, el si admet l'ús de múltiples i submúltiples de les unitats que s'indiquen mitjançant uns prefixos, que s'anteposen al nom de la unitat i al seu símbol. Per anomenar un múltiple o submúltiple d'una unitat composta es recomana fer servir només un prefix; si la unitat composta és un quocient, el prefix mai no ha d'acompanyar la unitat que es trobe al denominador. A les taules següents es mostren els més usuals: 


\begin{tabular}{|c|c|c|}
\hline \multicolumn{3}{|c|}{ MÚLTIPLES } \\
\hline Factor & Prefix & Símbol \\
\hline $10^{18}$ & exa & $\mathrm{E}$ \\
\hline $10^{9}$ & giga & $\mathrm{G}$ \\
\hline $10^{6}$ & mega & $\mathrm{M}$ \\
\hline $10^{3}$ & quilo & $\mathrm{k}$ \\
\hline $10^{2}$ & hecto & $\mathrm{h}$ \\
\hline $10^{1}$ & deca & $\mathrm{da}$ \\
\hline
\end{tabular}

\begin{tabular}{|c|c|c|}
\hline \multicolumn{3}{|c|}{ SUBMÚTIPLES } \\
\hline Factor & Prefix & Símbol \\
\hline $10^{-1}$ & deci & $\mathrm{d}$ \\
\hline $10^{-2}$ & centi & $\mathrm{c}$ \\
\hline $10^{-3}$ & mil·li & $\mathrm{m}$ \\
\hline $10^{-6}$ & micro & $\mu$ \\
\hline $10^{-9}$ & nano & $\mathrm{n}$ \\
\hline $10^{-18}$ & atto & $\mathrm{a}$ \\
\hline
\end{tabular}

\section{Normes del SI}

Qualsevol llenguatge conté regles per a escriure'l que eviten confusions i faciliten la comunicació. El si té les seues pròpies regles d'escriptura que permeten una comunicació correcta.

Pel que fa als símbols:

- Se escriuen amb caràcters romans rectes.

- S'utilitza lletra minúscula tret dels derivats de noms propis $(\mathrm{N}, \mathrm{Hz})$.

- No van seguits de punt ni prenen $s$ per al plural (17 m).

- No s'ha de deixar espai entre el prefix i la unitat (nanòmetre: $\mathrm{nm}$ ).

- El producte de dos símbols s'indica mitjançant un punt.

Pel que fa a les unitats:

- Si el valor s'expressa amb lletres, la unitat també (dèsset metres).

- Si el valor s'expressa amb nombres, la unitat pot expressar-se amb nom o amb símbol (17 metres o $17 \mathrm{~m}$ ).

- Les unitats derivades de noms propis s'escriuen igual que el nom propi però amb minúscules (dos newtons).

- Els noms de les unitats prenen una $s$ en el plural, llevat si acaben en s, x, z o ç (tres metres, catorze nus, vint hertz).

\subsection{Al tema}

L'objectiu del tema és aproximar l'alumnat de primària a les magnituds longitud, capacitat, massa, temps, sistema monetari, mesura d'angles, superfície i volum, així com posar de manifest la clara diferència entre els tipus de magnituds i les unitats corresponents. En el capítol 2 d'aquest tema es formalitzaran els conceptes de magnitud i mesura. Els aspectes bàsics referents a cada magnitud a estudiar, les unitats centrals, els seus múltiples i submúltiples, i les orientacions didàctiques per al desenvolupament d'aquests continguts amb els xiquets i xiquetes es presenten en el capítol 3 del mateix. 


\section{Formalització dels conceptes de magnitud i mesura}

L'esquema matemàtic que es necessita per tal d'abordar la definició formal de magnitud i mesura és el següent: una magnitud és un conjunt amb una determinada estructura algebraica (els elements del qual s'anomenen quantitats de la magnitud) i una mesura és una aplicació que a cadascuna de les quantitats li assigna un nombre. Aquest nombre serà la mesura d'eixe element.

Caldrà, doncs, determinar aquest conjunt i la seua estructura, les quantitats d'aquest i l'aplicació anomenada mesura.

\subsection{Magnitud}

Definirem una magnitud a partir d'un conjunt $\boldsymbol{S}$. Determinar aquest conjunt, en general, pot resultar complicat. Acompanyarem la definició amb un exemple, la longitud. $\boldsymbol{S}$ serà el conjunt de tots els objectes que tenen longitud. En aquest conjunt, cal definir una relació binària d'equivalència, $\boldsymbol{R}$, entre els seus elements. En el cas de la longitud, es relacionaran els objectes que tenen la mateixa longitud. Mitjançant aquesta relació, obtenim el conjunt $\boldsymbol{S} / \boldsymbol{R}$ anomenat conjunt quocient, on els elements són ara classes d'equivalència. Cadascuna d'aquestes classes estarà formada per tots els elements que, per mig d'aquesta relació, són equivalents. Per l'exemple triat, aquestes classes estaran formades per tots els objectes amb la mateixa longitud, és a dir, l'objecte en sí, ja no és important, ho és la longitud que hi té, la característica que interessa. Per tant, les classes d'equivalència són quantitats de longitud. Una quantitat de longitud la poden tenir molts objectes, tots els que pertanyen a la mateixa classe.

Perquè el conjunt quocient anterior siga una magnitud, necessitem definir en aquest una llei de composició interna (*), una relació d'ordre (s) i una llei de composició externa $(\cdot)$, complint-se les condicions que es desenvolupen a continuació:

- Llei de composició interna: $(*): S / R_{\mathbf{R}} \times \mathrm{S} / \mathrm{R} \rightarrow \mathrm{S} / \mathrm{R}$

$([\mathrm{a}][\mathrm{b}] \rightarrow[\mathrm{a}] *[\mathrm{~b}]$, que haurà d'acomplir les propietats associativa $\mathrm{i}$ commutativa. Per tant $(\mathbf{S} / \mathbf{R}, *)$ serà un semigrup commutatiu.

- Relació d'ordre: que denotarem per $\leq \mathrm{i}$ que es definirà com $\forall[\mathbf{a}],[\mathbf{b}] \in \mathbf{S} / \mathbf{R},[\mathbf{a}] \leq[\mathbf{b}] \leftrightarrow \exists[\mathbf{c}] \in \mathbf{S} / \mathbf{R} /[\mathbf{a}] *[\mathbf{c}]=[\mathbf{b}]$. Aquesta relació ha de ser compatible amb l'operació del semigrup, és a dir, ha de complir $\forall[\mathrm{a}],[\mathrm{b}],[\mathrm{c}] \in \mathrm{S} / \mathrm{R},[\mathrm{a}] \leq[\mathrm{b}] \rightarrow[\mathrm{a}] *[\mathrm{c}] \leq[\mathrm{b}] *[\mathrm{c}]$ 
- Llei de composició externa: amb el que s'ha definit fins ara, només coneixem les quantitats i el seu ordre (més o menys longitud, més o menys superfície, més o menys massa...). El que no sabem encara és quantes vegades una quantitat és més gran que una altra. Això es formalitza a partir del producte d'una quantitat de magnitud per un nombre no negatiu, és a dir, definint l'operació externa:

$$
(\cdot): \mathbb{R}^{+} \cup\{0\} \times \mathbf{S} / \mathbf{R} \rightarrow \mathbf{S} / \mathbf{R}
$$

$(\alpha,[\mathrm{a}] \rightarrow \alpha[\mathrm{a}]$, que acompleix les següents propietats:

$-\forall \alpha, \beta \in \mathbb{R}^{+} \cup\{0\} \wedge \forall[\mathrm{a}][\mathrm{b}] \in \mathrm{S} / \mathrm{R}$

$-(\boldsymbol{\alpha}+\boldsymbol{\beta}) \cdot[\mathrm{a}]=(\boldsymbol{\alpha} \cdot[\mathrm{a}]) *(\boldsymbol{\beta} \cdot[\mathrm{a}])$

- $\alpha \cdot([\mathrm{a}] *[\mathrm{~b}])=(\alpha \cdot[\mathrm{a}]) *(\alpha \cdot[\mathrm{b}])$

$-\alpha \cdot(\boldsymbol{\beta} \cdot[\mathrm{a}])=(\boldsymbol{\alpha} \times \boldsymbol{\beta}) *[\mathrm{a}]$

$-\operatorname{Si}[\mathrm{a}] \leq[\mathrm{b}] \rightarrow \boldsymbol{\alpha} \cdot[\mathrm{a}] \leq \boldsymbol{\alpha} \cdot[\mathrm{b}]$

Per tot açò, es diu que $(\mathbf{S} / \mathbf{R}, *, \leq, \cdot)$ és una magnitud si té estructura de semimòdul (vegeu l'annex) ordenat sobre el semianell format pels nombres reals no negatius. Cal notar que aquesta definició correspon a les magnituds escalars. No treballarem les vectorials.

La definició de llei externa que s'ha utilitzat es refereix a magnituds escalars contínues. Si el conjunt numèric que utilitzem és $\mathbb{N}$ en comptes de $\mathbb{R}^{+} \cup\{\mathbf{0}\}$, haurem definit una magnitud escalar discreta.

\subsection{Mesura d'una magnitud}

Mesurar serà l'acte segons el qual s'assigna un nombre a una quantitat de magnitud. Aquest acte (independentment de l'instrument de mesura, context i condicions ambientals), matemàticament, és una aplicació que relaciona les classes d'equivalència del conjunt quocient anteriorment definit amb els nombres naturals o amb els reals no negatius, segons el cas.

Formalment, s'anomena mesura d'una magnitud escalar continua $(\mathbf{S} / \mathbf{R}, *, \leq, \cdot)$ a qualsevol isomorfisme (aplicació bijectiva que conserva les lleis de composició definides) de semigrups $\mathbf{m}:(\mathbf{S} / \mathbf{R}, *) \rightarrow\left(\mathbb{R}^{+} \cup\{\mathbf{0}\},+\right)$ que és compatible a més amb l'ordre. En el cas de les magnituds discretes $\mathbf{m}:(\mathbf{S} / \mathbf{R}, *) \rightarrow(\mathbb{N},+)$.

Per tant, la mesura ens permet relacionar les quantitats d'una magnitud escalar amb nombres que, alhora, es poden representar per punts a sobre d'una semirecta 
(aquests punts se situaran al lloc dels nombres naturals, en el cas de magnituds discretes, $i$ en tots els punts de la semirecta real no negativa, en el cas de contínues). Les magnituds anomenades vectorials no satisfan els axiomes d'ordre que verifiquen les escalars i, en conseqüència, no es poden representar per punts d'una recta. Aquestes magnituds no es poden relacionar, per tant, sols amb valors numèrics per tal de donar la mesura. A més, cal tenir informació sobre la direcció en la qual s'apliquen i sobre el seu sentit, components que no tenen les magnituds escalars. Exemples d'aquest tipus de magnituds poden ser la velocitat, acceleració, força...

\subsection{Unitat de mesura}

Donada una magnitud escalar contínua $(\mathbf{S} / \mathbf{R}, *, \leq, \cdot)$ i una mesura $\mathrm{m}:(\mathrm{S} / \mathrm{R}, *) \rightarrow$ $\left(\mathbb{R}^{+} \cup\{\mathbf{0}\},+\right)$, s'anomena unitat de mesura de $\mathbf{m}$ a la quantitat $[\mathbf{n}] \in S / \mathbf{R} / \mathbf{m}([\mathbf{n}])=\mathbf{1}$. Anàlogament, es definirà la unitat per les magnituds discretes.

\section{Les magnituds i la mesura a l'aula de primària}

\subsection{Consideracions prèvies}

Encara que les qüestions relacionades amb la mesura són considerades com un coneixement social, mesurar una magnitud és un acte que els xiquets no poden realitzar d'una manera senzilla i espontània i, per això, és difícil realitzar mesuraments durant els primers anys de les etapes escolars. Aquesta dificultat es déu a què la realització de l'acte de mesurar du aparellades altres qüestions, com ara: estimacions, classificacions, ordenacions, aplicacions... Però això no treu que els xiquets i xiquetes prenguen contacte, des de ben menuts, amb situacions que els duguen a descobrir magnituds físiques (a l'escola i a fora) i a mesurar-les.

La mesura resulta necessària perquè l'alumnat puga conèixer la realitat que l'envolta a partir de la seua quantificació. Aquesta els permetrà interpretar-la millor i resoldre amb majors garanties d'èxit les situacions problemàtiques que troben relacionades amb ella.

No es tracta d'introduir les diferents unitats amb una gran quantitat de noms i símbols que sols es treballen en problemes de llapis i paper per a fer uns canvis entre elles sense massa sentit. Pel contrari, haurem d'oferir a l'alumnat situacions de treball en l'aula que els permetan descobrir les diferents magnituds i les unitats més adequades per a mesurar-les, en contextos interessants que els creen la necessitat d'utilitzar-les. Tanmateix tindrem en compte les dificultats dels escolars a l'hora 
d'aconseguir una conservació raonada de les quantitats de diferents magnituds i els ajudarem a construir-la progressivament (Chamorro, 2003).

\subsection{Quadre de capacitats}

El treball en educació primària referent al tema de magnituds i mesura, té com a objectiu contribuir a desenvolupar en l'alumnat les capacitats que s'expressen en el següent llistat, la finalitat de les quals es concreta en afavorir el desenvolupament de la competència matemàtica dels xiquets i les xiquetes, a més de representar una ajuda per al de la resta de competències d'aquesta etapa.

L'ordre proposat per a aquestes capacitats és seqüencial, és a dir, progressiu i d'intensitat de dificultat creixent, excepte la capacitat que es refereix a la resolució i invenció de problemes que està present en tot el treball que desenvolupa les restants capacitats:

1. Realitzar mesuraments de longitud, capacitat i massa, utilitzant unitats naturals $\mathrm{i}$ arbitràries, comprovant la relativitat de la mesura i descobrint la necessitat de l'existència d'una unitat patró per a realitzar-les.

2. Reconèixer i utilitzar les unitats de longitud, capacitat i massa: metre, decímetre, centímetre, litre i quilogram.

3. Conèixer i utilitzar correctament els múltiples i submúltiples del metre, el litre $i$ el quilogram, establint-ne les equivalències.

4. Expressar mesures de longitud, capacitat i massa de forma complexa. Transformar expressions de mesura complexes en incomplexes i a l'inrevés.

5. Identificar el valor de les monedes $i$ bitllets del nostre sistema monetari i utilitzar-los per a expressar quantitats de diners concretes.

6. Completar el coneixement del nostre sistema monetari, relacionant les monedes i bitllets amb dels nombres decimals.

7. Comprovar la relativitat de la percepció del temps i descobrir la necessitat d'una unitat patró per a mesurar-lo.

8. Reconèixer i utilitzar les unitats de temps: hores, mitges hores, quarts d'hora, minuts i segons. Interpretar les hores en el rellotge.

9. Expressar mesures de temps de forma complexa. Transformar expressions complexes en incomplexes i a l'inrevés.

10. Reconèixer i utilitzar les unitats de temps: dia, setmana, mes i any.

11. Realitzar mesuraments i transports d'angles.

12. Introduir la mesura de superfícies i volums mitjançant quadrats i cubs, respectivament.

13. Introduir el metre quadrat, el metre cúbic i els respectius submúltiples i múltiples. Utilitzar-los per a mesurar superfícies planes i volums molt senzills.

14. Esbrinar les unitats adequades per a mesurar quantitats de diferents magnituds. Realitzar estimacions d'algunes quantitats d'aquestes magnituds.

15. Utilitzar amb soltesa instruments de mesura.

16. Descobrir les expressions per a calcular les àrees de figures planes senzilles.

17. Aplicar els coneixements sobre magnituds i mesura per a resoldre i inventar problemes. 


\subsection{Desenvolupament de les capacitats}

\section{Realitzar mesuraments de longitud, capacitat i massa, utilitzant unitats naturals i arbitràries, comprovant la relativitat de la mesura i descobrint la necessitat de l'existència d'una unitat patró per a realitzar-les}

De manera pareguda a l'acció de comptar, en l'alumnat sorgeix la necessitat de mesurar com a solució en situacions de joc, treball, etc. Expressar quantitats de magnitud és una capacitat nova que van elaborant i que requereix accions personals de comparació d'objectes, de mesura, d'estimació, d'utilització d'unitats físiques, fins arribar a una concreció numèrica, a una aplicació immediata dels nombres que van aprenent.

El coneixement de diferents magnituds, a partir d'activitats de comparació d'objectes respecte de cadascuna d'elles, donarà pas a la realització de mesures. Les esmentades activitats s'iniciaran de manera experimental en educació infantil, utilitzant unitats corporals (pams, grapats...) i arbitràries (cordes, gots, pedres...), en un treball de discussió i reflexió sobre la validesa d'aquestes. Posteriorment, es treballaran les unitats normalitzades o convencionals, i cal procurar que sorgisquen com a superació de les anteriors.

Per aconseguir-ho, en 1r de primària, es plantejaran activitats semblants a les realitzades en l'etapa anterior, que siguen susceptibles de provocar el diàleg al voltant de la necessitat d'utilitzar la mateixa unitat per a cada magnitud. Potser encara no tinguen format el concepte d'unitat de mesura, ni sàpiguen com s'utilitzen amb precisió, només es tracta d'un treball intuïtiu.

Per exemple: volen fer un berenar, i necessiten saber quant de suc els farà falta. En un primer moment, s'ompli un gerro i es quantifica el contingut amb tots els gots $i$ recipients que es puguen trobar per l'aula. Si hi ha de molts diferents, algun xiquet o xiqueta hauria de dir que, si no se n'utilitza només un i del mateix tipus dels que després s'usaran al berenar, no tindrà sentit aquest còmput.

Aleshores, en un segon moment caldrà calcular la mesura, però només amb un got. Aquesta idea de mesura és molt inicial i es treballarà també als casos de la longitud i la massa, amb situacions semblants (esbrinar la quantitat de cinta que fa falta per marcar les línies exteriors d'un camp de futbol que estan reproduint en una cartolina, o la de sorra que es necessita per recobrir la superfície d'una platja que se està representant en un mural, per exemple). En principi, l'objectiu que es persegueix és només mesurar diferents magnituds i disposar la ment per al següent interrogant:

Si canviem la unitat de mesura, canvia el resultat? 
És a dir, si es canvia el got amb el que cada persona del berenar beurà, amb un gerro de suc, tindrem per a diferent nombre de persones? S'haurà de fer un treball semblant amb les altres dues magnituds esmentades.

Cal intentar arribar a descobrir que, malgrat la quantitat de suc és la mateixa, el repartiment que hi fem d'aquesta quantitat és diferent i els resultats de les mesures que n'obtenim no coincideixen. Això passava també quan es parlava dels sistemes de numeració: la quantitat d'elements que agrupàvem era la mateixa, però l'expressió que s'obtenia d'aquesta quantitat era diferent segons la base del sistema de numeració utilitzada.

De tota aquesta reflexió, la conclusió haurà de ser que s'ha de trobar una unitat patró, coneguda i acceptada per tothom, per garantir que el resultat de la mesura obtingut siga comprés per una altra persona que no hi era en el moment de fer el mesurament i li permeta avaluar correctament la quantitat corresponent.

\section{Reconèixer i utilitzar les unitats de longitud, capacitat i massa: metre, decímetre, centímetre, litre i quilogram}

Les tres primeres magnituds a estudiar en l'aula de primària són longitud, capacitat i massa, i aquest fet està justificat per la immersió que hi ha d'aquestes en la vida diària i per la facilitat d'experimentar físicament amb elles. A casa, al carrer, al seu voltant, es parla sovint de temes relacionats amb les esmentades magnituds.

Dedicarem els dos primers cursos de l'etapa a introduir les unitats convencionals fonamentals, metre, litre, quilogram i el submúltiple més comú de la primera.

Respecte de la longitud, al començament de l'etapa s'ha de partir dels seus coneixements previs sobre el metre. Segurament, el coneixeran gràcies a l'entorn familiar i sabran que s'utilitza per a mesurar «com és de llarga alguna cosa». Aquesta, doncs, serà la unitat patró que es buscava en la capacitat anterior i, és més, se'ls haurà de dir que és un consens, no només de l'aula en aqueix moment, sinó de tothom.

Aleshores, s'ha de fer una introducció significativa, amb un metre complet, que el puguen manipular i utilitzar. Cal presentar-lo en suports físicament diferents i comprovar la seua unicitat. Com ajuda per aquest treball, es poden utilitzar alguns materials didàctics, com les regles flexibles d'1 metre (figura 40), de diversos colors. Aquest material ajuda a fer-los conscients de la llargària d'un metre i els possibilita utilitzar-lo per a realitzar els primers mesuraments. Una característica que tenen les regles, al ser flexibles, és què permeten mesurar longituds que no estiguen en línia recta. 


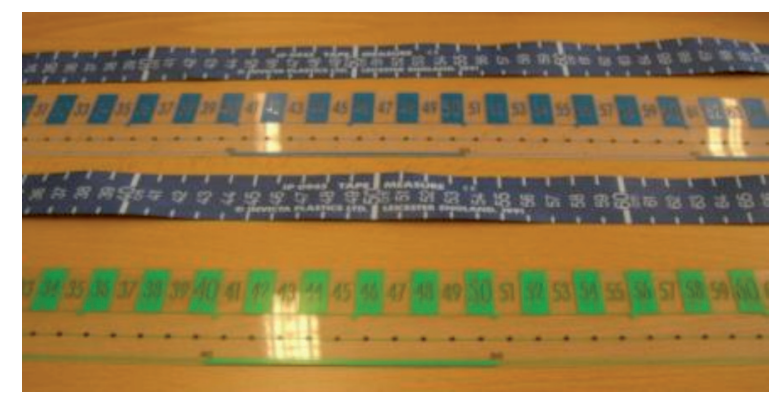

Figura 40. Regles flexibles d'1 metre (fabricades per HenBea)

Hi ha d'altres materials que es poden presentar, com la regla mètrica de pissarra, la cinta mètrica enrotllable o el metre articulat. Tots aquests representen la idea d'unitat a l'hora de mesurar longituds i han de comprovar que aquesta no depèn de la forma, color etc., que tinga l'instrument emprat.

També es pot utilitzar la roda contametres (figura 41) amb la que podrem esbrinar longituds un poc més llargues (passadís, pati, etc.) que resulten complicades de mesurar amb alguns dels instruments esmentats, per la gran quantitat de vegades que han de traslladar la unitat de mesura i les errades que això pot ocasionar.

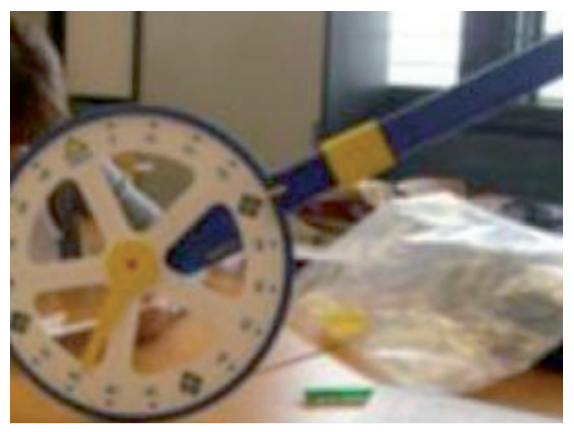

Figura 41. Roda contametres (fabricada per Invicta)

Després, caldrà representar el metre pel seu símbol, m, i usar-lo per a mesurar diferents objectes, la longitud dels quals siga un múltiple enter d'un metre (la paret de l'aula, la del passadís, la pissarra, per exemple). Paral·lelament a aquestes activitats de mesura, els xiquets i xiquetes verbalitzaran i representaran amb llapis i paper els resultats obtinguts, expressant de manera correcta els nombres que indiquen la mesura i el símbol de la unitat utilitzada.

Posteriorment, s'ha de crear en l'aula la necessitat de mesurar coses més curtes (llargària de la taula, d'una carpeta, d'un llibre...), menors que un metre i majors o iguals que un decímetre, i buscaran per l'aula algun objecte que els puga servir com a unitat. Si estan usant els blocs multibase per a treballar el sistema de numeració i les operacions, podem suggerir-los que utilitzen la llargària d'una de les barres d'aquest material com a unitat; si no, podem posar al seu abast pals, cordes, etc., que mesuren un decímetre per tal que els utilitzen com a unitat. Per a posar-li nom a aquesta nova unitat, els demanem que la comparen amb la que ja coneixien, 
el metre. En comprovar que es necessiten 10 d'aquestes noves unitats per a completar un metre, el nom que es triarà és decímetre i el seu símbol serà dm.

Seguint en la mateixa línia, els proposarem que mesuren objectes més curts encara (goma d'esborrar, amplada del llom d'un llibre...), i els oferirem com a unitat la llargària d'una de les arestes dels cubs dels blocs multibase o d'altres objectes que mesuren un centímetre preparats pel docent. De manera semblant al cas del decímetre i per tal de posar nom a aquesta nova unitat, comprovarem que en caben 100 en un metre, i serà, per això, centímetre el seu nom i cm el seu símbol.

Conegudes aquestes dues noves unitats i els seus símbols, les utilitzaran mitjançant les regles graduades usuals per tal de mesurar diferents objectes triant la unitat més adequada per a cadascun d'ells i expressaran, verbalment i per escrit, els resultats obtinguts.

Per tal d'ajudar-nos a relacionar el metre amb el decímetre i el centímetre, a més dels blocs multibase esmentats anteriorment, podem utilitzar la metrilínia (figura 42), que és un regle rígid d'un metre amb un solc central que el recorre, on es poden situar centicubs (cubs de plàstic encaixables d'un centímetre cúbic). Els cubs que s'introdueixen a dintre del regle serveixen per a relacionar el metre amb el decímetre, si els utilitzem agrupats de deu en deu, i per a relacionar el metre amb el centímetre, si els considerem de manera aïllada.

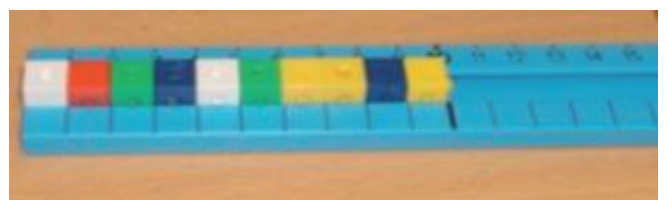

Figura 42. Metrilínia (fabricada per Osmiroid)

En referència a la capacitat, al començament de l'etapa, també poden saber que hi ha alguna cosa anomenada litre, i de la mateixa manera que el metre, és la unitat consensuada que s'usa per a mesurar ara una altra magnitud: «quant cap en un recipient».

Es presenta amb diversos envasos reals que mesuren un litre i que els poden portar de casa: bric de llet, ampolla d'aigua, de refresc, de batut... i es comprova que tots tenen la mateixa capacitat. A més dels recipients reals, podem utilitzar materials estructurats específics per aquest treball, com per exemple el material kit de litre (figura 43) composat per recipients de diverses formes (cilindre, ortoedre, tronc de con, cub, prisma triangular), però que tots mesuren un litre. Aquest material compta també amb un cilindre de mig litre de capacitat, que permet comprovar la igualtat de les capacitats dels altres recipients i, per tant, la conservació de la quantitat en transvasar materials d'un recipient a altre. 


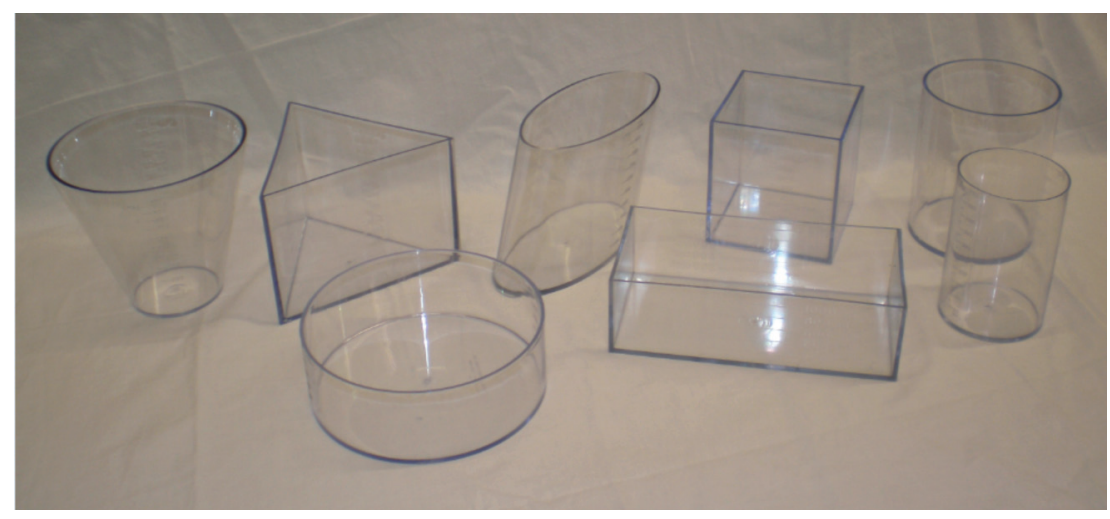

Figura 43. Kit de litre (fabricat per Invicta)

També existeixen diferents conjunts de vasos graduats que són recipients de diverses capacitats, dels quals utilitzarem en aquest moment només els d'un litre, per a comprovar que tenen tots la mateixa capacitat encara que no la mateixa forma.

Després, caldrà representar el litre pel seu símbol, 1 o L, i usar-lo per a mesurar quantitats de líquids que caben en diferents recipients, la capacitat dels quals siga un múltiple enter d'un litre (ampolles d'aigua de dos litres, garrafes de cinc, de vuit litres, etc.). Acompanyant la realització d'aquestes activitats de mesura, els xiquets i xiquetes en verbalitzaran i representaran per escrit els resultats, expressant de manera correcta els nombres que indiquen la mesura i el símbol de la unitat utilitzada.

Pel que fa a la massa, seguirem el mateix procediment. En 1r curs de primària saben que hi ha quelcom anomenat quilogram que serveix per a mesurar «quant pesa alguna cosa». Anàlogament a les magnituds anteriors, serà aquest la unitat patró per a la massa.

En un primer moment s'haurien de portar a l'aula objectes que pesen un quilogram i comparar-los (un paquet de sucre, de macarrons, d'arròs...). Per a realitzar aquestes comparacions utilitzarem balances de plàstic (figura 44) fàcilment manipulables $i$ indicades per a Infantil o els primers cursos de primària, amb cubetes profundes que permeten comparar, a més dels sòlids, masses de líquids $\mathrm{o}$ àrids.

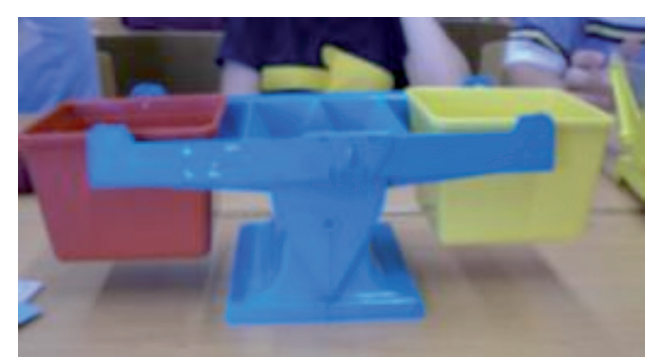

Figura 44. Balança de Plàstic (fabricada per Osmiroid) 
Per a completar la construcció de la idea de quilogram, caldrà utilitzar balances amb peses convencionals. Un exemple podria ser la balança Vulcano i les seues peses (figura 45).

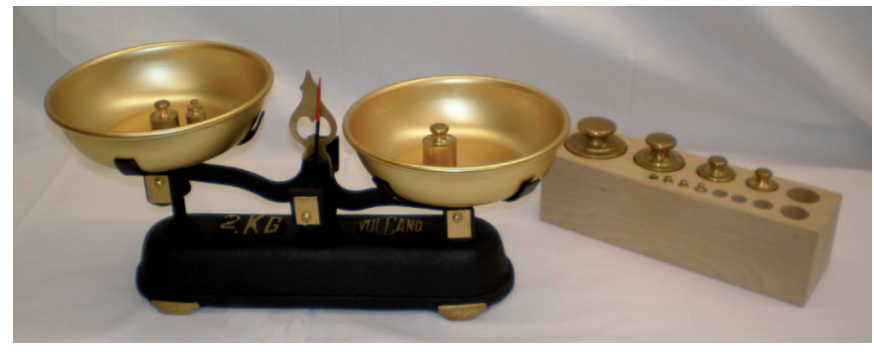

Figura 45. Balança Vulcano de $2 \mathrm{~kg}$ (fabricada per Vulcano)

A més d'aquestes, es poden utilitzar altres conjunts de peses com les que es mostren en la figura 46. L'alumnat haurà de comprovar la igualtat de massa de les diverses peses d'un quilogram per assegurar la unicitat d'aquesta unitat.

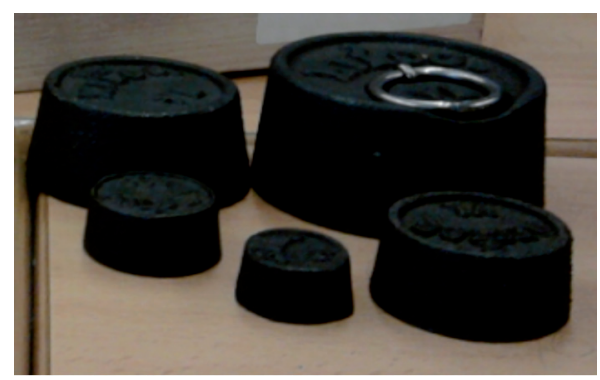

Figura 46. Peses de ferro (fabricades per Vulcano)

Després, caldrà representar el quilogram pel seu símbol, kg, i usar-lo per a mesurar objectes, la massa dels quals siga un múltiple enter d'un quilogram (sacs de terra, de patates, per exemple). En realitzar aquestes activitats de mesura, els xiquets i xiquetes verbalitzaran i representaran en el paper els resultats obtinguts, expressant de manera correcta els nombres que indiquen la mesura i el símbol de la unitat utilitzada.

Una vegada assolides les unitats fonamentals i atès l'estès ús social de les meitats o quartes parts d'aquestes, es poden introduir el mig metre, mig litre o mig quilogram i el quart de litre o de quilogram, si es fan necessaris en alguna situació que s'estiga treballant a l'aula. En aquests casos es dispondrà d'objectes, recipients 0 paquets de la vida real (l'amplada d'algunes taules escolars, ampolles d'un quart de libre de suc, paquets de mig quilogram de macarrons...) que mesuren les parts esmentades i es compararan amb les unitats fonamentals. L'objectiu serà arribar a comprovar que són necessàries dues o quatre de les noves unitats per completar les fonamentals.

A continuació, podem oferir-los materials didàctics que representen les noves unitats: regles de mig metre, recipients de mig o de quart de litre, peses de mig o de quart de quilogram, per què comproven, de nou, les relacions esmentades abans. 
A partir de les activitats realitzades, introduirem els noms d'aquestes unitats i la seua simbolització, que utilitza expressions formalment desconegudes per als xiquets i xiquetes, però que han pogut veure en alguna ocasió, com són les fraccions 1/2 o 1/4. Així, simbolitzarem 1/2 m, 1/2 1, 1/2 kg, 1/4 1, 1/4 kg.

Completarem el coneixement del mig metre, relacionant-lo amb el decímetre i el centímetre, comprovant per la mesura que cinc decímetres o cinquanta centímetres seran mig metre.

Al llarg dels esmentats dos primers cursos de l'etapa (encara que són experiències que es poden allargar a cursos posteriors) $\mathrm{i}$ amb la finalitat d'ajudar l'alumnat a arribar a la conservació de la quantitat, es realitzaran diferents activitats referents a les tres magnituds en les que s'utilitzaran les unitats de mesura treballades i, si s'escau, algunes arbitràries per tal de fer les comprovacions pertinents. Es faran activitats en les quals no es modifique la quantitat, com per exemple: plegar una corda que estava estirada, mesurant la longitud en els dos casos i comparant els resultats; canviar una quantitat d'aigua d'un recipient a altre, mesurant-la en ambdós casos i comparant de nou; fer una bola amb tota la plastilina d'una pastilla i pesar tant la bola com la pastilla per observar els resultats. I d'altres en les que sí es modifique, que respectivament a les anteriors poden ser: mesurar la longitud d'una corda, tallar-li un tros i mesurar-la de nou, comparant els resultats; mesurar la quantitat d'aigua que hi haja en un recipient, afegir-ne un poc més i tornar a mesurar; pesar una tableta de plastilina, llevar-li'n un pessic i pesar-la una altra vegada. La comparació dels resultats de les parelles d'activitats proposades per a cada magnitud, permetrà donar els primers passos amb l'alumnat perquè al llarg de tota l'etapa de primària arribe a la conclusió que la quantitat d'una determinada magnitud sols canviarà si afegim o llevem altra quantitat de la mateixa magnitud, i no quan aquella se sotmet a un canvi de disposició espacial, de recipient, o de forma, per exemple.

\section{Conèixer i utilitzar correctament els múltiples i submúltiples del metre, el litre i el quilogram, establint-ne les equivalències}

Al començament del 3r curs, es repassa la idea de metre, litre i quilogram com a unitats fonamentals de longitud, capacitat i massa, respectivament, amb diferents materials que a més permeten comprovar la unicitat d'aquestes. Es repassa també el decímetre i centímetre com a primers submúltiples del metre.

Per a completar els conjunts d'unitats de les tres magnituds i enllaçar amb el treball del dos cursos anteriors, introduirem al llarg dels restants cursos de l'etapa els submúltiples i els múltiples en cadascuna d'aquestes.

\section{Longitud}

S'introdueix un nou submúltiple del metre a partir de la necessitat de mesurar alguna cosa de menor longitud que el centímetre (la grossària d'una caixa de $\mathrm{CD}$, 
d'una planxa de suro...), utilitzant com a unitat la distància més curta que troben entre les marques dels regles usuals. De la mateixa manera que en els submúltiples coneguts, el nom d'aquesta unitat sorgeix de la seua comparació amb el metre, adonant-se que fan falta mil per a completar-ne un. Serà per això que el nom d'aquesta és mil·límetre i el símbol és mm.

Es relacionarà també amb el decímetre i el centímetre, comprovant al comparar-les que:

$$
10 \mathrm{~mm}=1 \mathrm{~cm} \quad 100 \mathrm{~mm}=1 \mathrm{dm}
$$

Coneguda aquesta nova unitat i el seu símbol, la usaran per tal de mesurar diferents objectes la longitud dels quals siga un múltiple enter d'un mil·límetre i expressaran, verbalment i per escrit, els resultats obtinguts, utilitzant de manera correcta els nombres que indiquen la mesura i el símbol corresponent de la unitat. Quan, a partir del 4t curs, els alumnes coneguen les fraccions i els nombres decimals, podrem expressar els submúltiples del metre utilitzant les expressions següents:

$$
\begin{aligned}
& 1 \mathrm{dm}=0,1 \mathrm{~m}=\frac{\mathbf{1}}{\mathbf{1 0}} \mathrm{m} \\
& 1 \mathrm{~cm}=0,01 \mathrm{~m}=\frac{\mathbf{1}}{\mathbf{1 0 0}} \mathrm{m} \\
& 1 \mathrm{~mm}=0,001 \mathrm{~m}=\frac{\mathbf{1}}{\mathbf{1 0 0 0}} \mathrm{m}
\end{aligned}
$$

i entendre el decímetre, el centímetre i el mil·límetre com el resultat de dividir un metre en 10, 100 o 1000 parts iguals, respectivament, o el que és el mateix, com una dècima, una centèsima o una mil·lèsima part del metre.

Si les longituds que necessiten expressar són molt més llargues que un metre (la distància entre dues poblacions, entre la Terra i la Lluna...), es fa necessari introduir noves unitats més grans. Començarem amb el quilòmetre per ser la que s'utilitza socialment per a expressar aquestes distàncies. La introduirem com una unitat equivalent a mil metres i el seu símbol serà km.

Com que en aquesta nova unitat no poden fer mesuraments de forma experimental, proposarem a l'alumnat que cerquen distàncies entre diferents poblacions, astres, etc., i que observen com les expressions trobades utilitzen els nombres i el símbol de la unitat.

Per tal de completar la seqüència de múltiples del metre, respectar l'estructura decimal del sistema mètric i per simetria amb els submúltiples, introduirem també el decàmetre i l'hectòmetre, com les unitats equivalents, respectivament, a deu i cent metres, així com els símbols dam i hm, i les relacions d'aquestes amb el metre i el quilòmetre: 


$$
\begin{array}{ll}
1 \mathrm{hm}=100 \mathrm{~m} & 1 \mathrm{dam}=10 \mathrm{~m} \\
10 \mathrm{hm}=1 \mathrm{~km} & 100 \mathrm{dam}=1 \mathrm{~km}
\end{array}
$$

Per donar sentit a aquestes noves unitats, els animarem a trobar situacions reals en les quals s'utilitzen (atletisme, natació, mesuraments topogràfics,...).

Novament, quan coneguen les fraccions i decimals, podran utilitzar aquestes expressions numèriques per a representar les esmentades relacions de manera anàloga al que hem comentat per als submúltiples.

\section{Capacitat}

A partir del coneixement del litre, i de forma semblant al treball desenvolupat amb la longitud, anirem introduint els submúltiples de la unitat fonamental per tal d'utilitzar-los en la mesura de diferents líquids. Portarem a l'aula diversos recipients la capacitat dels quals estiga indicada en centilitres o mil·lilitres (ampolles d'abonament per a plantes, xeringues, culleres de xarop,...), fixant-nos en el símbol cl o ml respectivament. Posarem a l'abast dels xiquets materials didàctics, com els vasos graduats de la figura 47, perquè puguen fer comparacions i mesuraments, i per a comprovar que fan falta $100 \mathrm{cl}$ o $1000 \mathrm{ml}$ per tal d'omplir 11.



Figura 47. Vasos graduats (fabricats per Vit Lab)

Per completar la seqüència de submúltiples del litre i respectar l'estructura decimal del sistema mètric, introduirem també el decilitre com la unitat que fa falta repetir deu vegades per a omplir un litre, així com el seu símbol, dl, i les relacions amb els submúltiples coneguts del litre:

$$
10 \mathrm{dl}=11 \quad 1 \mathrm{dl}=10 \mathrm{cl} \quad 1 \mathrm{dl}=100 \mathrm{ml}
$$

Utilitzaran aquestes unitats per tal de mesurar la capacitat de diferents recipients i expressaran verbalment i per escrit els resultats obtinguts usant els símbols de les diferents unitats.

De la mateixa manera que en el cas de la longitud, quan coneguen les fraccions i els nombres decimals, podran expressar els submúltiples del litre utilitzant les expressions següents: 


$$
\begin{aligned}
& 1 \mathrm{dl}=0,1 \mathrm{l}=\frac{\mathbf{1}}{\mathbf{1 0}} 1 \\
& 1 \mathrm{cl}=0,01 \mathrm{l}=\frac{\mathbf{1}}{\mathbf{1 0 0}} 1 \\
& 1 \mathrm{ml}=0,001 \mathrm{l}=\frac{\mathbf{1}}{\mathbf{1 0 0 0}} 1
\end{aligned}
$$

i entendre el decilitre, el centilitre i el mil-lilitre com el resultat de dividir un litre en 10, 100 o 1000 parts iguals, respectivament, o el que és el mateix, com una dècima, una centèsima o una milllèsima part del litre.

Quan les capacitats que necessiten expressar són molt més grans que un litre, es fa necessari introduir noves unitats majors que aquest (la capacitat d'un dipòsit d'aigua, d'una piscina, de la cisterna d'un camió...). Per similitud al que es va treballar en el cas de la longitud, aquestes noves unitats seran: decalitre, hectolitre i quilolitre, que equivalen respectivament a deu, cent i mil litres i se simbolitzen amb dal, hl i kl:

$$
1 \mathrm{dal}=101 \quad 1 \mathrm{hl}=1001 \quad 1 \mathrm{kl}=10001
$$

De forma semblant a la magnitud anterior, els animarem a trobar situacions reals en les quals s'utilitzen aquests múltiples del litre (dipòsits de vi, d'oli, marraixes de líquids...).

Novament, quan coneguen les fraccions i decimals, podran utilitzar aquestes expressions numèriques per a representar les esmentades relacions, d'acord amb el que hem explicat per als submúltiples.

\section{Massa}

Després de repassar el quilogram i de manera anàloga al treball desenvolupat amb la longitud i la capacitat, cal introduir els submúltiples de la unitat fonamental per tal d'utilitzar-los en la mesura de diferents pesos. Portarem a l'aula diversos envasos, el pes dels quals estiga indicat en grams (macarrons, llentilles, sucre...), fixant-nos en el símbol g i n'ajuntarem diversos d'aquests fins aconseguir equilibrar en una balança una pesa d'un quilogram, comprovant a continuació que hem necessitat sumar $1000 \mathrm{~g}$ per tal d'igualar-la. De la relació entre aquestes dues unitats, es dedueix fàcilment el nom gram per referir-se a la més menuda d'elles.

Completarem la seqüència de submúltiples del quilogram, respectant l'estructura decimal del sistema mètric, introduint també el decagram i l'hectogram com les unitats que fa falta repetir cent $i$ deu vegades respectivament per a equilibrar un quilogram, així com els símbols d'aquests dag i hg i les relacions que tenen amb el gram:

$$
1 \mathrm{dag}=10 \mathrm{~g} \quad 1 \mathrm{hg}=100 \mathrm{~g}
$$


Cal notar que, encara que aquestes unitats són submúltiples del quilogram (unitat central de la magnitud en el Sistema Internacional), les expressions que utilitzem per a representar-les tenen com a referent el gram, com si aquest fos la unitat fonamental de la massa (herència del Sistema Cegesimal).

Anàlogament a les magnituds anteriors, quan coneguen les fraccions i els nombres decimals, podrem expressar els submúltiples del quilogram utilitzant les expressions següents:

$$
\begin{aligned}
& 1 \mathrm{hg}=0,1 \mathrm{~kg}=\frac{\mathbf{1}}{\mathbf{1 0}} \mathrm{kg} \\
& 1 \mathrm{dag}=0,01 \mathrm{~kg}=\frac{\mathbf{1}}{\mathbf{1 0 0}} \mathrm{kg} \\
& 1 \mathrm{~g}=0,001 \mathrm{~kg}=\frac{\mathbf{1}}{\mathbf{1 0 0 0}} \mathrm{kg}
\end{aligned}
$$

i entendre l'hectogram, el decagram i el gram com el resultat de dividir un quilogram en 10, 100 o 1000 parts iguals respectivament, o el que és el mateix, com una dècima, una centèsima o una mil·lèsima part del quilogram.

Com que el gram era la unitat fonamental de la massa en el Sistema Cegesimal, encara que no ho és en el Sistema Internacional, hi ha també submúltiples del gram que cal conèixer. Començarem pel mil-ligram, per trobar-lo freqüentment en contextos reals associats a medicaments. Malgrat la gran dificultat de manipular aquesta unitat en l'aula de primària, la definirem com la massa que resulta de dividir un gram en mil parts iguals, per això el símbol, mg, i les expressions:

$$
1 \mathrm{mg}=0,001 \mathrm{~g}=\frac{1}{1000} \mathrm{~g}
$$

Completarem la seqüència de submúltiples del gram, respectant l'estructura decimal del sistema mètric, introduint també el decigram i el centigram com les masses que resulten de dividir un gram en deu i cent parts iguals, respectivament, per això els símbols, dg i cg, i les expressions:

$$
1 \mathrm{dg}=0,1 \mathrm{~g}=\frac{1}{\mathbf{1 0}} \mathrm{g} \quad 1 \mathrm{cg}=0,01 \mathrm{~g}=\frac{\mathbf{1}}{\mathbf{1 0 0}} \mathrm{g}
$$

Atesa la dificultat de fer mesuraments en aquestes unitats en l'aula de primària, proposarem a l'alumnat que busque situacions reals en les que s'usen (informacions de medicaments, metalls valuosos, adobs de bonsais...).

Un múltiple del quilogram molt important i que també es treballa per l'estès ús social que té és la tona. Aquesta unitat té un valor de $1000 \mathrm{~kg}$ i se simbolitza per t. Demanarem als xiquets i xiquetes que troben aquesta unitat en diferents contextos: pes d'una balena, d'un elefant, d'un dinosaure, càrrega d'un camió, d'un vaixell, d'un tren...

Cap al final del $4 \mathrm{t}$ curs de primària, es podrien reflectir totes les unitats treballades fins al moment al següent quadre resum: 


\begin{tabular}{|c|l|l|l|l|l|l|l|l|}
\hline LONGITUD & $\mathrm{mm}$ & $\mathrm{cm}$ & $\mathrm{dm}$ & $\mathrm{m}$ & $\mathrm{dam}$ & $\mathrm{hm}$ & $\mathrm{km}$ & \\
\hline CAPACITAT & $\mathrm{ml}$ & $\mathrm{cl}$ & $\mathrm{dl}$ & $\mathrm{l}$ & $\mathrm{dal}$ & $\mathrm{hl}$ & $\mathrm{kl}$ & \\
\hline MASSA & $\mathrm{mg}$ & $\mathrm{cg}$ & $\mathrm{dg}$ & $\mathrm{g}$ & $\mathrm{dag}$ & $\mathrm{hg}$ & $\mathrm{kg}$ & $\mathrm{t}$ \\
\hline
\end{tabular}

Per aconseguir de manera definitiva la conservació raonada de les quantitats de longitud, capacitat i massa, i com a complement del treball realitzat en els dos primers cursos de l'etapa, en 3r i 4t desenvoluparem amb els xiquets i xiquetes activitats semblants a les proposades en la capacitat anterior. Per tal de fer les comprovacions escaients podrem utilitzar totes les unitats de mesura que s'han treballat.

També es poden presentar en classe aquelles unitats autòctones (fanecada, arrova de massa o de capacitat...) que ells i elles hagen pogut sentir en la seua curta vida i relacionar-les amb les unitats del Sistema Internacional.

\section{Expressar mesures de longitud, capacitat i massa de forma complexa. Transformar expressions de mesura complexes en incomplexes i a l'inrevés}

Aquesta capacitat es desenvoluparà a partir de $4 \mathrm{t}$ curs, després que els xiquets $\mathrm{i}$ xiquetes coneguen els nombres decimals.

Quan realitzen experiències de mesura, poden expressar els resultats de dues maneres ben diferents. De forma complexa, utilitzant diferents unitats, per exemple $3 \mathrm{~m} 8 \mathrm{dm} 1 \mathrm{~cm}$ i de manera incomplexa (també anomenada simple), expressant-la només amb una, adequant el nombre a la unitat, per exemple 3,81 m. Aquesta darrera expressió pot variar si es trien altres unitats per representar el resultat. Així, per exemple, podríem escriure $38,1 \mathrm{dm}, 381 \mathrm{~cm}, 3810 \mathrm{~mm}, 0,0381 \mathrm{hm}, 0,00381 \mathrm{~km}$. S'insistirà molt en el fet que no estem representant diferents quantitats encara que utilitzem diferents escriptures. La quantitat és la mateixa i es conserva independentment de la manera d'expressar-la.

És clar que per tal de desenvolupar el treball que permet transformar unes expressions en unes altres, els alumnes han de dominar les diferents unitats de mesura estudiades i les relacions decimals entre aquestes.

\section{Identificar el valor de les monedes i bitllets del nostre sistema monetari i utilitzar-los per a expressar quantitats de diners concretes}

El sistema monetari que adopta una comunitat de persones no és fruit d'una propietat física dels objectes que hi tenen al voltant, com passava en les magnituds anteriors, encara que s'estudia junt amb elles perquè es comporta com si ho fos. 
És fruit d'un conveni, és un acord que es pren per atorgar valor als diferents «elements».

El sistema monetari actual posseeix quantitats fraccionàries centesimals i respecta les regles de funcionament del Sistema de Numeració Decimal. Quan l'alumnat tinga coneixements sobre fraccions i decimals, el treball es podrà normalitzar, però en els primers cursos de primària, encara que no els coneguen, cal treballar el sistema monetari per la necessitat que hi ha d'adaptar-se al medi i la quotidianitat dels diners.

Caldrà considerar, però, certs aspectes de manera especial en el moment de treballar amb l'alumnat aquests continguts:

- Les unitats: introduirem l'euro com la unitat del sistema monetari i presentarem el cèntim, no com la centèsima part de l'euro, sinó com «allò que, ajuntant-ne 100 , fa $1 €$ ».

- La coma: és la marca que s'ha de col-locar per a delimitar quina és la part del nombre que correspon als euros i quina la que correspon als cèntims, és a dir, a l'esquerra de la coma els euros enters i a la dreta, els cèntims.

- Les operacions: quan es necessite operar amb diners i mentre no es coneguen els nombres decimals i les operacions amb ells, es pot procedir, si cal, operant per separat els nombres que representen els euros i els que es refereixen als cèntims, $\mathrm{i}$ composant després els resultats.

Es començarà en el $1 \mathrm{r}$ curs de l'etapa introduint les monedes de cèntims $(1,2,5$, 10,20 i 50) i d'euros ( 1 i 2), incorporant a poc a poc els bitllets de $5 €, 10 €, 20 €$ i $50 €$. En 2 n curs de primària s'introduiran els de $100 €, 200 €$ i $500 €$.

Per tal de reforçar els càlculs mentals amb el valor de les monedes, podem ajudar-nos de l'eurodòmino (figura 48), que associa quantitats numèriques de diners amb la representació d'aquests utilitzant monedes.

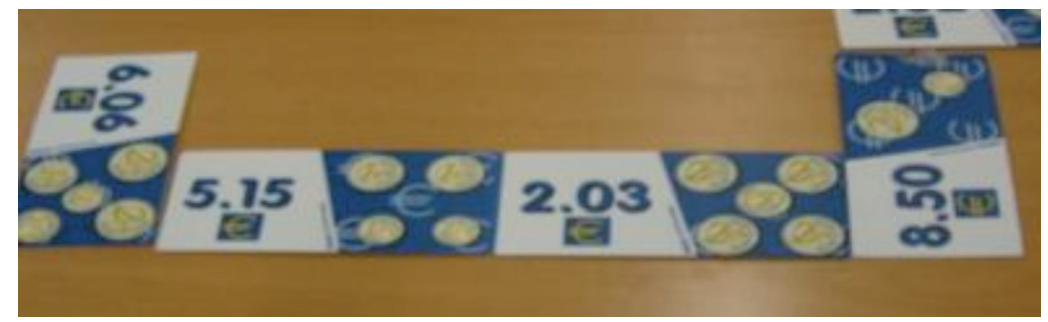

Figura 48. Eurodòmino (fabricat per HenBea)

Per treballar les relacions entre monedes i bitllets, podem realitzar a classe activitats de compravenda o uns altres càlculs amb diners (que verbalitzarem) utilitzant com ajuda el material de plàstic que reprodueix el sistema monetari amb bastant fidelitat i que es mostra en la imatge de la figura 49. 

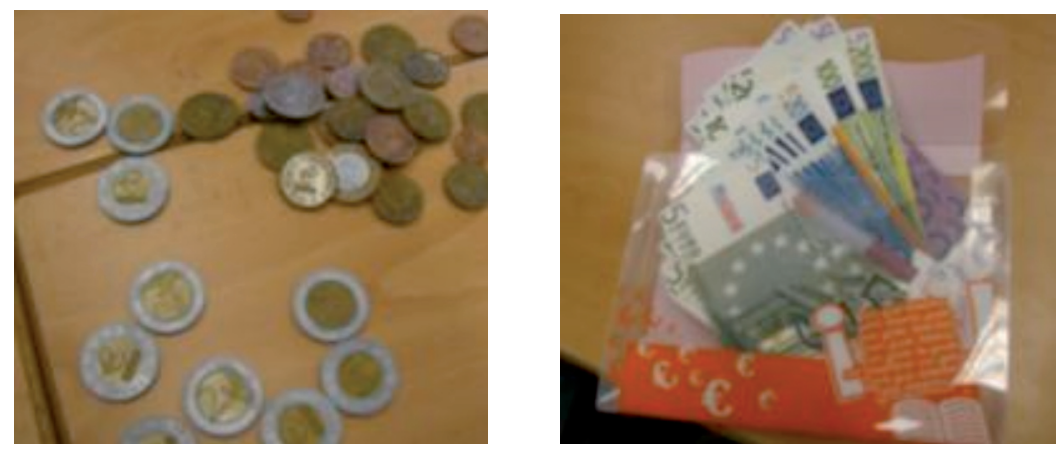

Figura 49. Monedes i Bitllets (fabricats per Miniland)

Mentre es realitzen aquestes activitats, es treballarà amb llapis i paper per reflectir les operacions implicades en elles (llista de la compra, el tiquet de despeses...). Per exemple, si necessiten saber quants diners han de reunir per a comprar dos joguets que han vist en un catàleg, sumaran els preus corresponents. Quan la part decimal del resultat no supere els 100 cèntims, no hi haurà molt de conflicte en operar com si fóra una addició de nombres naturals, i en el moment de col·locar la coma en el resultat, per imitació als sumands, quedaria al lloc corresponent. El problema pot vindre del cas contrari, si els preus dels joguets que vol comprar un xiquet o xiqueta són $42,75 € \mathrm{i} 12,91 €$, com podem veure en l'exemple numèric següent. S'usarà la manera d'operar de la dreta, separant els euros i els cèntims quan l'alumnat ho necessite, i expressaran el resultat final de manera correcta:

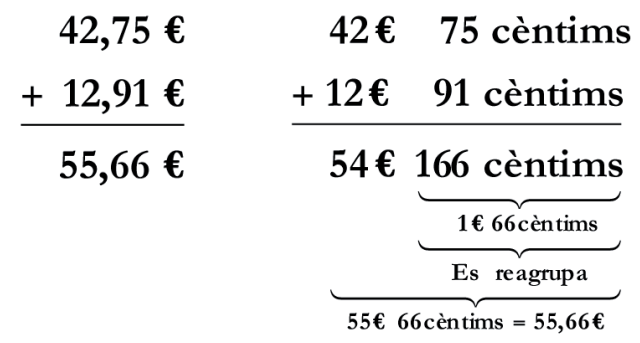

Per tal de comprovar si els diners que els tornen a l'hora de comprar són els correctes o si necessiten saber quants els en quedarien després d'haver comprat un joguet amb uns diners estalviats o altres situacions semblants, utilitzaran subtraccions. En el procés de resolució respectarem els nivells operatoris sense portar-ne i portant-ne proposats per aquesta operació amb nombres naturals i, en cas de ser necessari separar els euros dels cèntims, ho farem anàlogament al cas de l'addició.

En $3 r$ de primària, no cal introduir res de nou, es repassa el que s'ha vist en els dos cursos anteriors respecte de monedes i bitllets.

En situacions quotidianes recreades a l'aula es poden trobar en multiplicacions $i$ divisions amb decimals que es refereixen a quantitats de diners. Per exemple, si organitzem un quiosc a classe i fem activitats de comprar llepolies, pot resultar necessari multiplicar el preu que val una d'elles per la quantitat que hagen triat comprar. I tot això abans de pagar, perquè han de saber si porten suficients diners o no. Caldrà fer també divisions, quan per preparar una activitat de classe, cada 
grup de cinc xiquets i xiquetes ha d'aportar uns diners determinats i necessiten esbrinar la quantitat que haurà de dur cadascun, per exemple. En totes les situacions d'aquests tipus hauran de separar, si s'escau, el nombre d'euros i el de cèntims per tal de fer les operacions i unificar finalment els resultats obtinguts per expressar de manera correcta la quantitat final.

\section{Completar el coneixement del nostre sistema monetari, relacionant les monedes i bitllets amb els nombres decimals}

En 4t de primària, i aprofitant que s'estan treballant els nombres decimals, es pot aplicar aquest coneixement a les activitats amb diners, per tal de donar contingut matemàtic a les operacions intuïtives que es feien abans.

Ja es pot introduir-hi el cèntim com la centèsima part de l'euro i algunes monedes es poden presentar aleshores com la dècima o la centèsima part d'unes altres.

En els dos darrers cursos de l'Etapa no s'introdueix res de nou respecte del sistema monetari. S'utilitza quan és necessari per a resoldre situacions problemàtiques, que en alguns casos poden referir-se al canvi de moneda d'euros a dòlars o lliures esterlines i a l'inrevés.

\section{Comprovar la relativitat de la percepció del temps i descobrir la necessitat d'una unitat patró per a mesurar-lo}

A diferència de la longitud, la massa i la capacitat, la magnitud temps no es pot experimentar físicament, però cal treballar-la per estar sempre present en la vida diària. El coneixement del temps per l'alumnat avança més lentament que el de les altres tres magnituds esmentades. En educació infantil s'han treballat diferents coordenades temporals, com ara: molt de temps, poc de temps, de dia, de nit, abans, ara, després, pel matí, per la vesprada, per la nit, ahir, avui, demà... A més, es treballa amb seqüències en les quals ells i elles ordenen temporalment dibuixos senzills.

Amb cinc anys, ja poden treballar amb aproximacions de la quantificació del temps usant rellotges d'arena, d'aigua, d'espelmes... on es veu com es pot comparar de manera objectiva la durada de dues o més situacions diferents que no siguen simultànies. L'ajuda d'instruments aliens a nosaltres es fa necessària perquè segons l'estat d'ànim que hi tenim, el temps fa l'efecte de passar de manera diferent. Però les activitats amb aquests instruments no ens permeten saber quant de temps ha passat, només si una situació o un període ha durat més o menys que no pas un altre. Per tal de respondre a la pregunta essencial, necessitem mesurar el temps, i per fer-ho caldrà una unitat patró: l'hora.

En 1r curs de primària, convé recordar el treball realitzat per a la magnitud temps en Educació Infantil, reforçant les diferents nocions d'orientació temporal, ordenant seqüències més complicades (amb més escenes que en l'etapa anterior, veure figura 50) i reprenent l'estudi de l'hora com a unitat de mesura del temps. 


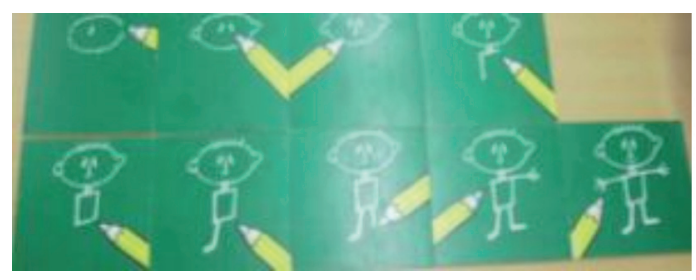

Figura 50. Seqüències lògiques (fabricat per Trusva)

\section{Reconèixer i utilitzar les unitats de temps: hores, mitges hores, quarts d'hora, minuts i segons. Interpretar les hores en el rellotge}

Com a conseqüència de la capacitat anterior, cal continuar amb el coneixement de l'hora. En les aules de primària, ens ajudarem de diferents tipus de rellotges analògics. La figura 51 correspon al rellotge d'engranatges, les agulles del qual no funcionen independentment: si la llarga fa una volta completa a l'esfera, la curta es desplaçarà d'un nombre al següent.

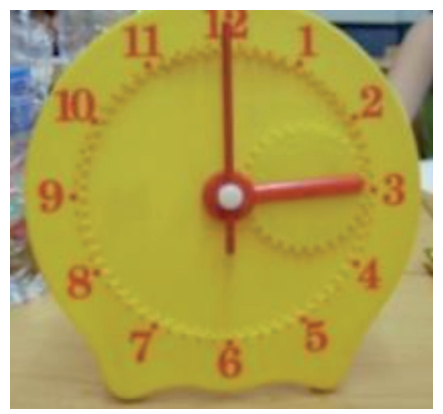

Figura 51. Rellotge d'engranatges (fabricat per Kalmarsund)

Cal aconseguir que identifiquen la durada d'una hora amb el temps que tarda l'agulla llarga en fer una volta completa a l'esfera del rellotge, o la curta en moure's des d'un nombre fins al següent. Representarem simbòlicament l'hora amb una $h$. Relacionat amb les activitats de l'aula, en diferents moments de la jornada escolar, treballarem la lectura, la representació gràfica i l'escriptura literal d'hores en punt (són les 10 hores en punt, són les 4 hores de la vesprada...). Podem utilitzar per ajudar-nos materials com els rellotges escolars de fusta, que consten d'un rellotge gran per al docent $\mathrm{i}$ vint més menuts per a l'alumnat (figura 52).
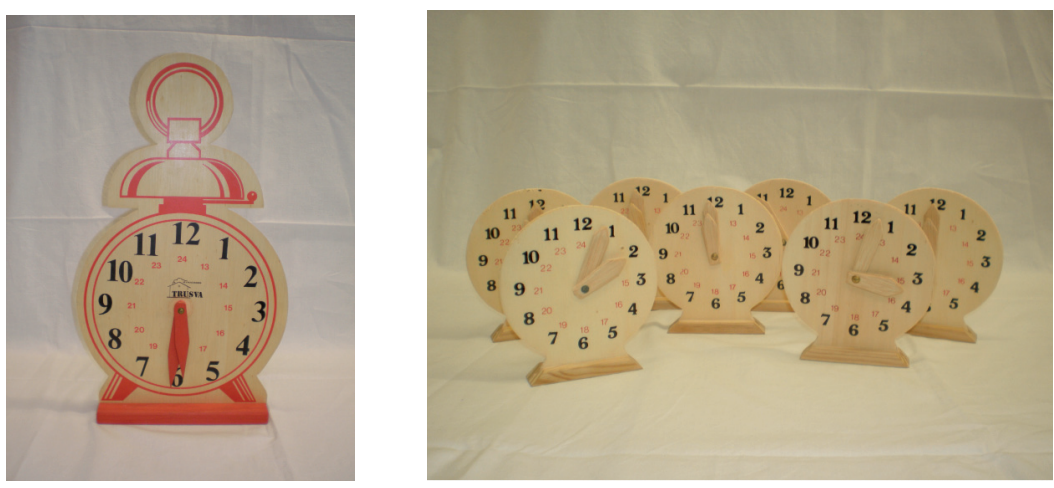

Figura 52. Rellotges escolars de fusta (fabricats per Trusva) 
El procés de coneixement de l'hora va aparellat amb el del dia com un període de 24 hores. Per aquest motiu, caldrà matisar algunes de les representacions horàries treballades fins aquest moment. Com que usualment en els rellotges analògics només s'utilitzen 12 nombres per a indicar les hores, haurem d'expressar d'alguna manera si ens trobem a les primeres dotze hores o a les segones. En un context més familiar o col-loquial, s'expressarà la diferència acompanyant l'hora de les expressions «del matí, de la vesprada o de la nit». En altres contextos (visites mèdiques, transports, espectacles, electrodomèstics...), es fa necessari saber que les hores posteriors a les $12 \mathrm{del}$ mig dia s'indiquen amb els nombres 13, 14... 24. Cal tenir en compte que hi ha rellotges escolars amb la doble numeració (figura 53) per tal d'ajudar-nos a treballar en l'aula les dues possibilitats d'anomenar les hores.

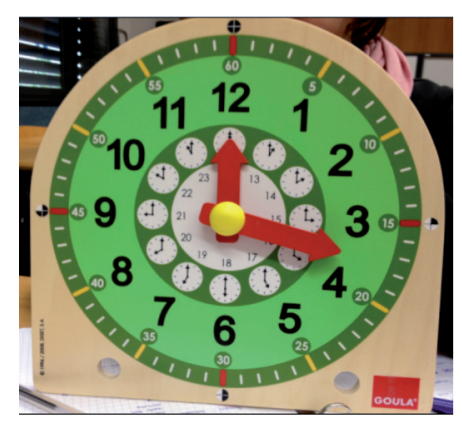

Figura 53. Rellotge escolar (fabricat per Goula)

A partir de conèixer quant dura una hora i treballant la durada del temps en situacions reals (per exemple, esbrinar el temps que passen al pati), poden sorgir preguntes del tipus: i si la agulla llarga fa només una part del recorregut, quant de temps ha passat? És aqueix el moment d'introduir la mitja hora, que s'identificarà amb el temps que tarda l'esmentada agulla en recórrer la meitat de l'esfera del rellotge, representant-la com $1 / 2 \mathrm{~h}$ (anàlogament a les magnituds anteriors) i comprovant la relació d'aquesta amb una hora.

De manera semblant al que s'ha esmentat al cas de l'hora, caldrà treballar la lectura de les mitges hores en el rellotge (són les nou i mitja o són dos quarts de deu), i de nou la seua representació i la seua escriptura, a més d'altres tipus d'expressions quotidianes: hora i mitja, falta mitja hora, després de mitja hora...

Posteriorment, i per la necessitat de mesurar quantitats de temps menors que mitja hora (per exemple, el temps que es dedica a l'esmorzar en el pati), en $2 \mathrm{n}$ curs de primària s'introduirà el quart d'hora, que s'associarà amb el temps que tarda l'agulla llarga en recórrer una de les quatre parts iguals de l'esfera del rellotge. Aquesta nova unitat es representarà per $1 / 4 \mathrm{~h}$ i es relacionarà amb l'hora i la mitja hora.

En la línia de treball de les unitats anteriors, procedirem a la lectura dels quarts d'hora en el rellotge analògic (són les nou i quart), la seua representació gràfica i l'escriptura literal. Cal tenir en compte la dificultat especial que per l'alumnat presenta aquesta nova unitat quan han de expressar que falta un quart d'hora per l'hora en punt següent (són les nou menys quart o són tres quarts de nou). Altres 
tipus d'expressions que treballarem també són: hora i quart, falta un quart d'hora, després de tres quarts d'hora...

Continuant en el coneixement d'unitats de temps menors que les treballades fins ara, $\mathrm{i}$ avançat el $2 \mathrm{n}$ curs de primària, s'introduirà el minut (per exemple, per mesurar el temps que els pot costar cantar una cançoneta). Caldrà utilitzar un rellotge analògic que dispose d'agulla dels segons i identificar el minut amb el temps que tarda aquesta en recórrer una volta completa a l'esfera del rellotge, representant-lo simbòlicament per min. A més d'utilitzar qualsevol rellotge analògic amb agulla dels segons, ens podem ajudar del rellotge gegant (figura 54) que és fàcilment manipulable pels alumnes i permet la instal·lació d'una bateria per a funcionar autònomament.

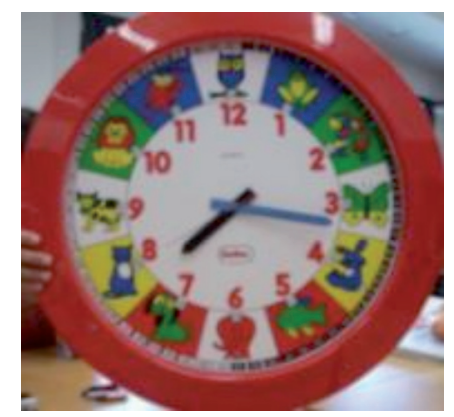

Figura 54. Rellotge gegant (fabricat per HenBea)

També s'ha de treballar la lectura, la representació gràfica i l'escriptura dels minuts en el rellotge analògic (són les nou i cinc minuts, són les nou menys vint minuts), i relacionar aquesta unitat amb l'hora, comprovant en algun dels rellotges esmentats que fan falta 60 minuts per a completar-la, i amb la mitja hora i el quart d'hora:

$$
60 \min =1 \mathrm{~h} \quad 30 \mathrm{~min}=1 / 2 \mathrm{~h} \quad 15 \mathrm{~min}=1 / 4 \mathrm{~h}
$$

Cap al final del $2 \mathrm{n}$ curs o en $3 \mathrm{r}$ de primària cal fixar definitivament la lectura dels minuts en els rellotges analògics i introduir també els rellotges digitals, que utilitzen només els nombres per a representar el temps. Aquests rellotges expressen la informació horària mitjançant dos o tres conjunts de nombres separats per dos punts, a l'esquerra dels quals se situa l'hora, immediatament a la dreta, els minuts i de vegades més a la dreta els segons.

És possible que en un primer moment siguen més senzills d'utilitzar pels xiquets i xiquetes, perquè només han de llegir els nombres. El que no sembla tan evident és que d'aquesta lectura es puga traduir una comprensió correcta del que suposa la fracció d'hora que ha transcorregut en relació als minuts llegits. Aquesta idea la representen molt més clarament els rellotges analògics i és per això que es justifica la seua introducció en l'aula de primària abans que aquests altres.

Es fa necessari llegir les hores en els dos tipus de rellotges, comparant les diferents maneres de representar-les i aconseguint que els xiquets i xiquetes les comprenguen 
i interpreten correctament, insistint especialment en situacions del tipus «són les 6 i 20 minuts del matí» o «són les 6 menys 20 de la vesprada» en el rellotge analògic. La interpretació de les hores ha de funcionar en un sentit (afegint minuts) i en un altre (descomptant minuts). Si el rellotge és digital, aleshores la informació es tradueix en llegir únicament «són les 6:20 h» o «són les 17:40 h». Cal saber les dues maneres d'expressar el temps i relacionar-les. Podem ajudar-nos del dòmino del rellotge digital, que es mostra a la figura 55, en el qual l'alumnat ha d'associar expressions de la mateixa hora en format analògic i digital.

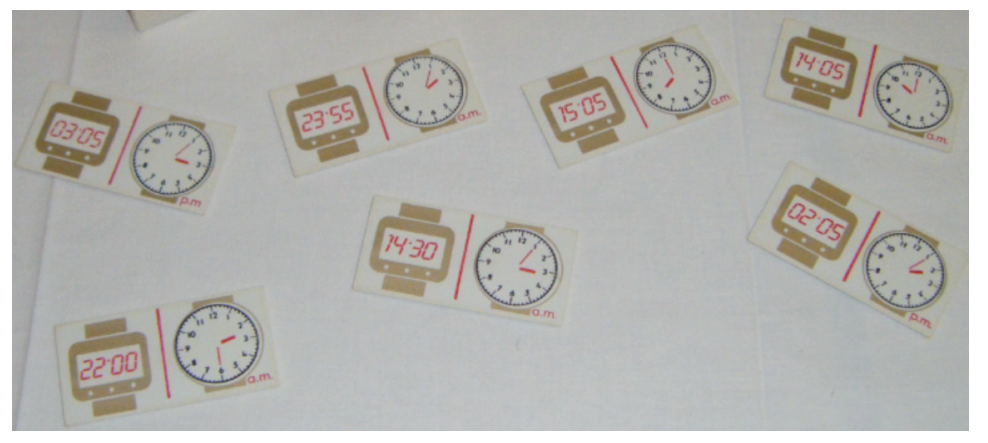

Figura 55. Dòmino del rellotge digital (fabricat per Taskmaster Limited)

De vegades, els rellotges digitals només utilitzen de l'1 al 12 per a representar les 24 hores del dia. En aquest cas els nombres s'acompanyen de dues lletres: a. m. (que es refereixen a les paraules llatines ante meridium), per a representar les primeres 12 hores del dia, o p. m. (post meridium), per a les segones 12 hores. Com que aquesta explicació pot ser un poc complicada per a l'aula de primària, es pot optar per la fórmula següent per tal que puguen comprendre i recordar aquestes expressions:

- Si és abans del migdia: a. m.

- Si és posterior al migdia: p. m.

Seguint amb les unitats que mesuren intervals de temps menors que una hora, avançat el $3 \mathrm{r}$ curs de primària, es presentarà el segon. Amb els rellotges analògics, caldrà utilitzar-ne de nou un que dispose d'agulla dels segons i identificar el segon amb el temps que tarda aquesta agulla en recórrer l'espai entre dues marques dels minuts; mentre que en el digital, un segon serà el temps que tarda el nombre dels segons en canviar al següent. El representarem simbòlicament per s i el relacionarem amb el minut i l'hora:

$$
60 \mathrm{~s}=1 \mathrm{~min} \quad 3600 \mathrm{~s}=60 \mathrm{~min}=1 \mathrm{~h}
$$

Utilitzaran aquesta unitat per tal de mesurar diferents intervals de temps i expressaran verbalment i per escrit els resultats obtinguts i el símbol.

Cal insistir en què aquestes primeres unitats funcionen segons el Sistema Sexagesimal, encara que en les posteriors les hores ja no es relacionen amb els dies amb el mateix sistema, i molt menys els dies i els mesos o els mesos i els anys. 
En 5é de primària i pel seu ús freqüent en el món de l'esport, tan proper moltes vegades a l'entorn de l'alumnat, seria convenient introduir unes noves unitats de mesura del temps: la dècima, la centèsima i la mil-lèsima de segon, imperceptibles per als sentits humans i que resulten de dividir un segon en 10, 100 o 1000 parts iguals respectivament. Aquesta justificació és la que es pot utilitzar per a donar peu a una altra, d'àmbit menys lúdic però totalment necessari, l'ús d'aquestes unitats en el món científic.

La dificultat més important a l'hora de treballar aquestes fraccions de segon es troba en el fet que, a partir dels segons, s'abandona el Sistema Sexagesimal i es funciona amb el Sistema Decimal. Es representen amb xifres decimals de la quantitat de segons. Així:

$$
\begin{aligned}
& 1 \text { dècima }=1 / 10 \mathrm{~s}=0,1 \mathrm{~s} \\
& 1 \text { centèsima }=1 / 100 \mathrm{~s}=0,01 \mathrm{~s} \\
& 1 \text { mil·lèsima }=1 / 1000 \mathrm{~s}=0,001 \mathrm{~s}
\end{aligned}
$$

\section{Expressar mesures de temps de forma complexa. Transformar expressions complexes en incomplexes i a l'inrevés}

El procediment és semblant al treballat anteriorment per a les magnituds longitud, capacitat i massa. La dificultat afegida és la combinació dels Sistemes Sexagesimal i Decimal, per això és un poc més complicat i s'introduirà en els darrers cursos de primària.

A partir d'activitats en les que l'alumnat necessite mesurar intervals de temps i expressar la durada total, podem trobar diferents maneres de representar el temps. En uns casos utilitzarem una sola unitat i en altres més d'una. Serà necessari saber convertir un tipus d'expressions en altre, per tal de poder operar-hi.

Quan calga passar una quantitat de temps expressada de manera incomplexa a complexa, per exemple 3,5832 h, procedirem de la següent manera: com que la unitat utilitzada és l'hora, la part entera del nombre, és a dir 3, serà les hores de l'expressió complexa. La fracció d'hora restant, $0,5832 \mathrm{~h}$, es multiplica per 60 per a esbrinar els minuts i el resultat és 34,992 min. Per tant, en l'expressió complexa ens queden $34 \mathrm{~min}$ i la fracció 0,992 min, es torna a multiplicar per 60 per a saber els segons, amb un resultat de 59,52 s. Aleshores, l'expressió final en forma complexa serà: 3 h 34 min 59,52 s.

$\mathrm{Si}$, pel contrari, disposem d'una quantitat expressada de manera complexa, per exemple 3 h 43 min 26,76 s i volem expressar-la com incomplexa, procedirem ara de la següent manera: si es tria l'hora com a unitat de la manera incomplexa, el que cal fer és expressar totes les quantitats en hores. Per això serà necessari dividir, d'acord amb la corresponent relació entre les diferents unitats. Així, per a calcular quants minuts són $26,76 \mathrm{~s}$, els dividirem entre 60 , obtenint 0,446 min. Al sumar aquesta quantitat als minuts que ja hi havia, el resultat és 43,446 min. Al dividir aquest nombre entre 60 , obtenim $0,7241 \mathrm{~h} \mathrm{i}$, per tant, l'expressió final serà $3,7241 \mathrm{~h}$. 
En el cas que la unitat triada no siga l'hora, caldrà adaptar les operacions a les necessitats de conversió d'unes unitats en altres.

A la vegada que es realitzen tots aquests càlculs, s'insistirà molt en el fet que l'expressió decimal no es transforma de manera directa en la sexagesimal, i així $2,5 \mathrm{~h}$ no és 2 h i 50 min, sinó dues hores i mitja o 2 h 30 min.

\section{Reconèixer i utilitzar les unitats de temps: dia, setmana, mes i any}

Paral·lelament a l'estudi realitzat amb l'hora i les unitats derivades que acabem de veure, hi ha un altre que, començant en el dia, recorre la setmana i el mes, finalitzant en l'any.

Respecte del dia i encara que són difícils per aquesta etapa, ja han treballat en educació infantil els conceptes d'ahir, avui i demà, que prenen com a referència pel canvi de dia el moment d'alçar-se del llit. El que cal, pel 1r curs de primària, és identificar el dia amb un període de 24 hores i traslladar el punt de referència del nou dia a les $0 \mathrm{~h}$, perfeccionant el coneixement dels esmentats conceptes. Com que aquesta és una hora en la qual l'alumnat no està en l'escola, es fa necessari sol-licitar l'ajuda de les famílies per a què algun cap de setmana puguen romandre desperts fins veure en un rellotge el canvi d'hora i de dia (podríem aprofitar per recordar el moment de les campanades de la Nit de cap d'any o el de banyar-se els peus en la mar la Nit de Sant Joan).

Les 24 hores d'un dia corresponen al temps aproximat que tarda la Terra en donar una volta sobre si mateixa. Es relacionarà aquest període de temps amb dues voltes completes de la agulla horària del rellotge analògic $i$, per tant, en 24 voltes de la minutera. Per visualitzar la representació social dels dies utilitzarem els calendaris, en els que cada dia té assignat un nombre distint, que ens dona la data associada.

El seguit de dies ens portarà de manera natural a la setmana. Haurem d'arribar a la idea de setmana com un període de set dies, de dilluns a diumenge, cinc dels quals són escolars i dos no escolars, sabent que de vegades hi ha algun dia festiu entre els escolars. Cadascun dels dies de la setmana té un nom, que cal aprendre i amb el seu ordre correcte.

Quan estiga clara la composició de la setmana i la seua durada, és important també que l'alumnat reconega com una setmana qualsevol període de set dies seguits, sense que siga necessari començar pel dilluns.

Continuant amb la introducció de les diferents unitats de mesura del temps, arribarem al mes, sent conscients que és una unitat de temps no constant. Haurem de treballar els noms, l'ordre i la durada dels mesos, prestant especial atenció al febrer que és diferent a tots. 
Per tal de finalitzar amb aquestes unitats de temps en $2 \mathrm{n}$ curs de primària, estudiarem l'any, identificant-lo amb un període de 12 mesos, que van de gener fins a desembre i diferenciant els bixestos dels no bixestos, segons la durada del mes de febrer. Per poder justificar a l'alumnat l'existència d'aquests anys de durada diferent, caldrà fer referència al fet que l'any és el temps aproximat que tarda la Terra en recórrer la seua òrbita al voltant del Sol, produint-se un desajust en els 365 dies que s'arregla cada quatre anys amb un bixest o de traspàs, en el que el mes de febrer té 29 dies.

De manera anàloga al cas de la setmana, quan estiga clara la composició i durada dels mesos i dels anys, és important també que l'alumnat reconega un mes com qualsevol període comprés entre dues dates iguals de mesos consecutius i, com un any, qualsevol període de 12 mesos o 365 dies seguits.

Aquestes unitats de mesura del temps resulten prou fàcils de treballar, pel costum diari de posar la data en l'aula al començament de la jornada escolar i per la necessitat habitual de situar en el temps la majoria dels fets quotidians: activitats de l'aula, excursions, deures escolars, festes, visites familiars, etc.

Podem completar el coneixement de l'any amb l'estudi de les estacions, treballant les característiques i fets socials importants de cadascuna d'elles (Nadal, les Falles, La Magdalena, Pasqua, vacances d'estiu...) a més de la seua durada i situació al llarg del mateix.

Com material d'ajuda per a treballar les unitats no horàries, podem utilitzar qualsevol calendari mensual/anual o el calendari magnètic de la figura 56, que recull informació referent a setmanes, mesos, estacions, any i on es poden assenyalar dates que es consideren importants.

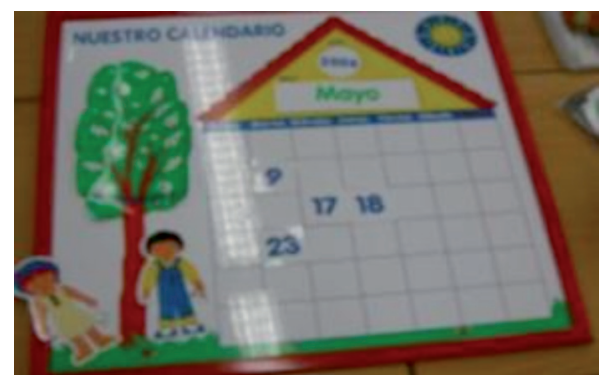

Figura 56. Calendari magnètic (fabricat per HenBea)

\section{Realitzar mesuraments i transports d'angles}

Des de 3r curs i dins del bloc de Geometria s'ha treballat el concepte d'angle a partir de la manipulació i construcció, de la definició intuïtiva, del dibuix i de la classificació d'aquests (prenent com a referència l'angle recte). 
En 5é curs s'inicia el treball de quantificació dels angles, buscant activitats que facen necessari mesurar-los: dibuixos, maquetes, construccions geomètriques... Aquestes activitats exigeixen la mesura d'una nova magnitud, l'amplitud angular i, per tant, es necessita una nova unitat, el grau sexagesimal, que es defineix com l'amplitud de l'angle que resulta de dividir l'angle recte en 90 parts iguals. Es representa per un zero de reduïdes dimensions, situat en posició exponencial a la dreta del nombre que indica la quantitat de graus.

Per tal de poder mesurar aquesta nova magnitud, s'utilitza el transportador d'angles o goniòmetre (figura 57). És un regle format, usualment, per un semicercle o semicorona circular que es recolza a sobre del diàmetre major, graduat en graus sexagesimals de $0^{\circ}$ fins a $180^{\circ}$. En l'esmentat diàmetre hi ha una marca central on es col-loca el vèrtex de l'angle a mesurar, fent coincidir el zero amb un dels seus costats. L'altre costat indicarà, en la graduació creixent, la quantitat de graus que mesura l'angle.

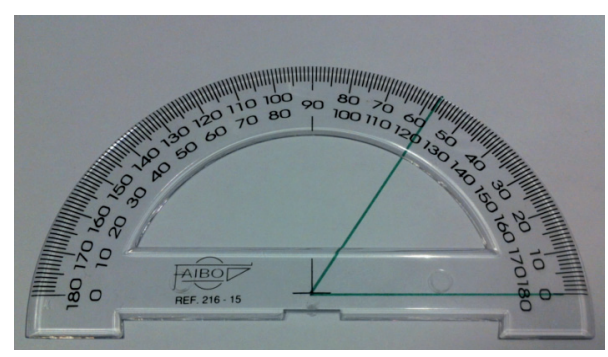

Figura 57. Transportador d'angles (fabricat per Faibo)

Una vegada conegut, simbolitzat, utilitzat i assolit el grau, s'estudien els seus submúltiples, com el minut i el segon sexagesimals, que són les unitats que sorgeixen al dividir, respectivament, el grau o el minut en 60 parts iguals. Se simbolitzen escrivint una o dues cometes a la dreta del nombre en posició exponencial.

És molt complicat trobar activitats que necessiten minuts i segons sexagesimals, perquè tornen a ser, de la mateixa manera que les dècimes i les centèsimes de segon, imperceptibles per als sentits humans. Caldrà dir, sense insistir-hi massa, que hi ha àmbits de la ciència que necessiten aquestes unitats i per això hem de conèixer-les.

Aquesta no és l'única manera de mesurar angles. També es pot utilitzar el Sistema Centesimal (totes les divisions són en 100 parts) i el Sistema Circular (utilitza el radian) però no es veuen en Educació primària. 


\section{Introduir la mesura de superfícies i volums mitjançant quadrats i cubs, respectivament}

Les magnituds estudiades en les capacitats anteriors són lineals. Això implica que cal considerar només una dimensió que haurem de mesurar amb la corresponent unitat. Per a completar l'estudi de les magnituds i la mesura en Educació primària introduirem altres magnituds que depenguen de més d'una dimensió: en $4 \mathrm{t}$ curs la superfície i en 6é, el volum.

Des d'Educació Infantil i, dins del bloc de Geometria, en 1r i 2n curs de primària, ja tenen una idea de superfície i volum. Han estudiat diferents tipus de superfícies: llises, rugoses, obertes, tancades, planes, corbes... i han diferenciat entre la superfície d'un cos i l'espai que aquest ocupa (idea intuïtiva de volum). Ens interessaran ara les superfícies que són planes i que ens conduiran, de manera senzilla, al concepte d'àrea, i els cossos de cares planes i paral·leles dues a dues, que ens portaran al de volum.

Per tal d'arribar a la necessitat de mesurar superfícies, en un primer moment, proposem situacions problemàtiques que impliquen comparacions. Aquestes situacions es poden resoldre de diferents maneres: directament (comparant dues o més superfícies visualment o per superposició), per descomposició (fraccionant les superfícies i comparant-les) o finalment mesurant. Ens interessa arribar a aquest tercer procediment per a treballar el concepte de mesura de superfície amb les unitats d'aquesta.

Partirem d'una situació real, per exemple: «Els alumnes d'una classe volen confeccionar un mural al panell de suro de l'aula, que és prou gran. Com que és incòmode treballar amb el panell a la paret, han pensat recolzar-lo a sobre de la taula del professor. No saben si cabrà i volen saber-ho abans de despenjar-lo». L'alumnat s'organitza en grups i cadascun pensa com solucionar el problema.

Inicialment, és probable que es fixen sols en una de les dimensions de la taula $\mathrm{i}$ del panell, mesurant-la i comparant-la. Així poden arribar a la conclusió que cap o no cap, només en funció de l'altura o de l'amplària del panell. El fet que un grup d'alumnes considere una de les dimensions i un altre grup l'altra, provocarà una discussió entre ells. S'ha d'orientar aquest diàleg per a ajudar-los a arribar a la conclusió que és necessari considerar les dues dimensions a la vegada. Se'ls demana que pensen alguna manera de comparar les dues superfícies.

Davant aquest dubte, normalment intenten fer un recobriment de les dues superfícies amb algun element pla que en aquell moment consideren com unitat (paper, cartolina...) i comptabilitzar els objectes que han necessitat per a cobrir l'una i l'altra.

En situacions semblants i a partir de la utilització d'unitats de diferents formes (rectangles, triangles, cercles, quadrats...), caldrà arribar a la conclusió que serà un element quadrat el que millor recobreix les superfícies a mesurar. Aquestes activitats poden costar temps, però és important dedicar-los el necessari per a aconseguir una 
construcció mental adequada del concepte de mesura d'una superfície i de les unitats d'aquesta. Una vegada trobada la necessitat que les unitats siguen superfícies quadrades, podem utilitzar-ne de diferents grandàries per a mesurar una mateixa superfície, comprovant que, en cada cas, el resultat és diferent, de manera anàloga al que ocorria amb la longitud, la capacitat i la massa. Amb això conclourem que necessitem una unitat patró, que treballarem en la capacitat següent.

Seguint un procediment semblant $i$ en situacions on es necessite comparar el volum de dos objectes (per exemple, saber si els paquets de fulls que tenim en una caixa que està trencant-se ens cabran en una altra nova que no té la mateixa forma que l'anterior i no sabem si manté la grandària), arribarem a les unitats de forma cúbica com les adequades per a mesurar volums i a la necessitat d'introduir una unitat patró per a aquesta magnitud.

\section{Introduir el metre quadrat, el metre cúbic i els respectius submúltiples i múltiples. Utilitzar-los per a mesurar superfícies planes i volums molt senzills}

Com a conseqüència de la darrera capacitat, introduirem les primeres unitats de mesura de superfície cap al final de $4 \mathrm{t}$ curs i les completarem durant 5é i 6é de primària. Aquestes es presentaran com quadrats, les longituds dels costats dels quals siguen les diferents unitats de mesura de la longitud. Per exemple, el centímetre quadrat serà un quadrat de costat un centímetre. A més del centímetre quadrat, iniciarem aquest treball amb el metre quadrat i el decímetre quadrat.

L'ordre d'aparició d'aquestes tres unitats estarà en funció de les situacions reals amb les quals iniciem el seu estudi: mesurar la superfície de l'aula, del pati, d'un llibre, d'una taula... Per a cadascuna de les activitats caldrà construir amb paper, cartolina... almenys la quantitat aproximada de cada unitat quadrada per tal de recobrir el que es vol mesurar. Hi ha pocs instruments de mesura de superfície adients en el mercat i, si no es disposa d'ells, és convenient crear-los en l'aula de primària en aquest moment inicial per a ajudar als xiquets i xiquetes a fer els mesuraments i a construir la imatge mental d'aquestes unitats. En la figura 58 es mostren les peces del metre cúbic descomponible que també es pot utilitzar per a construir metres quadrats.

Una vegada introduïda cada unitat i el seu nom, presentarem el símbol, en aquests casos $\mathrm{cm}^{2}, \mathrm{~m}^{2} \mathrm{o} \mathrm{dm}{ }^{2}$. Les utilitzarem per a mesurar diferents superfícies i les compararem entre sí (principalment amb el metre quadrat, que és la unitat central de la magnitud superfície) per a deduir les següents relacions:

$$
10.000 \mathrm{~cm}^{2}=1 \mathrm{~m}^{2} \quad 100 \mathrm{dm}^{2}=1 \mathrm{~m}^{2} \quad 100 \mathrm{~cm}^{2}=1 \mathrm{dm}^{2}
$$

S'introdueix un nou submúltiple del metre quadrat per tal de completar les unitats més menudes que aquest i a partir de la necessitat, en algun camp científic, de 
mesurar superfícies menors que el centímetre quadrat. Serà aquesta el mil·límetre quadrat i el seu símbol és $\mathrm{mm}^{2}$. Amb ajuda del paper mil·limetrat, per exemple, s'establiran les seues relacions amb les altres unitats de superfície estudiades, comprovant que:

$$
100 \mathrm{~mm}^{2}=1 \mathrm{~cm}^{2} \quad 10.000 \mathrm{~mm}^{2}=1 \mathrm{dm}^{2} \quad 1_{1} 000.000 \mathrm{~mm}^{2}=1 \mathrm{~m}^{2}
$$

Anàlogament a les magnituds longitud, capacitat i massa, podrem expressar els submúltiples del metre quadrat utilitzant les fraccions i els nombres decimals de la manera següent:

$$
\begin{aligned}
& 1 \mathrm{dm}^{2}=0,01 \mathrm{~m}^{2}=\frac{1}{100} \mathrm{~m}^{2} \\
& 1 \mathrm{~cm}^{2}=0,0001 \mathrm{~m}^{2}=\frac{1}{10000} \mathrm{~m}^{2} \\
& 1 \mathrm{~mm}^{2}=0,0000001 \mathrm{~m}^{2}=\frac{1}{\mathbf{1}_{\mathbf{1}} \mathbf{0 0 0 0 0 0}} \mathrm{m}^{2}
\end{aligned}
$$

i entendre el decímetre quadrat, el centímetre quadrat i el mil·límetre quadrat com el resultat de dividir un metre quadrat en 100, 10.000 o 1,000.000 de parts iguals, respectivament.

Quan les superfícies que necessiten mesurar són molt més grans que un metre quadrat, es fa necessari introduir noves unitats majors que aquest (expressar la superfície d'un país, d'un desert, d'un llac...). El quilòmetre quadrat és el múltiple més utilitzat en aquests casos. Equival a un quadrat d'un quilòmetre de costat i el seu símbol és $\mathrm{km}^{2}$. Per a completar l'escala d'unitats amb una estructura semblant $\mathrm{a}$ altres magnituds introduirem la resta de múltiples: decàmetre quadrat $\mathrm{i}$ hectòmetre quadrat, que se simbolitzen amb dam ${ }^{2} \mathrm{i} \mathrm{hm^{2 }}$. Les equivalències amb el metre quadrat són:

$$
1 \mathrm{dam}^{2}=100 \mathrm{~m}^{2} \quad 1 \mathrm{hm}^{2}=10.000 \mathrm{~m}^{2} \quad 1 \mathrm{~km}^{2}=10_{1} 000.000 \mathrm{~m}^{2}
$$

Per tal de reforçar aquestes unitats i veure la seua utilització en contexts reals, podrem demanar a l'alumnat que esbrine la mesura de la superfície del seu poble, comarca, província, etc.

La magnitud superfície té un sistema propi d'unitats de mesura, que introduirem en l'aula de primària pel seu ús agrari i forestal. La unitat fonamental d'aquest sistema és l'àrea, que equival a la superfície d'un quadrat de deu metres de costat i, per tant, a un decàmetre quadrat. El símbol és a. És més coneguda l'hectàrea, únic múltiple de l'anterior unitat, que equival a la superfície d'un quadrat de cent metres de costat, per tant, a un hectòmetre quadrat i que té per símbol ha. L'únic submúltiple de l'àrea és la centiàrea amb símbol ca, que equival a la superfície d'un quadrat d'un metre de costat, és a dir, a un metre quadrat, amb les següents relacions:

$1 \mathrm{ca}=1 \mathrm{~m}^{2}=0,01 \mathrm{a} \quad 1 \mathrm{a}=100 \mathrm{~m}^{2}=1 \mathrm{dam}^{2} \quad 1 \mathrm{ha}=10.000 \mathrm{~m}^{2}=100 \mathrm{a}=1 \mathrm{hm}^{2}$ 
De tot l'esmentat al voltant de la superfície es dedueix que les diferents unitats d'aquesta magnitud es relacionen de 100 en 100, a diferència del que ocorria amb la longitud, el que resulta prou evident si tenim en compte el caràcter lineal d'aquesta magnitud en front de la consideració bidimensional de la superfície.

En 6é curs de primària $i$ en situacions on es necessite mesurar el volum d'algun objecte, lloc o recipient (caixa, cub, piscina...) arribarem a les unitats d'aquesta magnitud amb el metre cúbic $\left(\mathrm{m}^{3}\right)$ com a unitat central, que es defineix com el volum d'un cub d'un metre d'aresta. És important poder realitzar en classe el muntatge de l'esmentada unitat amb pals d'un metre de llargària i peces que actuen de vèrtexs, per a que l'alumnat veja com és de gran i puga fer-se una idea del metre cúbic més ajustada a la realitat que la que li proporciona la definició. Podem ajudar-nos de material comercialitzat com el que es mostra a la figura 58.

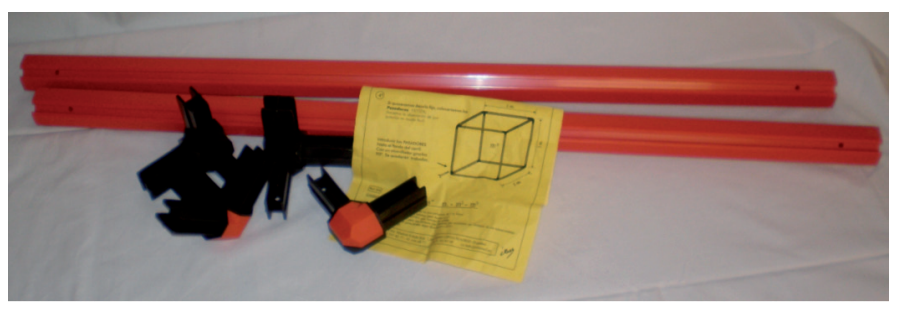

Figura 58. Metre cúbic desmuntable (fabricat per Lado)

La resta d'unitats de volum, múltiples i submúltiples del metre cúbic, es presenten davant la necessitat de mesurar volums majors o menors que aquest. Seguint el mateix esquema que amb les altres magnituds, aquestes unitats seran: decímetre cúbic, centímetre cúbic i mil·límetre cúbic com a submúltiples, i decàmetre cúbic, hectòmetre cúbic i quilòmetre cúbic com a múltiples. Respectivament, els símbols seran $\mathrm{dm}^{3}, \mathrm{~cm}^{3}, \mathrm{~mm}^{3}$ i dam ${ }^{3}, \mathrm{hm}^{3}, \mathrm{~km}^{3}$ i es relacionen de 1.000 en 1.000, podent-se comprovar de manera experimental amb el metre cúbic, el decímetre cúbic i el centímetre cúbic. En la figura 59 es presenta el decímetre cúbic descomponible, que permet visualitzar les relacions entre aquesta unitat i el centímetre cúbic.

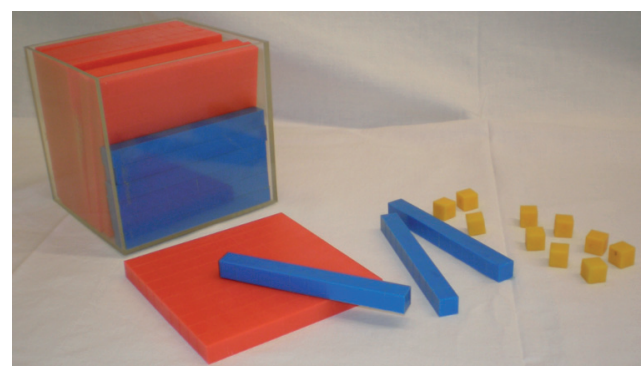

Figura 59. Decímetre cúbic descomponible (fabricat per Nes Arnold)

De totes aquestes unitats, les més fàcilment manipulables són el decímetre cúbic i el centímetre cúbic. La més freqüent en envasos que quotidianament estan a l'abast de l'alumnat és el centímetre cúbic que, de vegades, apareix simbolitzat incorrectament per cc, en lloc de $\mathrm{cm}^{3}$. Cal treballar aquesta representació amb els 
xiquets $\mathrm{i}$ xiquetes per a poder associar-la correctament a la unitat corresponent $\mathrm{i}$ evitar confusions amb el centilitre (cl).

Es pot estudiar, a més, la relació entre les unitats de capacitat i de volum, comprovant amb diversos recipients que un decímetre cúbic equival a un litre, així com que un centímetre cúbic equival a un mil-lilitre: $1 \mathrm{dm}^{3}=1 \mathrm{~L} \mathrm{i} 1 \mathrm{~cm}^{3}=1 \mathrm{ml}$.

\section{Esbrinar les unitats adequades per a mesurar quantitats de diferents magnituds. Realitzar estimacions d'algunes quantitats d'aquestes magnituds}

Aquesta capacitat s'ha de treballar al llarg de tota l'etapa com a complement de les anteriors, perquè s'ha de distingir i clarificar les paraules magnitud, unitat i mesura. I, potser, no pel nom, però sí pels fets. És a dir, s'ha d'establir un protocol segons el qual abans de realitzar un mesurament, caldrà que l'alumnat es faci les preguntes següents:

1. Què he de mesurar? Aquesta pregunta connecta directament amb la idea de magnitud. És a dir, he de mesurar longitud, massa, capacitat, superfície, etc.? És important que aquesta distinció estiga clara.

2. Per tant... amb quina unitat? En qualsevol cas, hauré d'adequar la unitat a la quantitat que mesuraré.

3. Quantes vegades? És el moment de mesurar les quantitats i, per tant, he d'indicar el nombre de vegades que he utilitzat la unitat triada.

També és important desenvolupar la capacitat d'estimació. Abans de calcular la mesura exacta d'una quantitat caldria que l'estimaren aproximadament, escrivint tot allò que pensen i que siga útil per a poder, després, incidir sobre les errades per tal de millorar l'estimació i la imatge mental de les diferents unitats.

\section{Utilitzar amb soltesa instruments de mesura}

Es treballa conjuntament amb totes les capacitats anteriors perquè, al temps que van comprenent $\mathrm{i}$ estudiant les unitats, van utilitzant instruments de mesura. Cal que tinguen cura i presten atenció al que estan fent.

Es pretén reforçar l'ús dels esmentats instruments, amb els detalls particulars d'aquests (fiabilitat, facilitat d'ús, seguretat...) i amb total correcció a l'hora de prendre la mesura. Hem d'aconseguir que siguen responsables en la cura del material, en la presa de dades correcta, en la coherència amb el que s'està mesurant $i$ en la transcripció correcta al paper. 


\section{Descobrir les expressions per a calcular les àrees de figures planes senzilles}

En 6é curs i una vegada s'ha fet l'estudi de les unitats de superfície, cal fer un treball un poc més abstracte per descobrir expressions que ens permetan calcular l'àrea d'un quadrat, d'un rectangle i d'un triangle.

Per al cas del rectangle podem ajudar-nos dels acetats centimetrats (figura 60).

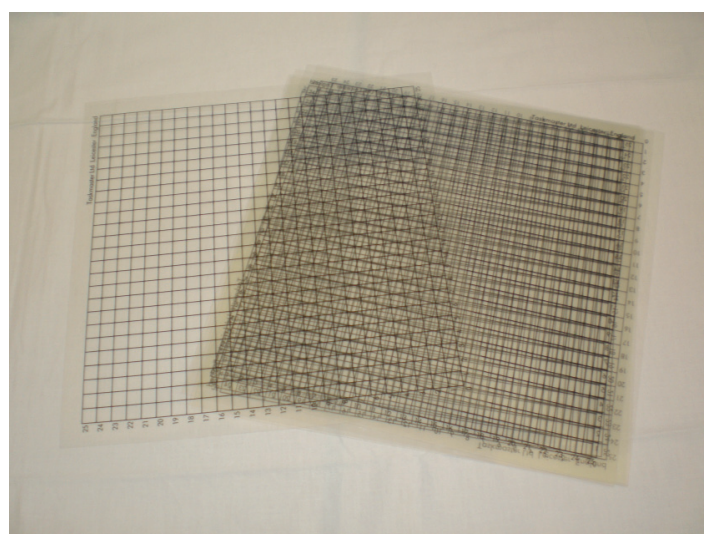

Figura 60. Acetats centimetrats (fabricats per Taskmaster Ltd.)

Es tracta de calcular l'àrea de vàries d'algunes figures (que haurem preparat i que tindran nombres enters com a longitud dels costats), superposant la quadrícula de l'acetat i comptabilitzant els centímetres quadrats que la recobreixen. En cada ocasió cal mesurar també els dos costats diferents de les figures i anotar-ho, formant així una taula en la qual, per a cada figura, tindrem el valor de l'àrea en una columna $\mathrm{i}$ les mesures dels costats en altra. Al final els demanem que troben una relació entre les dues columnes fins que arriben a concloure que la multiplicació de les longituds dels dos costats diferents dóna com a resultat el valor de l'àrea. L'enunciat geomètric d'aquesta conclusió serà «l'àrea del rectangle és igual al producte de la longitud de la base per la de l'altura».

Com a conseqüència immediata, el valor de l'àrea d'un quadrat es calcularà multiplicant la longitud d'un costat per ella mateixa.

Com ampliació de l'estudi de l'àrea d'un rectangle podem treballar la d'un parallelogram qualsevol, per exemple 1'ABCD de la figura 61 .

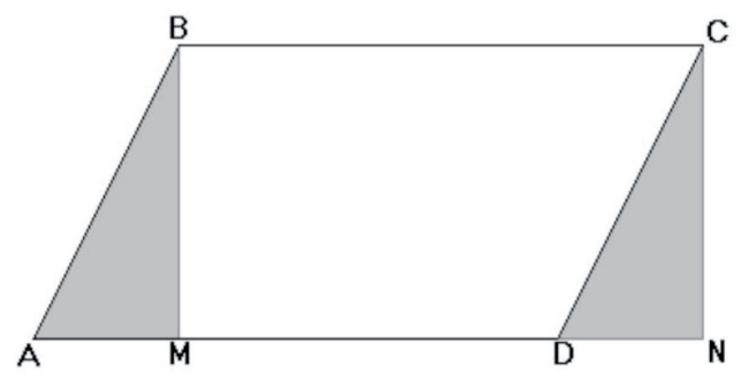

Figura 61. Representació gràfica per calcular l'àrea d'un paral·lelogram 
Per tal de calcular l'àrea d'aquest paral·lelogram, el transformarem en un rectangle tallant i traslladant el triangle $\mathrm{ABM}$ a la posició $\mathrm{DCN}$, amb la qual cosa obtindrem el rectangle $\mathrm{MBCN}$, que té la mateixa quantitat de superfície que el parallelogram inicial; per tant, tindrà la mateixa àrea. És evident que el rectangle i el paral·lelogram tenen la mateixa longitud per base i la mateixa longitud per altura. Com saben calcular l'àrea del rectangle, multiplicant la longitud de la base per la de l'altura, serà la mateixa expressió la que permetrà calcular, d'ara en endavant, l'àrea d'un paral·lelogram.

Al cas de l'àrea d'un triangle, dividirem entre dos la del paral·lelogram. El motiu és evident, la diagonal d'un paral·lelogram genera sempre dos triangles iguals, l'àrea dels quals és la meitat de la del paral·lelogram (figura 62). Així, per calcular l'àrea d'un triangle, caldrà «multiplicar la longitud de la base per la de l'altura i dividir el resultat entre dos».
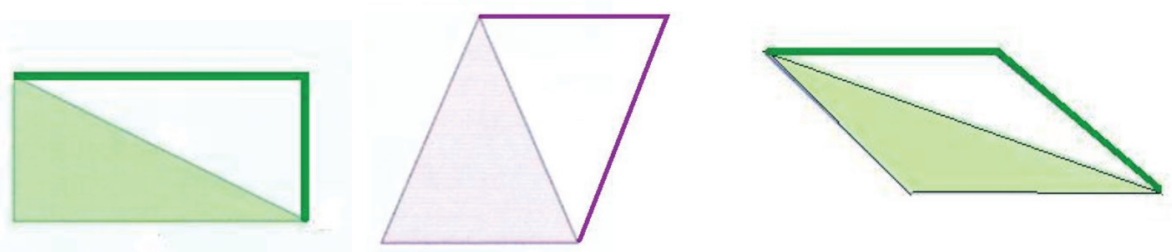

Figura 62. Representacions gràfiques per calcular àrees de triangles

\section{Aplicar els coneixements sobre magnituds i mesura per a resoldre i inventar problemes}

Aquesta capacitat no s'aconsegueix de manera aïllada, ni tampoc només quan estiguen assolides totes les anteriors. Anirà treballant-se a mesura que s'estudie cadascuna de les magnituds desenvolupades al llarg del tema, amb la finalitat que siguen conscients del que han aprés, és com un recordatori. S'entenen també com a problemes les activitats inicials que plantegen els primers interrogants necessaris per tal d'introduir un nou concepte, en aquest cas, de magnituds i mesura, a més de totes les emmarcades en situacions quotidianes que els generen preguntes relacionades amb aquests continguts.

En qualsevol cas, una vegada estiga introduïda cadascuna de les magnituds amb les unitats i relacions corresponents, s'ha de treballar la resolució de problemes relacionats amb ella, com a complement de les activitats experimentals que s'ha desenvolupat en les capacitats anteriors.

Anàlogament al tema dels nombres racionals, realitzarem aquesta tasca en el marc de les quatre fases de Polya (comprendre el problema, elaborar un pla, executar el pla i examinar la solució obtinguda) i reflexionant amb l'alumnat sobre la importància, desenvolupament i utilitat de cadascuna d'elles. 
Aprofitarem els errors que puguen sorgir per reflexionar amb els nens i potenciar noves situacions d'aprenentatge. És molt important diferenciar entre els errors experimentals de mesurament, els de càlcul i els errors de raonament ja que exigeixen mètodes diferents per al seu tractament.

Desenvoluparem aquest treball en tots els cursos de l'etapa, respectant en cadascun d'ells els nivells cognitius de l'alumnat respecte dels nombres naturals, racionals i sobre les operacions entre ells.

L'alumnat ha de treballar també la invenció de problemes relacionats amb aquests conceptes. El que es pretén és comprovar si són capaços de generar situacions que es resolguen amb ells. La tasca d'inventar problemes serà posterior al de resoldre'ls. No els demanarem mai que inventen un problema d'un tipus que encara no s'haja resolt.

Cada vegada que els proposem la invenció d'un tipus nou de problemes recorrerem els passos següents, que es troben seqüenciats per nova dificultat, independentment del curs en què es trobem:

- Amb ajudes:

- Els donarem els nombres, les magnituds, el context i/o les operacions que intervenen en la situació.

- Els donarem els nombres, les magnituds, i/o les operacions, però no el context.

- Sense ajudes: els donarem sols els tipus de nombres, les magnituds i/o les operacions que han d'aparèixer en la situació problemàtica.

Després d'inventar les situacions problemàtiques, les intercanvien amb els companys per a què cap xiquet o xiqueta resolga la que ha inventat, amb la finalitat de potenciar la seua capacitat tant de redacció com d'expressió matemàtica, que implicarà l'exigència de claredat $i$ de totalitat en dades i incògnites. 


\section{ANNEX}

Presentem a continuació alguns conceptes bàsics de la teoria de conjunts, necessaris per a fonamentar els continguts referents als nombres naturals que es treballen en aquesta publicació. No són objecte d'estudi per als futurs Mestres, però tenen la finalitat de facilitar la seua consulta, als lectors que ho necessiten.

\section{Formalització de conceptes de Teoria de Conjunts}

La teoria de conjunts és l'encarregada de simbolitzar el llenguatge matemàtic. És per això que formant conjunts expressem alguns conceptes que composen el currículum escolar i afavorim el seu aprenentatge.

Presentem a continuació una breu formalització dels conceptes de la Teoria de Conjunts, necessaris per treballar els continguts d'aquesta publicació.

\subsection{Introducció}

El concepte de conjunt és intuïtiu i es podria entendre com «una agrupació d'elements feta amb qualsevol criteri». El criteri pot no ser una propietat característica comuna, sinó simplement el desig o la necessitat d'agrupar certs elements. Així, podem parlar d'un conjunt de persones, de ciutats, de bolígrafs, o del conjunt d'objectes que hi ha en un moment determinat damunt d'una taula.

Un conjunt està ben determinat si se sap si un element donat pertany o no al conjunt; així, el conjunt dels bolígrafs blaus està ben definit, perquè en veure un bolígraf podem saber si és blau o no. El conjunt de les persones altes no està ben definit, perquè, en veure una persona, no sempre es podrà dir si és alta o no, o poden haver-hi diferents persones que opinen si eixa persona és alta o no ho és.

Els conjunts es representen, normalment, amb una lletra majúscula: $A, B, K \ldots$

Anomenarem element cadascun dels objectes (físics o abstractes) que formen part d'un conjunt. Aquests elements tenen caràcter individual, qualitats que ens permeten diferenciar-los i cadascun d'ells és únic, de manera que no hi ha elements duplicats o repetits. Els representarem generalment amb una lletra minúscula: $a, b, k \ldots$

Es defineix cardinal d'un conjunt com «la quantitat d'elements que hi ha en el conjunt». 
S'anomena conjunt universal o referencial, que habitualment representarem amb la lletra $\boldsymbol{U}$, el conjunt de totes les coses de les quals s'estiga tractant; així, si parlem de nombres naturals, $\boldsymbol{U}$ és el conjunt dels nombres naturals; si parlem de ciutats, $\boldsymbol{U}$ és el conjunt de totes les ciutats; aquest conjunt universal pot esmentar-se explícitament $\mathrm{o}$, en la majoria dels casos, es dóna per conegut atès el context que s'estiga treballant.

Sempre ha estat molt utilitzada la idea de conjunt al llarg de la història, en qualsevol representació o explicació matemàtica. Però no serà fins el segle XIX quan se li atorgarà rigor. En aquest segle, Cantor posa les bases per la construcció de la Teoria de Conjunts: definicions, introducció a cardinals, conjunt ben ordenat...

Apareixen escletxes en aquesta teoria, com ara la paradoxa de Russell, que sorgeix quan se suposa un conjunt $\mathbf{A}=\{\mathbf{C}$ conjunts / $\mathbf{C} \notin \mathbf{C}\}$, a partir del qual es fa la pregunta de la pertinença d'A a sí mateix, és a dir ¿ $\mathbf{A} \in \mathbf{A}$ o $\mathbf{A} \notin \mathbf{A}$ ?La resposta ens du a la conclusió que $\mathbf{A} \in \mathbf{A} \leftrightarrow \mathbf{A} \notin \mathbf{A}$, que constitueix la paradoxa esmentada.

Per tal de resoldre aquests problemes de la teoria de conjunts es creen els sistemes axiomàtics corresponents (són conjunts d'afirmacions admeses com a vertaderes sense necessitat de demostració) i així tenim els de Zermelo-Frenkel, els de Newman...

\subsection{Conjunts}

En aquest apartat es fa un recorregut per alguns conceptes (operacions, relacions...) que es poden definir en relació als conjunts.

\subsubsection{Definicions i conceptes bàsics}

Com s'ha esmentat al punt anterior, s'admet la idea de conjunt com l'agrupació en un tot de determinats objectes ben caracteritzats i diferenciats els uns dels altres.

- Conjunts iguals: aquells que, element a element, són iguals.

- Determinacions d'un conjunt:

- Per comprensió: explicitant la propietat característica dels seus elements.

- Per extensió: enumerant, un per un, tots els elements que el composen.

- Representacions d'un conjunt:

- Representació gràfica: diagrama lineal, diagrama de Venn (línia corba tancada que delimita els elements del conjunt) o qualsevol altra línea tancada.

- Representació simbòlica: com s’ha esmentat abans, s'utilitzaran lletres en minúscula per tal de representar els elements d'un conjunt $i$ en majúscula per a representar els conjunts. 
- Subconjunts: $\mathbf{A} \subset \mathbf{C} \leftrightarrow \forall \mathbf{a} \in \mathbf{A} \rightarrow \mathbf{a} \in \mathbf{C}$

- Conjunt universal o referencial: es representa amb la lletra $\boldsymbol{U}$.

- Conjunt complementari d'un subconjunt:

$\mathbf{A} \subset \mathbf{U}: \mathbf{A}_{\mathbf{U}}{ }^{\mathbf{c}}=\{\mathbf{x} \in \mathbf{U} / \mathbf{x} \notin \mathbf{A}\}$

- Conjunt buit: $\phi$, aquell que no té cap element.

- Conjunt de parts d'un conjunt: és un conjunt que està format per tots els subconjunts d'un conjunt donat, és a $\operatorname{dir}: P(A)=\{B / B \subset A\}$. És important notar que d'aquesta definició es dedueix que $A \in P(A)$ i $\phi \in P(A)$.

Utilitzant nombres combinatoris es pot demostrar que el conjunt $\boldsymbol{P}(\boldsymbol{A})$ té com a cardinal $2^{\text {card }(A)}:$ card $[P(A)]=2^{\text {card }(A)}$

\subsubsection{Operacions entre conjunts}

- Unió: $\mathbf{A} \cup \mathbf{B}=\{\mathbf{x} / \mathbf{x} \in \mathbf{A} \vee \mathbf{x} \in \mathbf{B}\}$

- Intersecció: $\mathbf{A} \cap \mathbf{B}=\{\mathbf{x} / \mathbf{x} \in \mathbf{A} \wedge \mathbf{x} \in \mathbf{B}\}$. Si la intersecció de dos conjunts és el conjunt buit, aquests s'anomenen conjunts disjunts.

$$
\begin{aligned}
& \text { Propietats de la unió i de la intersecció: } \\
& \text { 1. Commutativa: } \mathbf{A} \cup \mathbf{B}=\mathbf{B} \cup \mathbf{A} \text { i } \mathbf{A} \cap \mathbf{B}=\mathbf{B} \cap \mathbf{A} \\
& \text { 2. Associativa: } \mathbf{A} \cup(\mathbf{B} \cup \mathbf{C})=(\mathbf{A} \cup \mathbf{B}) \cup \mathbf{C} \text { i } \mathbf{A} \cap(\mathbf{B} \cap \mathbf{C})=(\mathbf{A} \cap \mathbf{B}) \cap \mathbf{C} \\
& \text { 3. Idempotència: } \mathbf{A} \cup \mathbf{A}=\mathbf{A} \text { i } \mathbf{A} \cap \mathbf{A}=\mathbf{A} \\
& \text { 4. Absorció: } \mathbf{A} \cup(\mathbf{A} \cap \mathbf{B})=\mathbf{A} \text { i } \mathbf{A} \cap(\mathbf{A} \cup \mathbf{B})=\mathbf{A} \\
& \text { 5. Distributiva: } \\
& A \cup(B \cap C)=(A \cup B) \cap(A \cup C) \text { i } A \cap(B \cup C)=(A \cap B) \cup(A \cap C) \\
& \text { 6. } \mathbf{A} \cup \mathbf{A}^{\mathrm{c}}=\mathbf{U} \text { i } \mathbf{A} \cup \phi=\mathbf{A} \\
& \text { 7. } \mathbf{A} \cap \mathbf{A}^{\mathrm{c}}=\boldsymbol{\phi} \text { i } \mathbf{A} \cap \phi=\phi \\
& \text { Nota: Lleis de De Morgan: } \\
& \text { - }(\mathbf{A} \cup \mathbf{B})^{\mathrm{C}}=\mathbf{A}^{\mathrm{C}} \cap \mathbf{B}^{\mathbf{C}} \\
& \text { - }(\mathbf{A} \cap \mathbf{B})^{\mathrm{C}}=\mathbf{A}^{\mathrm{C}} \cup \mathbf{B}^{\mathrm{C}}
\end{aligned}
$$

- Partició d'un conjunt: $\left\{N_{1}, N_{2} \ldots N_{n}\right\}$ és una partició d'un conjunt $A$, si i només si (en endavant sii): 


$$
\begin{aligned}
& \text { 1. } N_{i} \subset A \wedge N_{i} \neq \phi, \forall i=1 \ldots n \\
& \text { 2. } \bigcup_{i=1}^{n} N_{i}=A \\
& \text { 3. } N_{i} \cap N_{j}=\phi, \forall i \neq j
\end{aligned}
$$

- Diferència de conjunts: $A-B=\{x \in A / x \notin B\}$

- Producte cartesià: $A \times B=\{(a, b) / a \in A \wedge b \in B\}$

$$
\begin{aligned}
& \text { Propietats: } \\
& \text { 1. } \mathbf{c a r d}(\mathbf{A} \times \mathbf{B})=\mathbf{c a r d}(\mathbf{A}) \cdot \mathbf{c a r d}(\mathbf{B}) \\
& \text { 2. } \mathbf{A} \times \mathbf{B} \neq \mathbf{B} \times \mathbf{A} \\
& \text { 3. } \mathbf{A}^{\prime} \subset \mathbf{A}, \mathbf{B}^{\prime} \subset \mathbf{B} \leftrightarrow \mathbf{A}^{\prime} \times \mathbf{B}^{\prime} \subset \mathbf{A} \times \mathbf{B} \\
& \text { 4. } \mathbf{A} \times \mathbf{B}=\boldsymbol{\phi} \leftrightarrow \mathbf{A}=\boldsymbol{\phi} \vee \mathbf{B}=\boldsymbol{\phi} \\
& \text { 5. } \mathbf{A} \times(\mathbf{B} \cup \mathbf{C})=(\mathbf{A} \times \mathbf{B}) \cup(\mathbf{A} \times \mathbf{C}) \\
& \text { 6. } \mathbf{A} \times(\mathbf{B} \cap \mathbf{C})=(\mathbf{A} \times \mathbf{B}) \cap(\mathbf{A} \times \mathbf{C}) \\
& \text { 7. } \mathbf{A} \times(\mathbf{B}-\mathbf{C})=(\mathbf{A} \times \mathbf{B})-(\mathbf{A} \times \mathbf{C})
\end{aligned}
$$

\subsection{Correspondències}

Una correspondència $\mathbf{f}$ és una terna $(\mathbf{A}, \mathbf{B}, \mathbf{G})$, on:

- A, B són conjunts i $f: A \rightarrow B$ associa elements d'A amb elements de $\mathbf{B}$, anomenant-se A conjunt inicial i B conjunt final.

- $\mathbf{D}(\mathbf{f})=\{\mathbf{x} \in \mathbf{A} / \exists \mathbf{y} \in \mathbf{B}: \mathbf{f}(\mathbf{x})=\mathbf{y}\}$, és el conjunt Domini de la correspondència $i$ està format pels elements (anomenats origen o antiimatge) del conjunt inicial que tenen algun element corresponent en el conjunt final.

- $\mathbf{I m}(\mathbf{f})=\{\mathbf{y} \in \mathbf{B} / \exists \mathbf{x} \in \mathbf{A}: \mathbf{f}(\mathbf{x})=\mathbf{y}\}$ és el conjunt Imatge de la correspondència $i$ està format pels elements (anomenats imatge) del conjunt final que es corresponen amb algun element del domini de la correspondència.

- $\mathbf{G} \subset \mathbf{A x B}$, s'anomena Graf de la correspondència i està format per parells $(\mathbf{x}, \mathbf{y})$ on $\mathbf{x} \in \mathbf{D}(\mathbf{f})$ i $\mathbf{y} \in \operatorname{Im}(\mathbf{f})$ :

$G(f)=\{(x, y) \in A \times B / x \in D(f) \wedge y \in \operatorname{Im}(f) \wedge f(x)=y\}$ 
Qualsevol correspondència $\mathbf{f}$ ens permet definir la seua correspondència recíproca o inversa, de la següent manera:

$$
\mathbf{f}^{-1}: \mathbf{B} \rightarrow \mathbf{A} / \mathrm{D}\left(\mathbf{f}^{-1}\right)=\operatorname{Im}(\mathbf{f}) \text { i } \operatorname{Im}\left(\mathbf{f}^{-1}\right)=\mathbf{D}(\mathbf{f})
$$

Algunes correspondències poden ser:

- Unívoca: a cada element d'A li correspon un element o cap de B.

- Biunívoca: tant $f$, com $\boldsymbol{f}^{-1}$, són unívoques.

- Aplicació: tot element d'A té imatge en $\boldsymbol{B} i$ aquesta és única. És a dir, $\forall a \in A, \exists ! b \in B / f(a)=b$

Algunes aplicacions poden ser:

- Suprajectiva: tot element de B és imatge d'algun element d'A:

$\forall b \in B, \exists a \in A / f(a)=b$

- Injectiva: elements distints d'A tenen imatges distintes en B:

$\forall a, b \in A: a \neq b \rightarrow f(a) \neq f(b)$

- Bijectiva: suprajectiva i injectiva al mateix temps.

- Composició d'aplicacions: donada una aplicació $f: A \rightarrow B$ una altra $g: B \rightarrow C$ de forma que $\forall a \in A f(a)=b \wedge \forall b \in B \quad g(b)=c$, es defineix la composició d'aplicacions com una altra aplicació $g \circ f: A \rightarrow C$, acomplint que $\forall a \in A \quad g \circ f(a)=g(f(a))=g(b)=c$. Si les aplicacions $f$ i $g$ són bijectives la seua composició $g$ o $f$ també ho és.

\subsection{Relacions binàries}

Una Relació Binària és una associació o connexió que s'estableix entre parelles d'elements d'un conjunt. Poden haver-hi moltes definides en un mateix conjunt. Analíticament, podem dir que una relació $\mathbf{R}$ és una terna $(\mathbf{A}, \mathbf{A}, \mathbf{G})$, on $\mathbf{G} \subset \mathbf{A} \times \mathbf{A}$, com ocorre al punt anterior, aleshores direm que $\mathbf{x R y} \operatorname{sii}(\mathbf{x , y})$ pertany a $\mathbf{G}$.

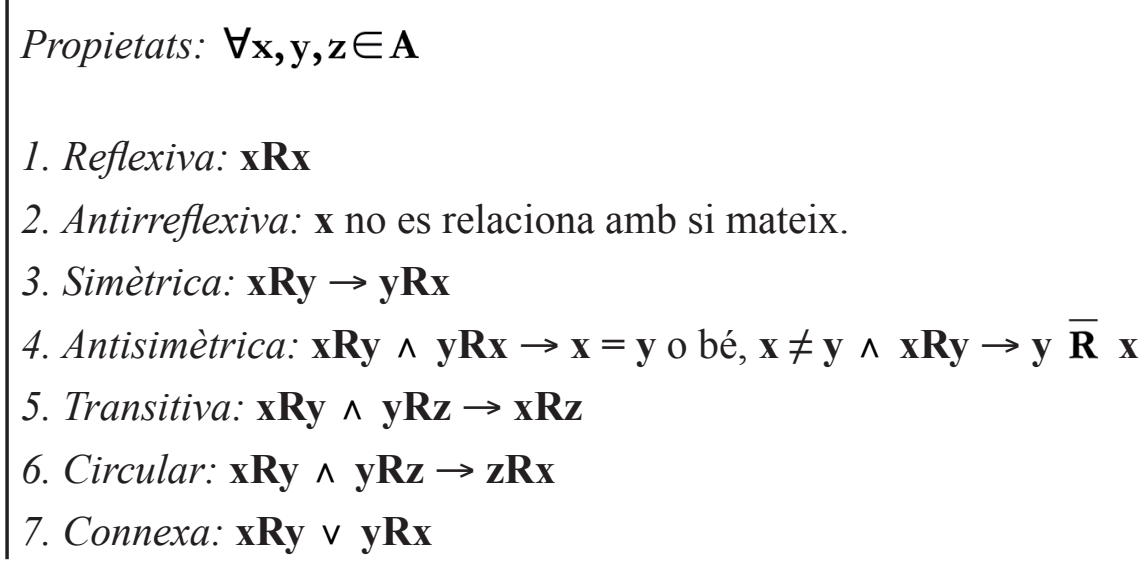


Nota: si una relació binària definida en un conjunt compleix algunes de les propietats anteriors, rep el nom de:

- Relació binària d'equivalència: compleix reflexiva, simètrica i transitiva.

- Relació binària de preordre: compleix reflexiva i transitiva.

- Relació binària d'ordre (també anomenada d'ordre ampli): compleix reflexi$v a$, antisimètrica i transitiva.

- Relació binària d'ordre estricte: compleix antireflexiva, antisimètrica i transitiva.

- Qualsevol relació d'ordre definida anteriorment s'anomenen d'ordre parcial, perquè no se li ha exigit que complisca la propietat connexa. Si aquesta propietat es compleix, les relacions d'ordre s'anomenen d'ordre total.

\subsubsection{Classes d'equivalència}

Una Relació Binària d'Equivalència definida en un conjunt organitza els seus elements en subconjunts que constitueixen una partició del conjunt (veure annex 1.2.2). Aquesta organització s'anomena Classificació i cadascun dels subconjunts s'anomena Classe d'Equivalència i està format pels elements del conjunt que es relacionen mitjançant la relació.

\subsubsection{Conjunt quocient}

Una vegada establerta una classificació, les classes d'equivalència formen un conjunt que s'anomena Conjunt Quocient. Si $\boldsymbol{A}$ és el conjunt on tenim definida la relació d'equivalència $\boldsymbol{R}$, el conjunt quocient es representa per $\boldsymbol{A} / \boldsymbol{R}$.

\subsection{Estructures algebraiques}

Quan s'estudia les propietats de les operacions en els diferents conjunts numèrics, s'observen algunes que es repeteixen de manera regular en tots ells, i altres que es presenten de manera específica. Aquestes contribueixen a determinar l'estructura algebraica dels esmentats conjunts numèrics.

En general, quan parlem d'estructura algebraica ens referim a les propietats que acompleixen les operacions definides entre els elements d'un conjunt. D'acord amb aquestes s'estableix una classificació dels conjunts, en la qual cadascuna de les classes d'equivalència correspon a una de les estructures que es recullen a continuació. 
Les operacions necessàries per a determinar una estructura poden ser Internes o Externes:

- Es defineix operació interna com una aplicació (*) : $\mathbf{A} \times \mathbf{A} \rightarrow \mathbf{A}$. És a dir, operant elements d'un conjunt $\mathbf{A}$, obtenim elements del mateix conjunt.

- Es defineix operació externa com una aplicació $(\cdot): \mathbf{K} \times \mathbf{A} \rightarrow \mathbf{A}$. És a dir, operant elements d'un conjunt $\mathbf{A}$ amb elements d'un altre conjunt $\mathbf{K}$, anomenat d'escalars, obtenim elements del conjunt $\mathbf{A}$.

Les operacions definides poden complir algunes de les següents propietats:

- Associativa (asso): $\forall \mathbf{a}, \mathbf{b}, \mathbf{c} \in \mathbf{A}:(\mathbf{a} * \mathbf{b}) * \mathbf{c}=\mathbf{a} *(\mathbf{b} * \mathbf{c})$

- Commutativa (com): $\forall \mathbf{a}, \mathbf{b} \in \mathbf{A}: \mathbf{a} * \mathbf{b}=\mathbf{b} * \mathbf{a}$

- Element Neutre (en): $\exists \mathbf{n} \in \mathbf{A} / \forall \mathbf{a} \in \mathbf{A}: \mathbf{a} * \mathbf{n}=\mathbf{n} * \mathbf{a}=\mathbf{a}$

- Element Simètric (es): $\forall \mathrm{a} \in \mathbf{A}, \exists \mathrm{a}^{\prime} \in \mathbf{A} / \mathbf{a}^{*} \mathbf{a}^{\prime}=\mathbf{a}^{*} \mathbf{a}^{\prime}=\mathbf{n}$

- Distributiva de * respecte de $\square: \forall \mathbf{a}, \mathbf{b}, \mathbf{c} \in \mathbf{A}: \mathbf{a} *(\mathbf{b} \square \mathbf{c})=(\mathbf{a} * \mathbf{b}) \square(\mathbf{a} * \mathbf{c})$, on $\square$ és un altra operació interna definida en $A$

Les principals estructures són:

Per a l'operació interna:

\begin{tabular}{|l|c|c|c|c|}
\hline & Associativa & Commutativa & $\begin{array}{c}\text { Element } \\
\text { neutre }\end{array}$ & $\begin{array}{c}\text { Element } \\
\text { simètric }\end{array}$ \\
\hline Semigrup & $\mathrm{X}$ & $\mathrm{X}$ & $\mathrm{X}$ & \\
\hline $\begin{array}{l}\text { Semigrup } \\
\text { commutatiu }\end{array}$ & $\mathrm{X}$ & $\mathrm{X}$ & $\mathrm{X}$ & \\
\hline Monoide & $\mathrm{X}$ & $\mathrm{X}$ & $\mathrm{X}$ & \\
\hline $\begin{array}{l}\text { Monoide } \\
\text { commutatiu }\end{array}$ & $\mathrm{X}$ & $\mathrm{X}$ & $\mathrm{X}$ & $\mathrm{X}$ \\
\hline Grup & & & & \\
\hline $\begin{array}{l}\text { Grup } \\
\text { commutatiu o abelià }\end{array}$ & \multicolumn{2}{|c|}{} \\
\hline
\end{tabular}


Per a dues operacions internes:

\begin{tabular}{|c|c|c|c|c|c|c|c|c|c|}
\hline & \multicolumn{4}{|c|}{ Primera operació } & \multicolumn{4}{|c|}{ Segona operació } & \multirow{2}{*}{$\begin{array}{l}\text { Distributiva } \\
\text { de la } 2 \text { a } \\
\text { respecte } \\
\text { de la } 1 \text { a }\end{array}$} \\
\hline & asso & $\mathrm{com}$ & en & es & asso & com & en & es & \\
\hline Semianell & $\mathrm{X}$ & $\mathrm{X}$ & $\mathrm{X}$ & & $\mathrm{X}$ & & & & $\mathrm{X}$ \\
\hline $\begin{array}{l}\text { Semianell } \\
\text { commutatiu }\end{array}$ & $X$ & $X$ & $\mathrm{X}$ & & $X$ & $\mathrm{X}$ & & & $X$ \\
\hline $\begin{array}{l}\text { Semianell } \\
\text { commutatiu } \\
\text { unitari }\end{array}$ & $\mathrm{X}$ & $X$ & $\mathrm{X}$ & & $\mathrm{X}$ & $\mathrm{X}$ & $\mathrm{X}$ & & $\mathrm{X}$ \\
\hline Anell & $\mathrm{X}$ & $\mathrm{X}$ & $\mathrm{X}$ & $\mathrm{X}$ & $\mathrm{X}$ & & & & $\mathrm{X}$ \\
\hline $\begin{array}{l}\text { Anell } \\
\text { commutatiu }\end{array}$ & $\mathrm{X}$ & $X$ & $\mathrm{X}$ & $X$ & $\mathrm{X}$ & $X$ & & & $\mathrm{X}$ \\
\hline $\begin{array}{l}\text { Anell } \\
\text { commutatiu } \\
\text { unitari }\end{array}$ & X & $X$ & $\mathrm{X}$ & $X$ & $\mathrm{X}$ & X & $\mathrm{X}$ & & X \\
\hline $\operatorname{Cos}$ & $X$ & X & $X$ & $X$ & $X$ & & $X$ & $\underset{(*)}{X}$ & $X$ \\
\hline $\begin{array}{l}\text { Cos } \\
\text { commutatiu }\end{array}$ & $\mathrm{X}$ & $\mathrm{X}$ & $\mathrm{X}$ & $\mathrm{X}$ & $\mathrm{X}$ & $\mathrm{X}$ & $\mathrm{X}$ & $\underset{(*)}{X}$ & $\mathrm{X}$ \\
\hline
\end{tabular}

(*): Exceptuant l'element neutre de la primera, tots els elements del conjunt tenen simètric per a la segona operació.

Caldria afegir, finalment, les definicions de semimòdul i espai vectorial:

Un conjunt $(M, *, \cdot)$, amb una operació interna * i una altra externa $\cdot$, definida amb l'ajuda d'un semianell $(\mathbf{A},+, \mathbf{x})$, és un semimòdul sii:

- $(\mathbf{M}, *)$ és un semigrup commutatiu.

- $\forall \boldsymbol{\alpha}, \boldsymbol{\beta} \in \mathbf{A} \wedge \forall \mathrm{a}, \mathrm{b} \in \mathbf{M}$ s'acompleixen les següents propietats:

$$
\begin{aligned}
& (\alpha+\beta) \cdot a=(\alpha \cdot a) *(\beta \cdot a) \\
& \alpha \cdot(a * b)=(\alpha \cdot a) *(\alpha \cdot b) \\
& \alpha \cdot(\beta \cdot a)=(\alpha \times \beta) * a
\end{aligned}
$$


Un conjunt $(\mathbf{V}, *, \cdot)$, amb una operació interna * i una altra externa $\cdot$ definida amb l'ajuda d'un $\cos (\mathbf{K},+, \times)$ és un espai vectorial sii:

- $(\mathrm{V}, *)$ és un grup abelià.

- $\forall \boldsymbol{u}, \boldsymbol{v} \in V, \forall \boldsymbol{\lambda}, \boldsymbol{\mu}, 1 \in K$ s'acompleixen les següents propietats:

$-(\lambda+\mu) \cdot v=(\lambda \cdot v) *(\mu \cdot v)$

$-\lambda \cdot\left(u^{*} v\right)=(\lambda \cdot u) *(\lambda \cdot v)$

$-\lambda \cdot(\mu \cdot v)=(\lambda \times \mu) \cdot v$

$-1 \cdot \mathrm{v}=\mathrm{v}$ 


\section{Referències bibliogràfiques}

Chamorro, C. (coord.) (2003): Didàctica de las Matemáticas para primaria. Madrid. Pearson Educación.

Colectivo Periódica Pura (1982): Didáctica de los números enteros. Madrid. Nuestra Cultura.

IfrAH, G. (2001): Historia universal de las cifras. La inteligencia de la humanidad contada por los números y el cálculo. Madrid. Espasa Calpe.

Llinares, S.; SÁnchez, M. ${ }^{a}$ V. (1988): Fracciones. La relación parte-todo. Matemáticas: cultura y aprendizaje, núm. 4. Madrid. Síntesis.

Mankiewicz, R. (2005): Historia de las matemáticas. Madrid. Paidós.

\section{Bibliografia recomanada}

Alsina, C. (1993): Del número 0 al 99. Fem comptes amb els contes. InstrumentsGuix: 10. Barcelona. Graó.

Centeno, J. (1988): Números decimales. ¿Por qué? ¿Para qué? Matemáticas: cultura y aprendizaje, núm. 5. Madrid. Síntesis.

Chamorro, C.; Belmonte, J. M. (1988): El problema de la medida. Didáctica de las magnitudes lineales. Matemáticas: cultura y aprendizaje, núm. 17. Madrid. Síntesis.

Dickson, L. et al. (1991): El aprendizaje de las matemáticas. Madrid. Labor-MEC.

FARre, E.; SEgura, C. (1989): 24 rellotges i altres instruments per a la mesura del temps. Barcelona. Graó.

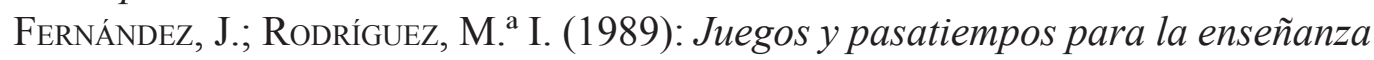
de la matemática elemental. Matemáticas: cultura y aprendizaje, núm. 32. Madrid. Síntesis.

Fiol, M. ${ }^{a}$ L.; Fortuny, J. M. (1990): Proporcionalidad directa. La forma y el número. Matemáticas: cultura y aprendizaje, núm. 20. Madrid. Síntesis.

GARCíA, R. (1992): Cómo enseñar o aprender el sistema métrico. Madrid. Escuela Española SA.

Gómez, P. et al. (1993): «Adaptaciones curriculares individualizadas», Cuadernos de Pedagogía, núm. 212, marzo 1993, pp. 40-44.

GonzÁLez, J. L. et al. (1990): Números enteros. Matemáticas: cultura y aprendizaje, núm. 6. Madrid. Síntesis.

JimÉnez, V. (1990): Cómo lograr una enseñanza activa de la matemática. Barcelona. CEAC.

MAZA, C.; Arce, C. (1991): Ordenar y clasificar. Matemáticas: cultura y aprendizaje, núm. 31. Madrid. Síntesis.

Moreno, P. (1986): «La construcció infantil de la mesura de superfície», en AJunTAMent de BarCelona (1986): La Pedagogia Operatòria, avui. Col-lecció Estudis i 
recerques. Barcelona. Ajuntament de Barcelona, Publicacions, pp. 219-234 (castellà: pp. 511-526).

Nortes, A. (1993): Matemáticas y su didáctica. Murcia. Tema-DM.

Nortes, A.; Serrano, J. M. ${ }^{a}$ (1991): «Un análisis psicoeducativo del paso de las operaciones concretas a las formales: el caso del bloque numérico en los contenidos de matemáticas de $6^{\circ}$ EgB», en Nortes, A.; Serrano, J. M. (1991): Operaciones concretas y formales. Murcia. Universidad de Murcia, Secretariado de Publicaciones, pp. 139-152.

Olmo, M. ${ }^{a}$ A. del et al. (1989): Superficie y volumen. ¿Algo más que el trabajo con fórmulas? Matemáticas: cultura y aprendizaje, núm. 19. Madrid. Síntesis.

Orduña, S. (1992): «Aprendiendo a medir», Cuadernos de Pedagogía, núm. 199, enero 1992, pp. 36-37.

SEgovia, I. et al. (1989): Estimación en cálculo y medida. Matemáticas: cultura y aprendizaje, núm. 9. Madrid. Síntesis.

Skemp, R. R. (1980): Psicología del aprendizaje de las matemáticas. Matemáticas. Madrid. Morata. 


\section{Índex de figures}

Figura 1. Representació de conjunts numèrics

Figura 2. Representació parcial de $\mathbf{N} \times \mathbf{N}$

Figura 3. Representació d'alguns parells de $\mathbf{N} \times \mathbf{N}$

Figura 4. Representació d'alguns nombres enters a partir de les seues classes d'equivalència

Figura 5. Representació d'alguns nombres enters en la recta numèrica

Figura 6. Representació del model didàctic de l'escala per a nombres enters

Figura 7. Representació de l'addició $(-4)+(+3)$ amb l'ajuda de l'escala .....

Figura 8. Representació de l'addició $(+2)+(-3)$ amb l'ajuda de l'escala .....

Figura 9. Representació parcial de $\mathbf{Z} \times \mathbf{Z}^{*}$

Figura 10. Representació d'alguns parells de la classe d'equivalència de $(2,3)$

Figura 11. Representació d'algunes classes d'equivalència de $\mathbf{Z} \times \mathbf{Z}^{*}$

Figura 12. Representació d'una pizza dividida en tres parts iguals

Figura 13. Representació de la selecció d'una pizza sencera i una part d'un altra

Figura 14. Representació d'una pizza dividida en 6 parts i destacades 4

Figura 15. Representació de la semirecta numèrica positiva

Figura 16. Representació d'algunes fraccions en la semirecta numèrica ........

Figura 17. Representació d'un paquet de 8 galetes.

Figura 18. Representació de la selecció de 5 galetes d'un paquet de 8

Figura 19. Representació de la selecció d'un paquet sencer i dues galetes d'un altre

Figura 20. Representació d'un paquet de 8 galetes, embossades de 2 en 2

Figura 21. Representació de la selecció de 3 bosses d'un paquet de 4

Figura 22. Representació de la selecció d'un paquet sencer i una bossa d'un altre

Figura 23. Representació gràfica d'una dècima

Figura 24. Representació gràfica d'una centèsima

Figura 25. Representació gràfica de 7 dècimes i 70 centèsimes

Figura 26. Representació de $\frac{2}{5}$ i $\frac{3}{5}$ a la recta numèrica

Figura 27. Representació de $\frac{1}{3}$ i $\frac{1}{2}$ a la recta numèrica

Figura 28. Representació de $\frac{1}{2}$ i $\frac{3}{5}$ a la recta numèrica

Figura 29. Representació de 7 dècimes i 66 centèsimes.

Figura 30. Representació de l'addició de $\frac{3}{8}$ i $\frac{2}{8}$

Figura 31. Representació de l'addició de $\frac{3}{8}$ i $\frac{6}{8}$

Figura 32. Representació de $\frac{6}{8}$ 
Figura 33. Representació de la subtracció $\frac{6}{8}$ menys $\frac{4}{8}$

Figura 34. Representació de $\frac{1}{3}, \frac{2}{6}$ i $\frac{4}{12}$

Figura 35. Representació de $\frac{2}{3}$ i $\frac{1}{4}$.

Figura 36. Representació de $\frac{2}{3}$ i $\frac{1}{4}$ sobre dues cartolines, una dividida en terços i l'altra en quarts

Figura 37. Representació de $\frac{2}{3}$ i $\frac{1}{4}$ sobre una cartolina dividida en dotzenes parts

Figura 38. Representació de les successives divisions del bescuit fins arribar a $\frac{2}{5}$ de $\frac{3}{4}$

Figura 39. Representació, com a fracció de la unitat, del bescuit que s'ha menjat

Figura 40. Regles flexibles d'1 metre (fabricades per HenBea)

Figura 41. Roda contametres (fabricada per Invicta).

Figura 42. Metrilínia (fabricada per Osmiroid)

Figura 43. Kit de litre (fabricat per Invicta)

Figura 44. Balança de Plàstic (fabricada per Osmiroid)

Figura 45. Balança Vulcano de $2 \mathrm{~kg}$ (fabricada per Vulcano)

Figura 46. Peses de ferro (fabricades per Vulcano)

Figura 47. Vasos graduats (fabricats per Vit Lab)

Figura 48. Eurodòmino (fabricat per HenBea)

Figura 49. Monedes i Bitllets (fabricats per Miniland)

Figura 50. Seqüències lògiques (fabricat per Trusva)

Figura 51. Rellotge d'engranatges (fabricat per Kalmarsund)

Figura 52. Rellotges escolars de fusta (fabricats per Trusva)

Figura 53. Rellotge escolar (fabricat per Goula)

Figura 54. Rellotge gegant (fabricat per HenBea)

Figura 55. Dòmino del rellotge digital (fabricat per Taskmaster Limited)

Figura 56. Calendari magnètic (fabricat per HenBea)

Figura 57. Transportador d'angles (fabricat per Faibo)

Figura 58. Metre cúbic desmuntable (fabricat per Lado)

Figura 59. Decímetre cúbic descomponible (fabricat per Nes Arnold)

Figura 60. Acetats centimetrats (fabricats per Taskmaster Ltd.)

Figura 61. Representació gràfica per calcular l'àrea d'un paral·lelogram ........

Figura 62. Representacions gràfiques per calcular àrees de triangles. 